\title{
Inteligência artificial e COVID-19
}

\author{
Andréa Jesus dos Santos ${ }^{1}$ \\ Daniela Santos Almeida ${ }^{2}$ \\ Everton Mendonça de Jesus ${ }^{3}$ \\ Juracy Bertoldo dos Santos Juniort \\ Mirlei Moura da Silva ${ }^{5}$ \\ Marcos Ennes Barreto ${ }^{6}$
}

1 Mestranda em Ciência da Computação pelo Programa de Pós-Graduação em Ciência da Computação (PGCOMP) da Universidade Federal da Bahia (UFBA). Instituição de atuação: AtylmoLab da UFBA, Serviço Federal de Processamento de Dados (Serpro).

2 Mestranda em Ciência da Computação pelo Programa de Pós-Graduação em Ciência da Computação (PGCOMP) da Universidade Federal da Bahia (UFBA). Instituição de atuação: AtylmoLab da UFBA.

3 Doutorando em Ciência da Computação pelo Programa de Pós-Graduação em Ciência da Computação (PGCOMP) da Universidade Federal da Bahia (UFBA), mestre em Ciência da Computação. Instituição de atuação: AtylmoLab da UFBA.

4 Mestre em Ciência da Computação pelo Programa de Pós-Graduação em Ciência da Computação (PGCOMP) da Universidade Federal da Bahia (UFBA). Instituição de atuação: AtylmoLab da UFBA e Instituto de Saúde Coletiva (ISC-UFBA).

5 Doutoranda em Ciência da Computação pelo Programa de Pós-Graduação em Ciência da Computação (PGCOMP) da Universidade Federal da Bahia (UFBA), mestre em Ciência da Computação pela PGCOMP da UFBA. Instituição de atuação: AtylmoLab da UFBA.

6 Doutor em Ciência da Computação pela Universidade Federal do Rio Grande do Sul (UFRGS). Especialização e pós-doutorado em Health Data Science (University College London, UK, 20162018). Instituição de atuação: AtylmoLab da Universidade Federal da Bahia (UFBA), Department of Statistics, London School of Economics and Political Science (UK).

SANTOS, A. J. dos; ALMEIDA, D. S.; JESUS, E. M. de; SANTOS JUNIOR, J. B. dos; SILVA, M. M. da; BARRETO, M. E. Inteligência artificial e COVID-19. In: BARRETO, M. L.; PINTO JUNIOR, E. P.; ARAGÃO, E.; BARRAL-NETTO, M. (org.). Construção de conhecimento no curso da pandemia de COVID-19: aspectos biomédicos, clínico-assistenciais, epidemiológicos e sociais. Salvador: Edufba, 2020. v. 2. 


\section{Conceitos gerais}

\section{de Inteligência Artificial}

Inteligência Artificial (IA) é uma área de pesquisa e desenvolvimento na qual se busca identificar como o raciocínio humano, empregado rotineiramente em tarefas de percepção, entendimento, predição e manipulação, pode ser modelado e aplicado na construção de sistemas inteligentes. (RUSSELL, 2020) A maior parte do progresso observado em IA, desde o seu surgimento por volta de 1950, está associado ao desenvolvimento de sistemas com inteligência "restrita”, os quais são desenvolvidos e treinados para executar tarefas específicas - por exemplo, veículos autônomos, sistemas médicos e financeiros, segurança e monitoramento -, em vez de sistemas de inteligência "genérica", os quais presumidamente podem executar qualquer tarefa que o ser humano realiza. (NG, 2020)

Da mesma forma que o raciocínio humano é complexo, a área de IA emprega um vasto conjunto de formalismos, modelos e ferramentas para permitir que sistemas ajam de forma inteligente. Essa complexidade e diversidade resultam em diferentes subdomínios, tais como lógica e raciocínio sob incerteza, agentes inteligentes, aprendizado de máquina e redes neurais. (ERTEL, 
2017) A Figura 1 ilustra alguns destes subdomínios: aprendizado de máquina (machine learning) incorpora modelos capazes de aprender a partir dos dados e das interações com os ambientes nos quais estão inseridos. O aprendizado profundo (deep learning) é uma categoria específica de aprendizado de máquina na qual redes artificiais imitando os neurônios são capazes de aprender, geralmente a partir de grandes volumes de dados, e de autoajustarem seus parâmetros de funcionamento a partir da avaliação do seu aprendizado.

Figura 1 - Recorte de subdomínios da IA

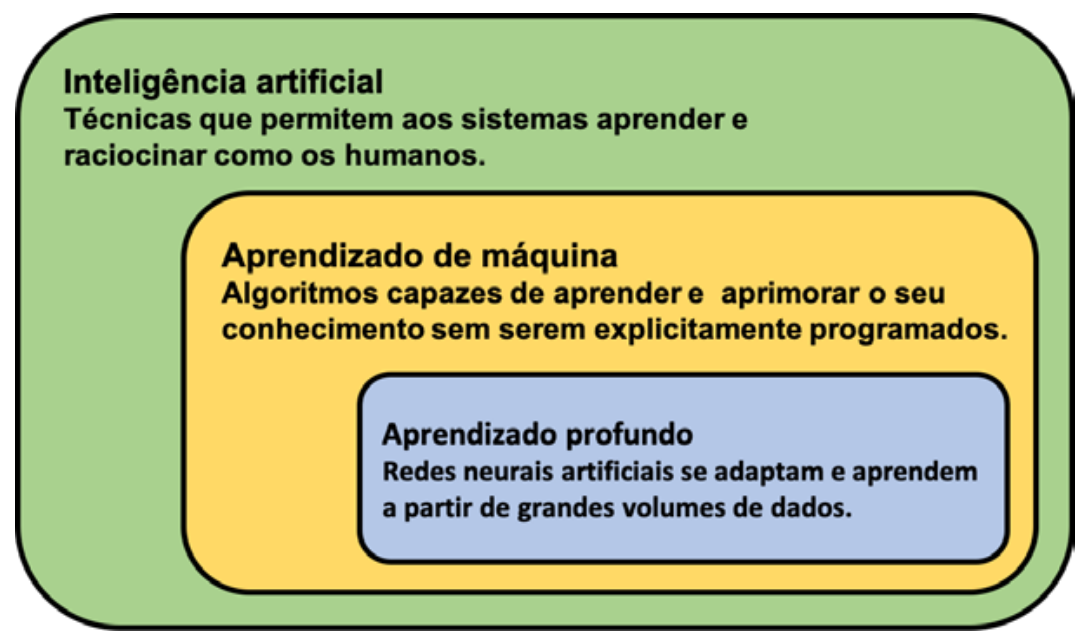

Fonte: adaptada de Goodfellow, Bengio e Courville (2016).

O aprendizado de máquina pode ocorrer de forma supervisionada, não supervisionada, por reforço ou por transferência. No aprendizado "supervisionado", o modelo aprende a fazer o mapeamento de um conjunto de dados de entrada (A) para uma determinada saída (B), como por exemplo: classificação de e-mails 
como spam ou não, tradução de um idioma para outro, reconhecimento de fala - mapeamento de áudio para texto - e detecção de objetos em imagens. Nesse tipo de aprendizado, os modelos são treinados a partir de dados rotulados - ou seja, dados para os quais o mapeamento A=>B é conhecido -, sendo depois aplicados e validados em novos conjuntos de dados para os quais não se conhece esse mapeamento.

No aprendizado "não supervisionado", os dados não são rotulados e os modelos aprendem observando similaridades - padrões - e diferenças entre os dados. A aplicação mais comum desse tipo de modelo é no agrupamento de dados, como por exemplo: segmentação de clientes em diferentes categorias ou deteç̧ão de fraudes - ou anomalias - em transações financeiras. O aprendizado "por reforço" engloba uma classe de modelos que aprendem a partir da interação com o ambiente em que atuam. Dependendo do estado em que o modelo se encontra e da ação que ele executa, uma recompensa - positiva ou negativa - é atribuída e um novo estado é definido. O objetivo geral desse tipo de modelo é maximizar a recompensa recebida ao longo da sua execução. Sistemas autônomos e de robótica são exemplos desse tipo de modelo.

Por fim, o aprendizado "por transferência" engloba um conjunto de modelos nos quais o conhecimento adquirido por um modelo ao resolver um problema é armazenado e posteriormente transferido para um novo modelo encarregado de resolver um problema similar. Essa transferência minimiza ou elimina a necessidade de treinamento do novo modelo, ao mesmo tempo em que permite um aprimoramento desse conhecimento. Tipicamente, aplicações de processamento de imagens se encaixam nesse cenário, nas quais se pode treinar um modelo para a detecção de automóveis e transferir esse aprendizado para uma aplicação de detecção de caminhões, por exemplo. 
No aprendizado profundo de Goodfellow, Bengio e Courville (2016), os modelos adotam a estrutura de uma rede neural artificial. Um "neurônio" é basicamente uma função matemática que realiza o mapeamento $A=>B$. Por exemplo, dado o preço de um produto (A), o modelo estima a demanda (B). As redes neurais podem conter uma sequência de camadas, cada uma composta por diferentes quantidades de neurônios e cada neurônio recebendo diferentes conjuntos de entrada (A) e gerando diferentes saídas (B). Os casos mais típicos da aplicação de redes neurais artificiais envolvem o processamento de imagens em tarefas de classificação (diagnóstico médico) e detecção (de objetos e pessoas), geralmente a partir de grandes quantidades de dados.

O Quadro 1 sumariza os principais modelos empregados em cada uma dessas categorias de aprendizado de máquina e suas finalidades.

Quadro 1 - Modelos de IA segundo o tipo de aprendizado empregado

\begin{tabular}{|c|c|}
\hline Categoria de aprendizado & $\begin{array}{c}\text { Mogressão linear, regressão logística, máquinas de vetores de } \\
\text { suporte (SVM), classificador Bayesiano, árvores de decisão, } \\
\text { análise de discriminantes lineares, k-Nearest Neighbors (KNN), } \\
\text { redes neurais. }\end{array}$ \\
\hline Não-supervisionado & $\begin{array}{c}\text { Agrupamento (clustering), detecção de anomalias, redes neurais, } \\
\text { modelos de variáveis latentes. }\end{array}$ \\
\hline Por reforço & $\begin{array}{c}\text { Modelos Markovianos, métodos de Monte Carlo, diferenças } \\
\text { temporais, redes neurais recorrentes (RNN), redes neurais } \\
\text { convolucionais (CNN). }\end{array}$ \\
\hline Por transferência & $\begin{array}{c}\text { Inception-v3, ResNet, AlexNet, outros modelos baseados em } \\
\text { redes neurais convolucionais (CNN). }\end{array}$ \\
\hline Profundo & $\begin{array}{c}\text { Redes neurais recorrentes (RNN), redes neurais convolucionais } \\
\text { (CNN), modelos generativos (Boltzmann, GAN, deep belief). }\end{array}$ \\
\hline
\end{tabular}

Fonte: elaborada pelos autores. 
Este capítulo apresenta trabalhos enfocando o uso prático de modelos de IA no contexto da COVID-19. Assim, os critérios adotados para a seleção dos trabalhos são descritos na seção "Metodologia de pesquisa”; os trabalhos são apresentados na seção "Principais aplicações da Inteligência Artificial no contexto da Covid-19”, de acordo com a categoria de aplicação, com destaque para os modelos de IA empregados em cada categoria; e, por sua vez, uma síntese do capítulo, incluindo a relação de todos os trabalhos analisados, encontra-se na última seção.

\section{Metodologia de pesquisa}

O fluxo descrito na Figura 2 foi executado para o levantamento das contribuições. As bases de dados da Association for Computing Machinery (ACM), do Institute of Electrical and Electronics Engineers (IEEE), PubMed, Scopus e MedRxiv foram consultadas, usando os critérios de busca descritos no Quadro 2. Os trabalhos recuperados foram então processados para remoção de duplicatas e obtenção de versões mais recentes daqueles trabalhos com múltiplas versões. Os critérios de inclusão e exclusão foram aplicados, garantindo que somente trabalhos enfocando COVID-19 e uso prático de modelos de IA - incluindo resultados e análise - fossem considerados. Ao final, os trabalhos foram categorizados de acordo com a aplicação. 
Figura 2 - Fluxo de revisão empregado para a concepção deste capítulo

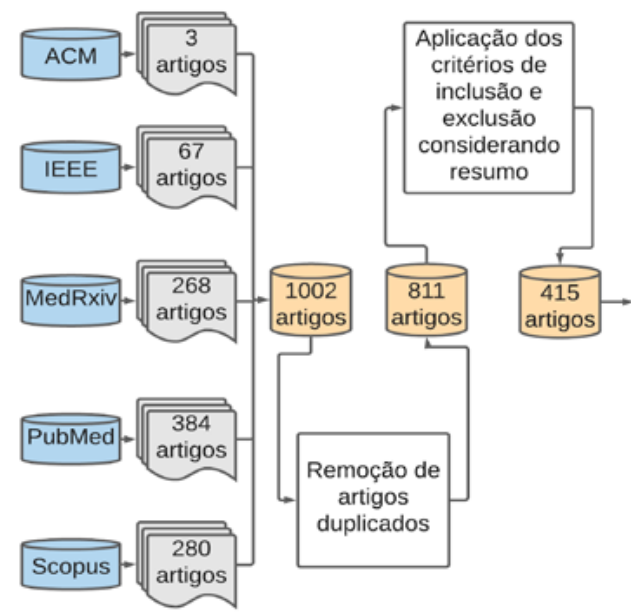

\begin{tabular}{|c|c|c|}
\hline & \multicolumn{2}{|l|}{ Categorias } \\
\hline & $\begin{array}{c}\text { Diagnóstico baseado em } \\
\text { imagens }\end{array}$ & 151 \\
\hline & $\begin{array}{l}\text { Modelos preditivos para } \\
\text { diversos desfechos }\end{array}$ & 72 \\
\hline & $\begin{array}{c}\text { Diagnóstico baseado em dados } \\
\text { (exceto imagens) }\end{array}$ & 27 \\
\hline \multirow{9}{*}{$\begin{array}{c}\text { Segunda } \\
\text { revisão } \\
\text { considerando } \\
\text { todo o texto do } \\
\text { artigo e } \\
\text { categorização } \\
\text { conforme } \\
\text { aplicação }\end{array}$} & Triagem hospitalar & 15 \\
\hline & $\begin{array}{c}\text { Identificaçăo de padrōes I } \\
\text { estratificação }\end{array}$ & 15 \\
\hline & Pesquisa de fármacos & 12 \\
\hline & $\begin{array}{l}\text { Monitoramento de contato I } \\
\text { rastreamento }\end{array}$ & 9 \\
\hline & Análise genômica & 8 \\
\hline & Mineração de texto & 8 \\
\hline & Análise espacial & 4 \\
\hline & Outros desfechos & 4 \\
\hline & TOTAL & 325 \\
\hline
\end{tabular}

Fonte: elaborada pelos autores.

Quadro 2 - Bases de dados, critérios de busca, inclusão

e exclusão de trabalhos

\begin{tabular}{|c|c|c|}
\hline Bases de dados & Critério (string) de busca & $\begin{array}{c}\text { Quantidade } \\
\text { de } \\
\text { trabalhos }\end{array}$ \\
\hline $\mathrm{ACM}$ & $\begin{array}{l}\text { "query": \{ Title:(("covid*19" OR "covid19" OR "sars*cov²" OR "sarscov2" OR "novel } \\
\text { coronavirus" OR "coronavirus disease 2019" OR "ncov" OR "sars2" OR "sars*2" } \\
\text { OR "2019 novel coronavirus" OR "coronavirus disease-19" OR "2019-nCoV" OR } \\
\text { "severe acute respiratory syndrome coronavirus 2") AND ("deep learning" OR } \\
\text { "cluster" OR "artificial intelligence" OR "machine learning" OR "neural network" } \\
\text { OR "natural language processing" OR "nlp")) AND Abstract:(("covid*19" OR } \\
\text { "covid19" OR "sars*cov²" OR "sarscov2" OR "novel coronavirus" OR "coronavirus } \\
\text { disease 2019" OR "ncov" OR "sars2" OR "sars²" OR "2019 novel coronavirus" OR } \\
\text { "coronavirus disease-19" OR "2019-nCoV" OR "severe acute respiratory syndrome } \\
\text { coronavirus 2") AND ("deep learning" OR "cluster*" OR "artificial intelligence" } \\
\text { OR "machine learning" OR "neural network" OR "natural language processing" } \\
\text { OR "nlp")) \}"filter": \{ Media Format: PDF, Publication Date: (11/01/2019 TO } \\
07 / 31 / 2020), \text { ACM Content: DL, NOT VirtualContent: true \} }\end{array}$ & 3 \\
\hline
\end{tabular}




\begin{tabular}{|c|c|c|}
\hline Bases de dados & Critério (string) de busca & $\begin{array}{c}\text { Quantidade } \\
\text { de } \\
\text { trabalhos }\end{array}$ \\
\hline IEEE & $\begin{array}{l}\text { (("Abstract":"covid*19" OR "covid19" OR "sars*cov²" OR "sarscov2" OR "novel } \\
\text { coronavirus" OR "coronavirus disease 2019" OR "ncov" OR "sars2" OR "sars*2") } \\
\text { AND ("Abstract": "deep learning" OR "clustering" OR "artificial intelligence" OR } \\
\text { "machine learning" OR "neural network*" OR "natural language processing" OR } \\
\text { "nlp")) (("Abstract": "covid*19" OR "covid19" OR "sars*cov²" OR "sarscov2" OR } \\
\text { "novel coronavirus" OR "coronavirus disease 2019" OR "ncov" OR "sars2" OR } \\
\text { "sars*2" OR "2019 novel coronavirus" OR "coronavirus disease-19" OR "2019- } \\
\text { nCoV" OR "severe acute respiratory syndrome coronavirus 2") AND ("Abstract": } \\
\text { "deep learning" OR "clustering" OR "artificial intelligence" OR "machine learning" } \\
\text { OR "neural network" OR "natural language processing" OR "nlp"))OR(("Title": } \\
\text { "covid*19" OR "covid19" OR "sars*cov²" OR "sarscov2" OR "novel coronavirus" OR } \\
\text { "coronavirus disease 2019" OR "ncov" OR "sars2" OR "sars²")AND ("Title": "deep } \\
\text { learning" OR "clustering" OR "artificial intelligence" OR "machine learning" OR } \\
\text { "neural network*" OR "natural language processing" OR "nlp")) Filtros aplicados: } \\
2019-2020\end{array}$ & 67 \\
\hline Scopus & $\begin{array}{l}\text { ABS ("COVID-19" OR "2019 novel coronavirus" OR "COVID19" OR "coronavirus } \\
\text { disease 2019" OR "coronavirus disease-19" OR "2019-nCoV" OR "severe acute } \\
\text { respiratory syndrome coronavirus 2" OR "SARS-CoV-2" OR "SARS2" ) AND ABS } \\
\text { ("deep learning" OR "clustering" OR "artificial intelligence" OR "machine learning" } \\
\text { OR "neural network*" OR "natural language processing" OR "nlp") AND } \\
\text { PUBYEAR > } 2018 \text { AND (LIMIT-TO ( DOCTYPE, "ar") OR LIMIT-TO ( DOCTYPE, } \\
\text { "re") OR LIMIT-TO ( DOCTYPE, "cp") ) AND ( LIMIT-TO (LANGUAGE, "English" )) }\end{array}$ & 280 \\
\hline PubMed & $\begin{array}{l}\text { ("2019/11/01"[Date - Publication] : "2020/07/31" [Date - Publication]) AND } \\
\text { (("covid*19"[Title/Abstract]) OR ("covid19" [Title/Abstract]) OR ("sars*'cov²" [Title/ } \\
\text { Abstract]) OR (sarscov2[Title/Abstract]))) OR (novel coronavirus[Title/Abstract])) } \\
\text { OR (coronavirus disease 2019[Title/Abstract]) OR (ncov[Title/Abstract]) OR } \\
\text { (sars2[Title/Abstract])) OR ("sars*2"[Title/Abstract])) AND ((deep learning[Title/ } \\
\text { Abstract]) OR (clustering[Title/Abstract]) OR (artificial intelligence[Title/Abstract]) } \\
\text { OR (machine learning[Title/Abstract]) OR ("neural network*"[Title/Abstract]) OR } \\
\text { (natural language processing[Title/Abstract]) OR (nlp[Title/Abstract])) }\end{array}$ & 384 \\
\hline
\end{tabular}




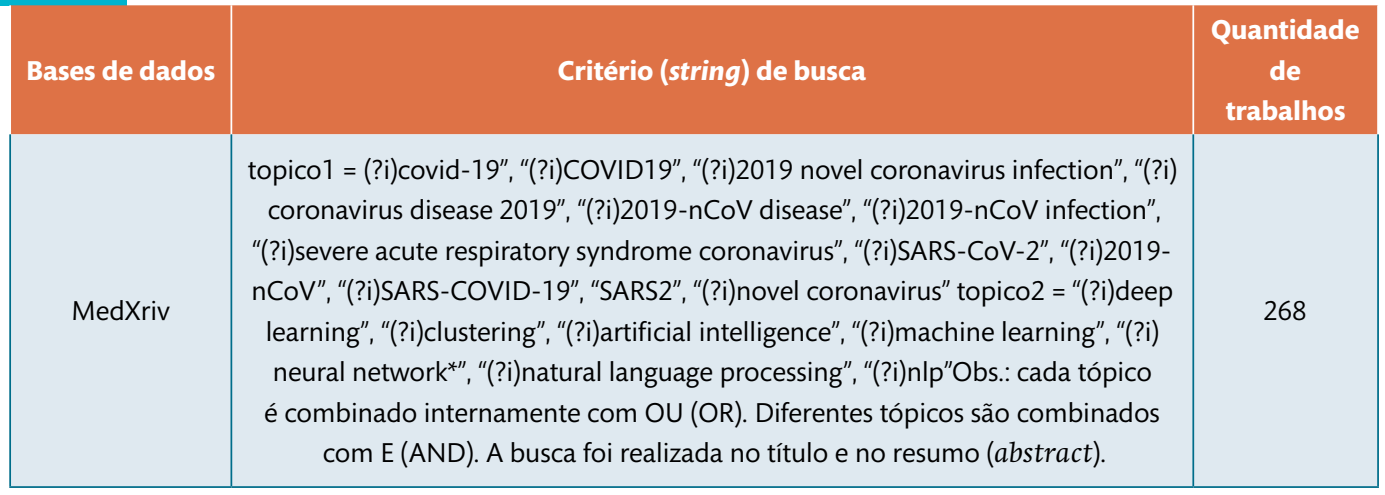

Fonte: elaborada pelos autores.

\section{Principais aplicações da Inteligência Artificial no contexto da GOVID-19}

No contexto da pandemia de COVID-19, a IA tem sido usada como uma importante ferramenta para diversas finalidades, as quais incluem o apoio ao diagnóstico da doença, a concepção de modelos de predição, o suporte à pesquisa clínica, epidemiológica e de fármacos, bem como apoio para a tomada de decisões e ações de combate à pandemia. Esta seção sumariza os principais uso da IA no contexto da COVID-19.

\section{Diagnóstico baseado em imagem}

O diagnóstico baseado por imagem é uma abordagem consolidada em diversas áreas do conhecimento. Na área da saúde, nossa revisão identificou uma quantidade significativa de trabalhos (151) empregando imagens de raio-X e tomografia computadorizada para o diagnóstico de infecções respiratórias e outros desfechos associados à COVID-19. 
Neste tipo de aplicação, imagens de raio-X e tomografia computadorizada são analisadas por modelos de aprendizado profundo (deep learning), a maior parte deles sendo Redes Neurais Convolucionais (CNNs), para a identificação de padrões específicos - por exemplo, sinais de tumores, regiões mais claras ou escuras, desvios em tecidos e artérias etc. - do desfecho que se quer diagnosticar. A Figura 3 ilustra o fluxo básico de uso de redes neurais para o processamento de imagens - nesse exemplo, a classificação de imagens de raio-X em relação aos desfechos normal, pneumonia viral, pneumonia bacteriana e COVID-19.

Figura 3 - Exemplo do uso de CNN para processamento de imagem médica

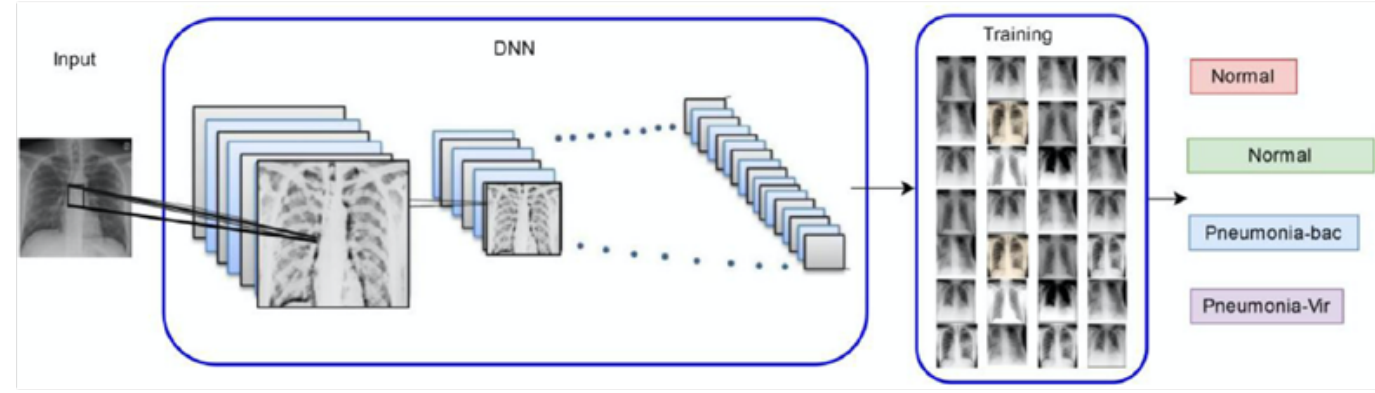

Fonte: Khan, Shah e Bhat (2020, p. 3).

As CNNs calculam probabilidades de a imagem conter ou não cada uma das categorias consideradas no desfecho em questão, com base no conjunto de padrões encontrados ou não naquela imagem. Dessa forma, os modelos baseados em CNNs são muito úteis e altamente eficazes para o apoio ao diagnóstico.

Além de CNNs, outros modelos de IA vêm sendo empregados para o diagnóstico baseado em imagem, conforme sumariza a Figura 4. 
Figura 4 - Principais modelos de IA usados para diagnóstico baseado em imagem

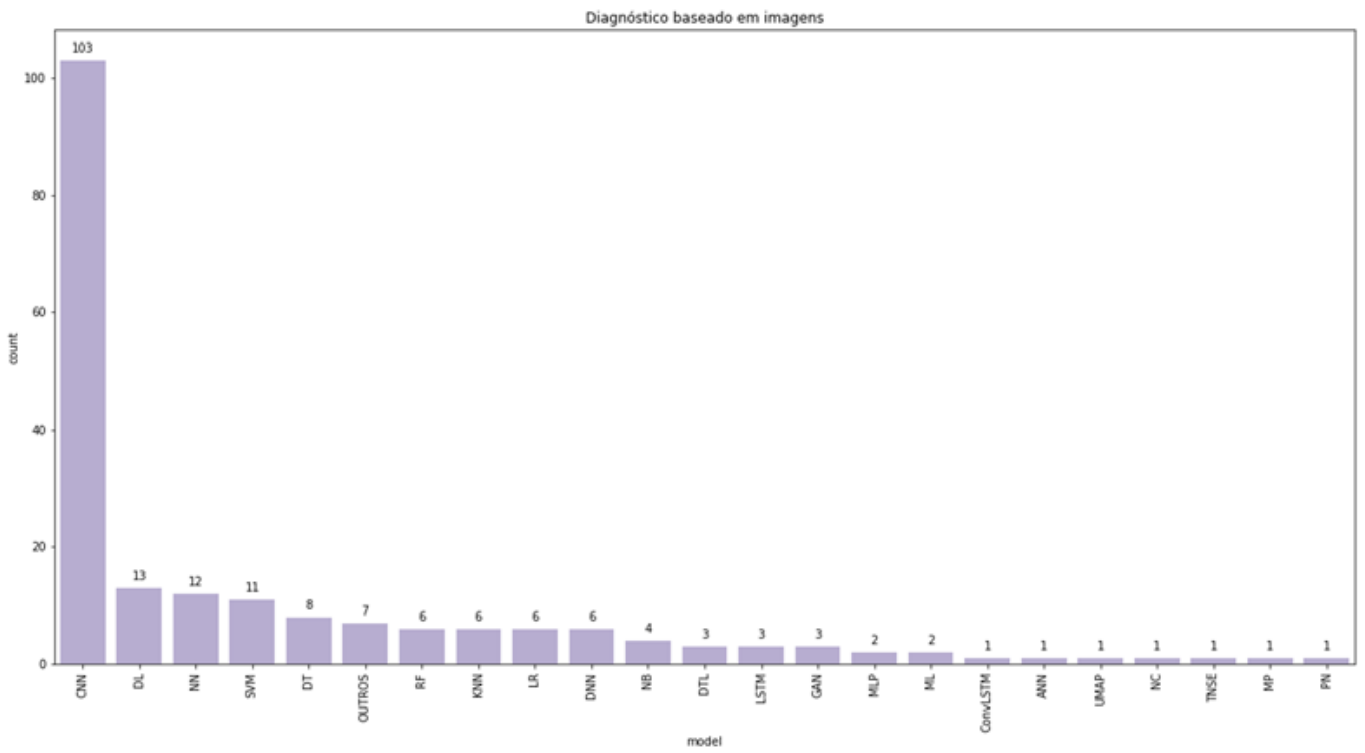

Fonte: elaborada pelos autores.

Nota: Convolutional Neural Networks (CNN); Deep Learning (DL); Neural Networks (NN); Support Vector Machines (SVM); Decision Trees (DT); Random Forest (RF); K-Nearest Neighbours (KNN); Logistic Regression (LR); Deep Neural Networks (DNN); Naïve Bayes (NB); Deep Transfer Learning (DTL); Long Short-Term Memory (LSTM); Generative Adversarial Networks (GAN); Multilayer Perceptron (MLP/ MP); Machine Learning (ML); Convolutional LSTM (ConvLSTM); Artificial Neural Networks (ANN); UMAP clustering (UMAP); Nearest Centroid (NC); T-NSE Clustering (TNSE); e Perceptron Networks (PN).

Modelos preditivos para desfechos diversos Os trabalhos enfocando modelos preditivos objetivam identificar o comportamento futuro de um determinado desfecho com base em dados históricos - séries temporais, por exemplo - ou 
na combinação de variáveis ditas "preditoras", as quais influenciam no desfecho em estudo de acordo com um respectivo peso. Esse peso pode ser atribuído manualmente, por especialistas no domínio (desfecho) em questão, ou calculados a partir de métodos estatísticos.

Nesta categoria, foram encontrados 72 trabalhos e a maior parte refere-se à previsão do número de casos de COVID-19 em diferentes países - Alemanha, Austrália, Brasil, China, Espanha, Estados Unidos, França, Índia, Irã, Itália, México, Peru, Reino Unido, Rússia, Turquia, entre outros. Também foram identificados trabalhos que buscam prever o risco de contágio, o número de pessoas recuperadas e o comportamento global da pandemia.

A Figura 5 apresenta os principais modelos utilizados nas predições, com predominância do modelo LSTM (Long short-term memory). É importante ressaltar que o modelo LSTM é uma arquitetura de Rede Neural Recorrente (RNN) que apresenta memória de curto e longo prazo favorecendo o seu uso em predições. Além de LSTM, a maior parte dos trabalhos empregam modelos supervisionados (random forest, decision tree, support vector machines e logistic regression), os quais são mais adequados para a tarefa de predição em razão da possibilidade de treinamento a partir de dados rotulados, apresentando, assim, maior acurácia. 
Figura 5 - Principais modelos de IA usados em modelos preditivos para diversos desfechos

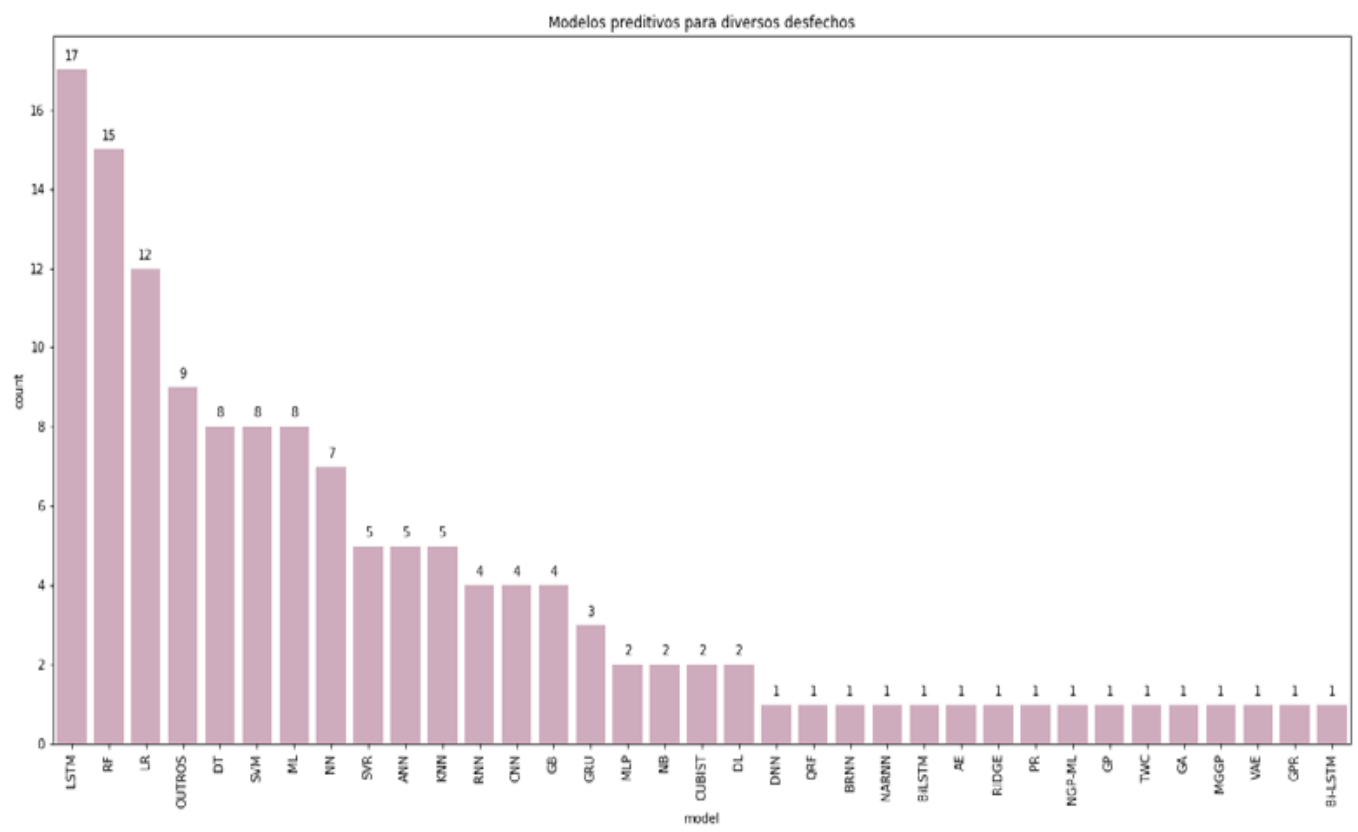

Fonte: elaborada pelos autores.

Diagnóstico baseado em outros dados (exceto imagens)

De forma semelhante ao diagnóstico baseado por imagem, outros dados podem ser usados para apoiar o diagnóstico da COVID-19 e desfechos associados. Neste estudo, foram identificados 27 trabalhos utilizando diferentes tipos de dados, tais como hemograma, secreção nasal e plasma.

A Figura 6 sumariza os principais modelos usados nesta categoria de aplicação, com predominância de modelos de classificação (random forest, decision trees e support vector machines). 
Dependendo do tipo de dado utilizado, os modelos analíticos são ajustados para testar diferentes combinações de variáveis (features) e seus respectivos pesos a fim de gerar escores ou probabilidades para cada desfecho de interesse.

Figura 6 - Principais modelos de IA usados para diagnóstico baseado em outros dados (exceto imagem)

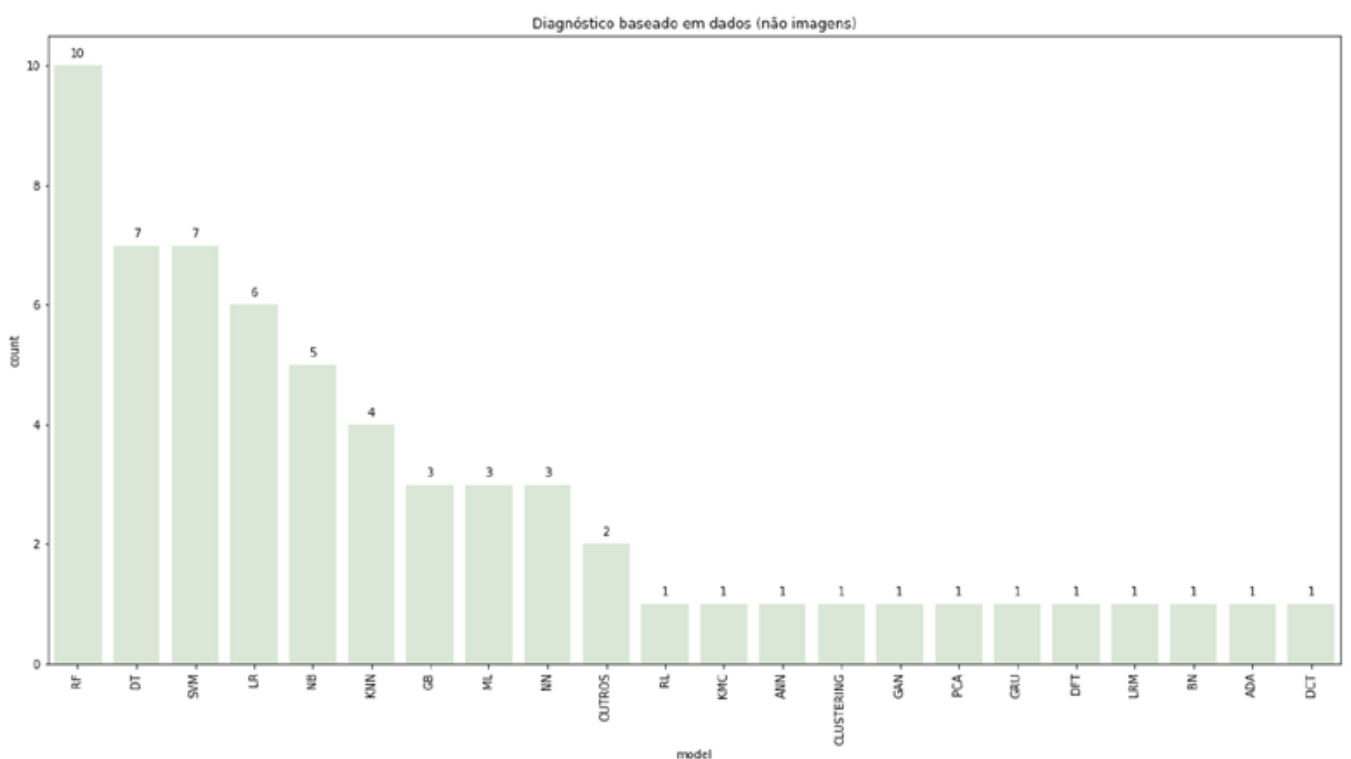

Fonte: elaborada pelos autores.

\section{Triagem e estratificação}

Nesta categoria, foram encontrados 30 trabalhos no total, 15 em cada subcategoria. Os trabalhos em triagem utilizam modelos de IA para identificar a gravidade do paciente com COVID-19 e assim proceder ao atendimento clínico/hospitalar adequado. Dessa forma, a equipe hospitalar tem apoio na tomada de decisão ao 
priorizar pacientes com risco de desfechos mais graves, inclusive morte. A Figura 7 apresenta os principais modelos utilizados para triagem, com predominância de modelos supervisionados.

Figura 7 - Principais modelos de IA usados em modelos de triagem hospitalar

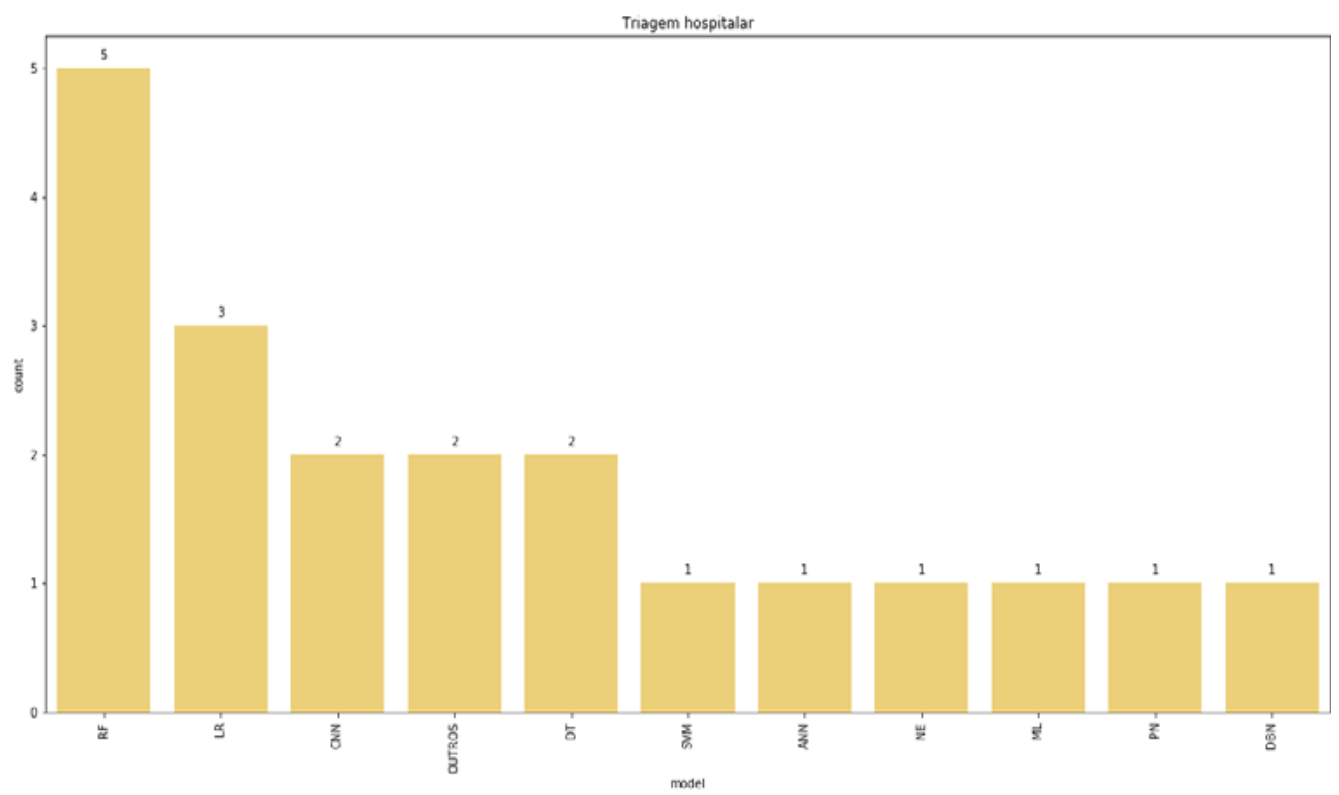

Fonte: elaborada pelos autores.

Na estratificação, a ideia básica é separar os dados em diferentes grupos de forma que os dados em um determinado grupo apresentem características semelhantes entre si e, ao mesmo tempo, bastante diferentes dos dados pertencentes a outros grupos. Modelos de agrupamento são frequentemente usados para essa finalidade, principalmente quando a estrutura dos dados e o número de grupos resultantes não são conhecidos. Porém, 
modelos supervisionados também são empregados para a estratificação. Por exemplo, determinar se uma pessoa vai desenvolver um determinado desfecho ou não, utilizando modelos que classifiquem cada pessoa como pertencente a um dos grupos de desfecho de interesse.

A Figura 8 apresenta os principais modelos identificados nesta categoria. Observa-se uma predominância intercalada entre modelos supervisionados (support vector machines e random forest) e modelos de aprendizado profundo (convolutional neural networks), a qual se justifica pela quantidade de variáveis (features) utilizadas pelos modelos para a tarefa de classificação (estratificação). Modelos de aprendizado profundo são capazes de analisar cenários com um grande número de variáveis e explorar de forma mais eficiente as diferentes combinações (e respectivos pesos) entre essas variáveis.

Figura 8 - Principais modelos de IA usados em modelos de estratificação

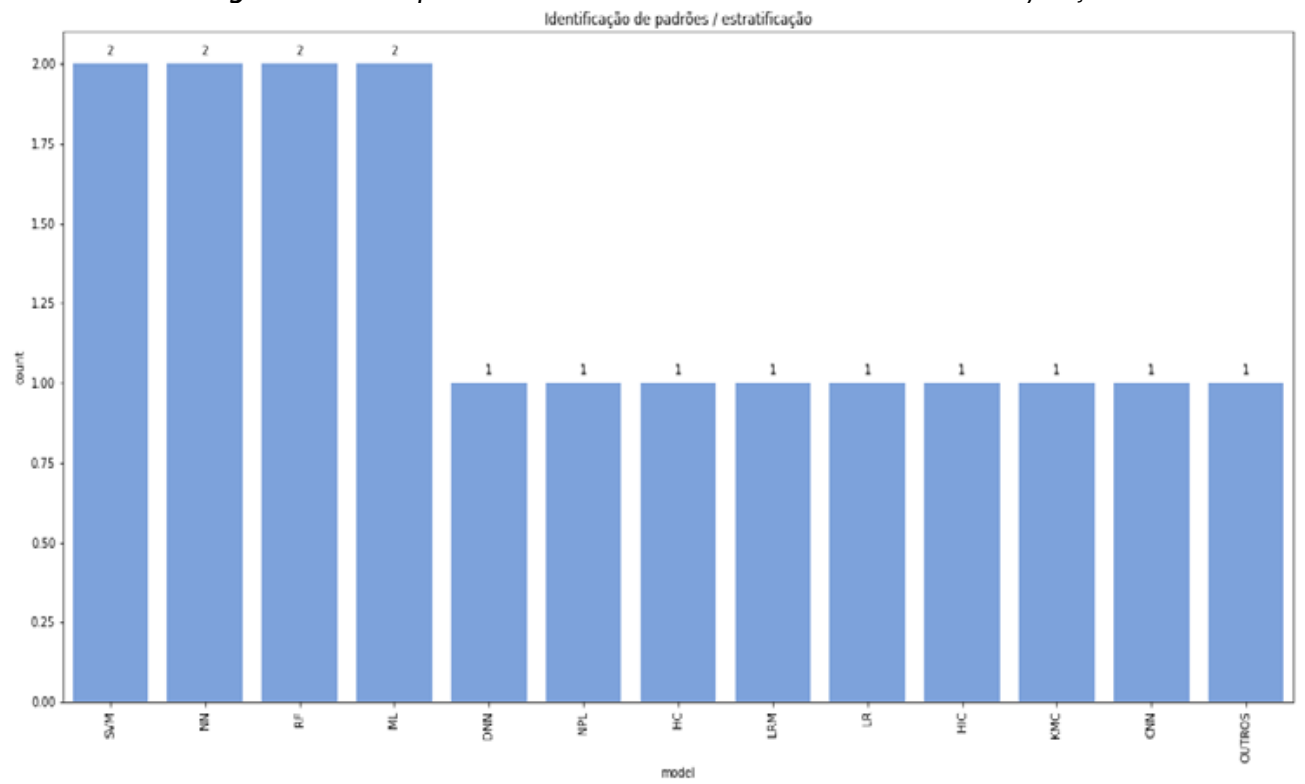

Fonte: elaborada pelos autores. 


\section{Triagem hospitalar}

Nesta categoria, foram encontrados 15 trabalhos que fazem uso de modelos de IA e modelos multicritério para a tomada de decisão em diferentes contextos da triagem hospitalar. Os modelos foram empregados para:

1. indicação de pacientes graves de COVID-19 aptos a receber transfusão de plasma de pacientes recuperados;

2. estratificação de pacientes graves de COVID-19 a partir de dados clínicos e exames de sangue e urina;

3. estabelecimento de perfis proteômicos e metabolômicos de soros de pacientes com COVID-19 (conforme ilustrado na Figura 9), entre outros desfechos.

A Figura 10 ilustra os modelos de IA empregados nesses trabalhos. Uma vez que a triagem é majoritariamente uma tarefa de classificação (ou estratificação), observa-se uma predominância de modelos supervisionados (random forest e logistic regression). CNNs também são empregadas, principalmente em tarefas de triagem baseadas na análise de imagens. 
Figura 9 - Triagem de pacientes a partir de perfis sorológicos

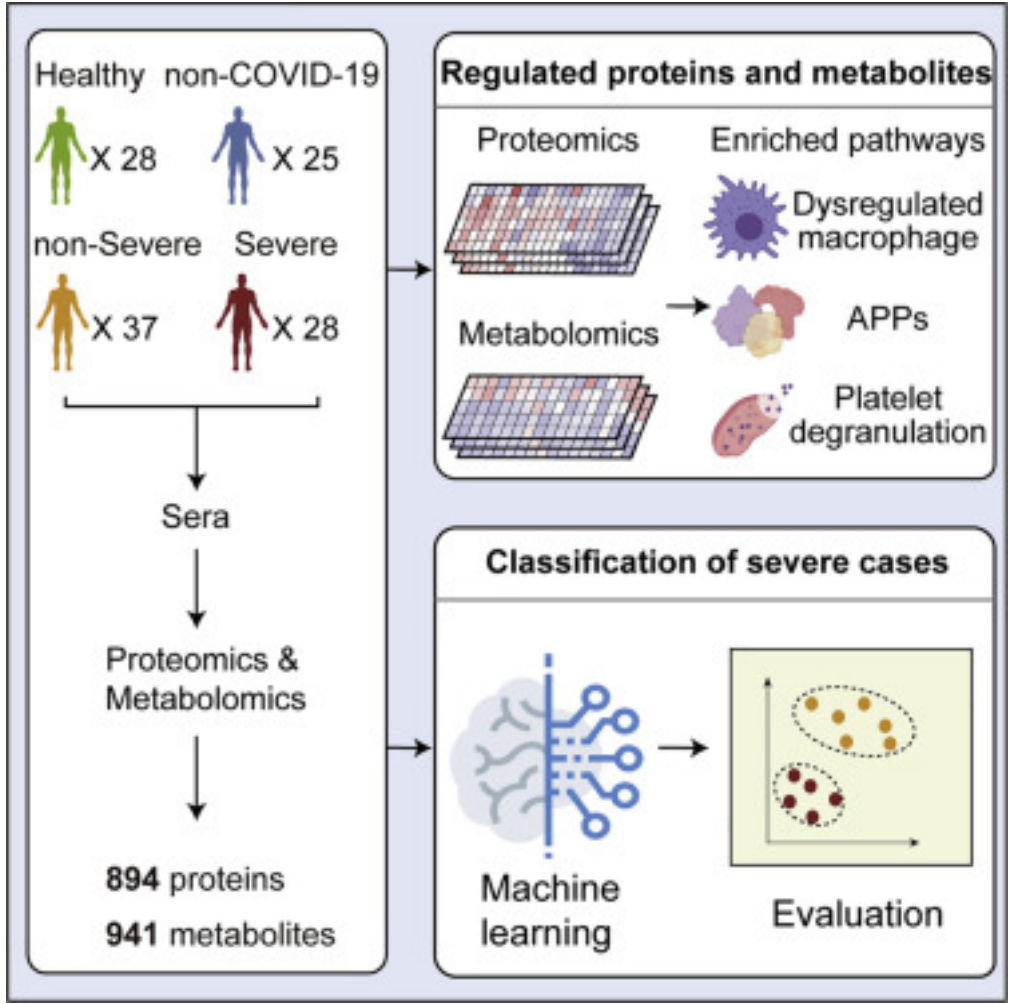

Fonte: Shen e demais autores (2020, p. 2). 
Figura 10 - Modelos de IA empregados em aplicações de triagem hospitalar.

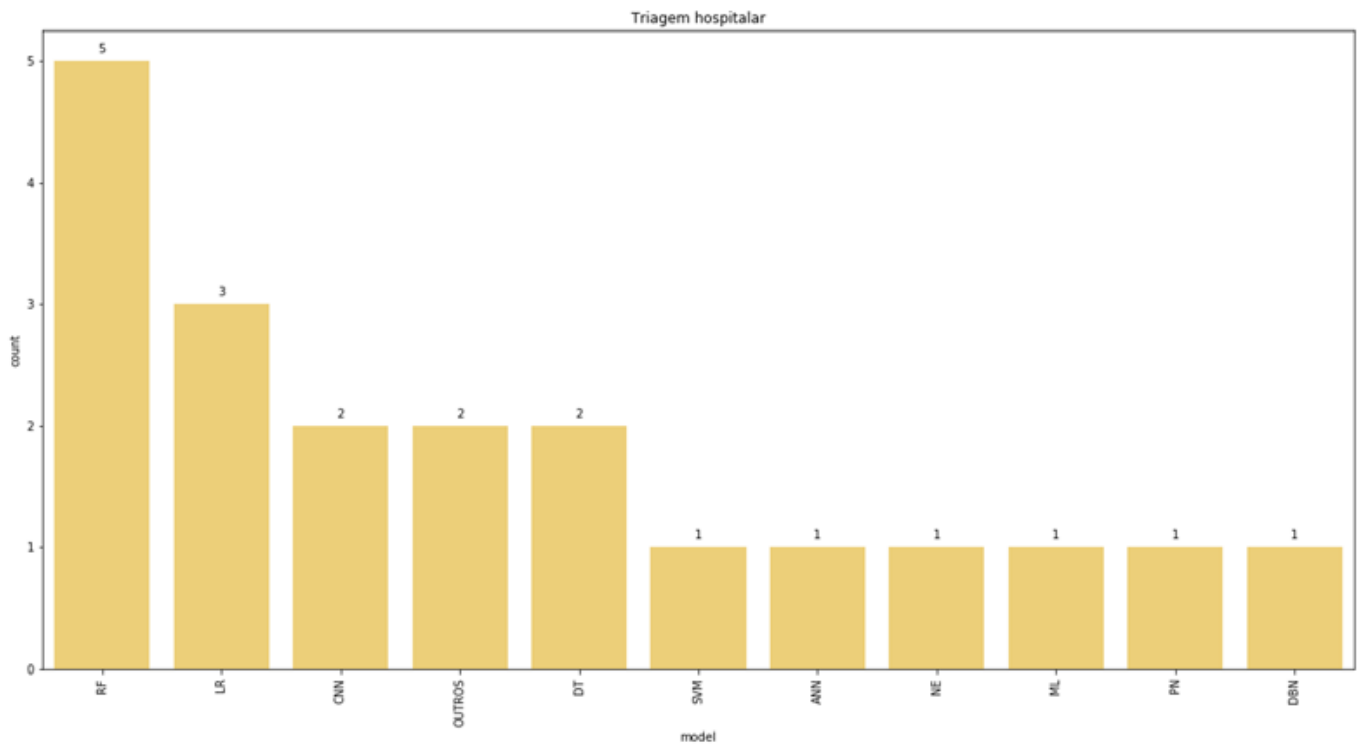

Fonte: elaborada pelos autores.

Análise genômica e pesquisa de fármacos Nesta categoria, encontram-se trabalhos enfocando a análise molecular do vírus SARS-CoV-2, alguns deles comparando com outros tipos de vírus, bem como trabalhos relacionados à pesquisa e reposicionamento de fármacos, incluindo o desenvolvimento de vacinas. Neste estudo, foram identificados 8 e 12 trabalhos que aplicam modelos de IA para análise genômica e pesquisa de fármacos, respectivamente.

$\mathrm{Na}$ análise genômica, objetiva-se identificar a estrutura do vírus e compará-la com a estrutura de vírus semelhantes ou ainda entender como essa estrutura pode sofrer alterações (mutações) ao longo do tempo. Para este tipo de aplicação, modelos de IA para 
classificação e predição são empregados para a análise e comparação de sequências de DNA, de variações estruturais e análise funcional de diferentes genomas (transcriptômica e proteômica).

$\mathrm{Na}$ pesquisa de fármacos, o principal objetivo é testar um conjunto de moléculas candidatas que podem apresentar um bom acoplamento às moléculas do vírus SARS-CoV-2 e, dessa forma, atuar como inibidores do desenvolvimento viral (conforme ilustrado na Figura 11). 
Figura 11 - Uso de modelos de IA para análise de químicos que interagem com alvos SARS-COV-2

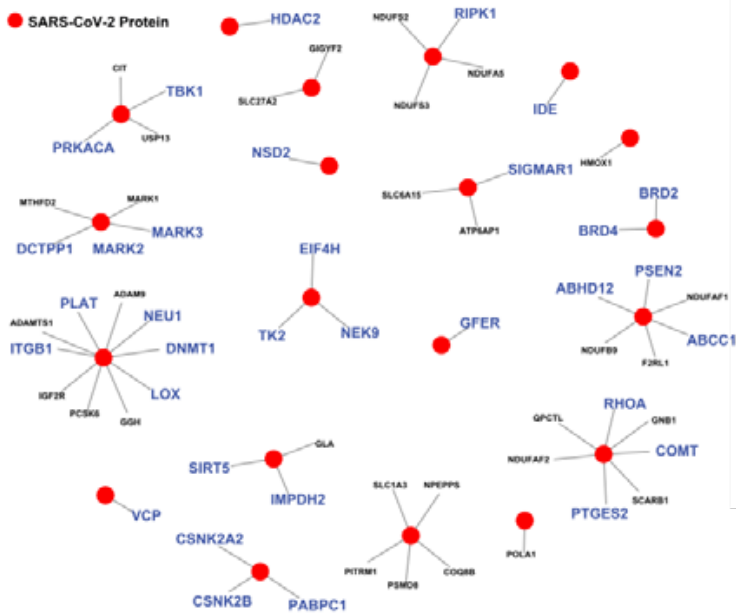

33 human target proteins + ACE2

Fit machine learning models to identify new chemicals that disrupt human proteins targeted by SARS-CoV-2 on different chemical feature sets

validation with $R$

validation with ROC

correlating predicted vs

observed activity on test sets
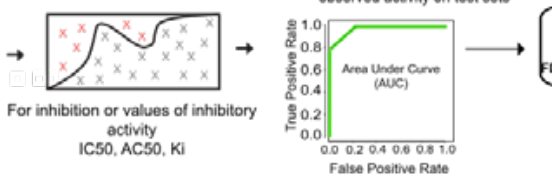

Predict from ZINC (purchasable) $10+$ million chemicals A registered chemicals and approved drugs

Fonte: adaptada de Kowalewski e Ray (2020, p. 3).

As Figuras 12 e 13 sumarizam os principais modelos usados em aplicações de análise genômica e pesquisa de fármacos. Pode-se observar uma grande variabilidade de modelos, o que 
reflete a complexidade e os diversos desafios de pesquisa e desenvolvimento presentes nessas áreas.

Figura 12 - Principais modelos de IA usados em aplicações de análise genômica.

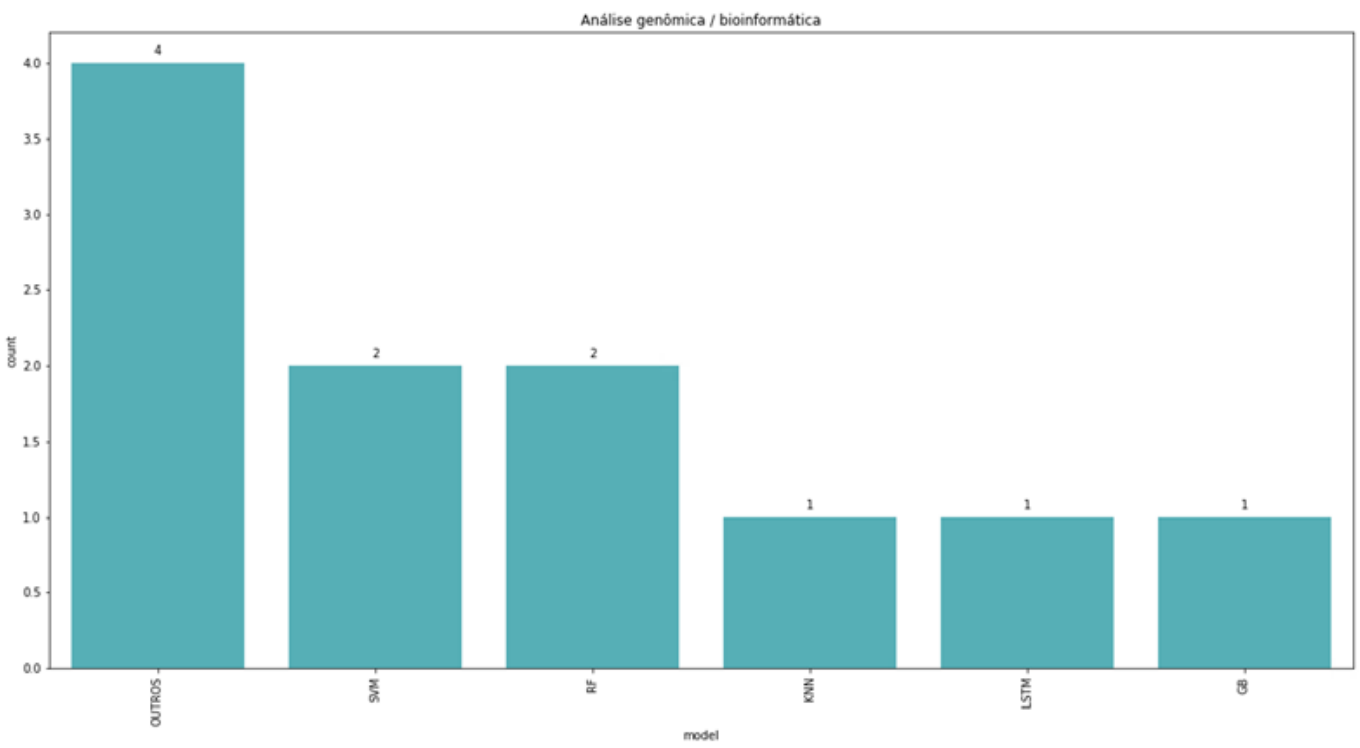

Fonte: elaborada pelos autores. 
Figura 13 - Principais modelos de IA usados em aplicações de pesquisa de fármacos.

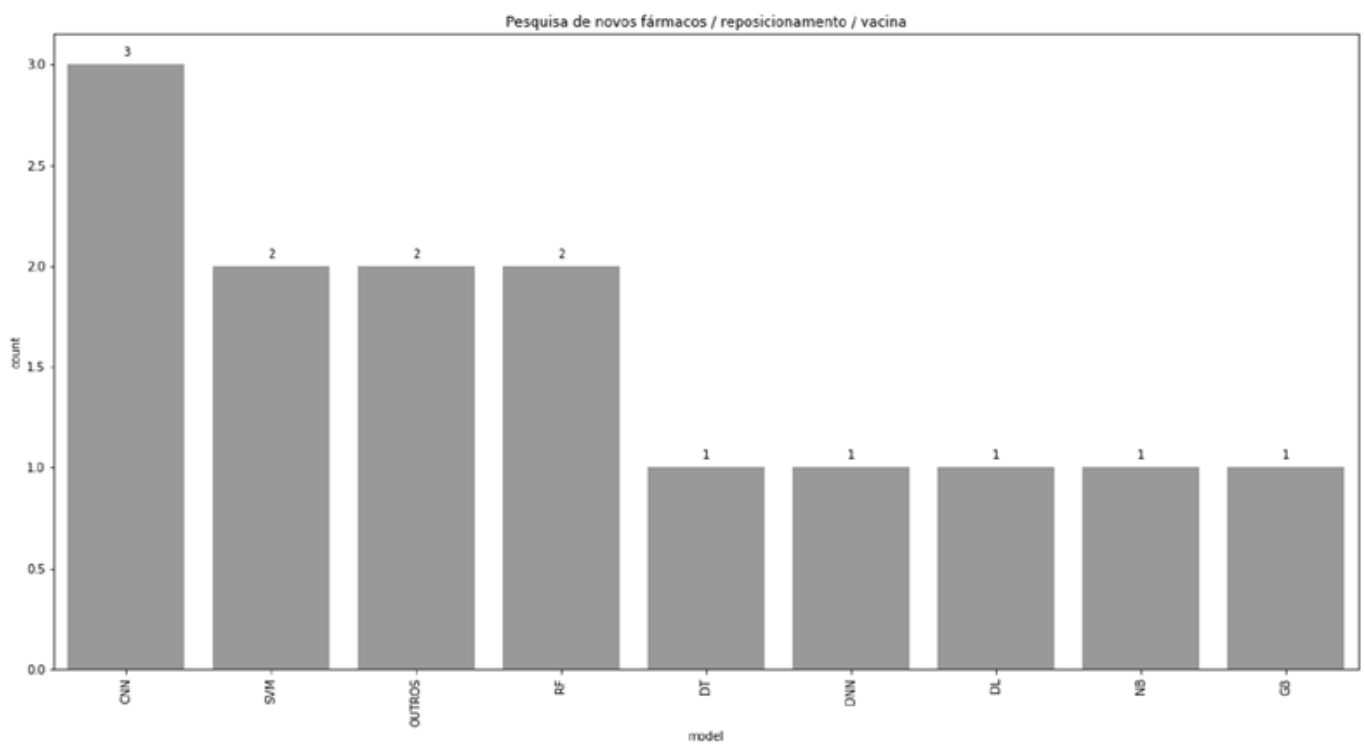

Fonte: elaborada pelos autores.

\section{Monitoramento de contato e rastreamento}

Nesta categoria, aparecem trabalhos que usam dados capturados através de diferentes tipos de sensores, tais como câmeras e sinalizadores do Sistema de Posicionamento Global (GPS), para identificar locais com indicação ou confirmação de casos de COVID-19. A partir desses dados, os modelos auxiliam na identificação de pessoas que estiveram em contato com pacientes de COVID-19 e que devem ser avisadas e monitoradas para uma possível transmissão da doença. Diversos aplicativos para dispositivos móveis foram desenvolvidos nesse contexto, no intuito de promover a 
captação desses dados de contato e o estabelecimento de redes de monitoramento ativo por parte das pessoas.

Alguns trabalhos utilizam dados de sensores "vestíveis" (wearable devices) para o monitoramento ativo de pacientes. Por exemplo, dados de frequência cardíaca e ciclo circadiano foram combinados para a detecção de indícios de COVID-19 em um sistema de alerta. (ZHU et al., 2020) Outros trabalhos enfocam o uso de dados públicos de mobilidade e distanciamento social para mensurar os efeitos da quarentena na transmissão da doença, apoiados por modelos matemáticos - tal como SIR (HARKO; LOBO; MAK, 2014) - e de inteligência artificial.

A Figura 14 ilustra os modelos de IA empregados nos nove trabalhos selecionados. A diversidade desta categoria, com monitoramento e rastreamento aplicados a diversos contextos, se reflete na mistura de modelos supervisionados e de aprendizado profundo.

Figura 14 - Principais modelos de IA usados em aplicações de monitoramento e rastreamento de contato

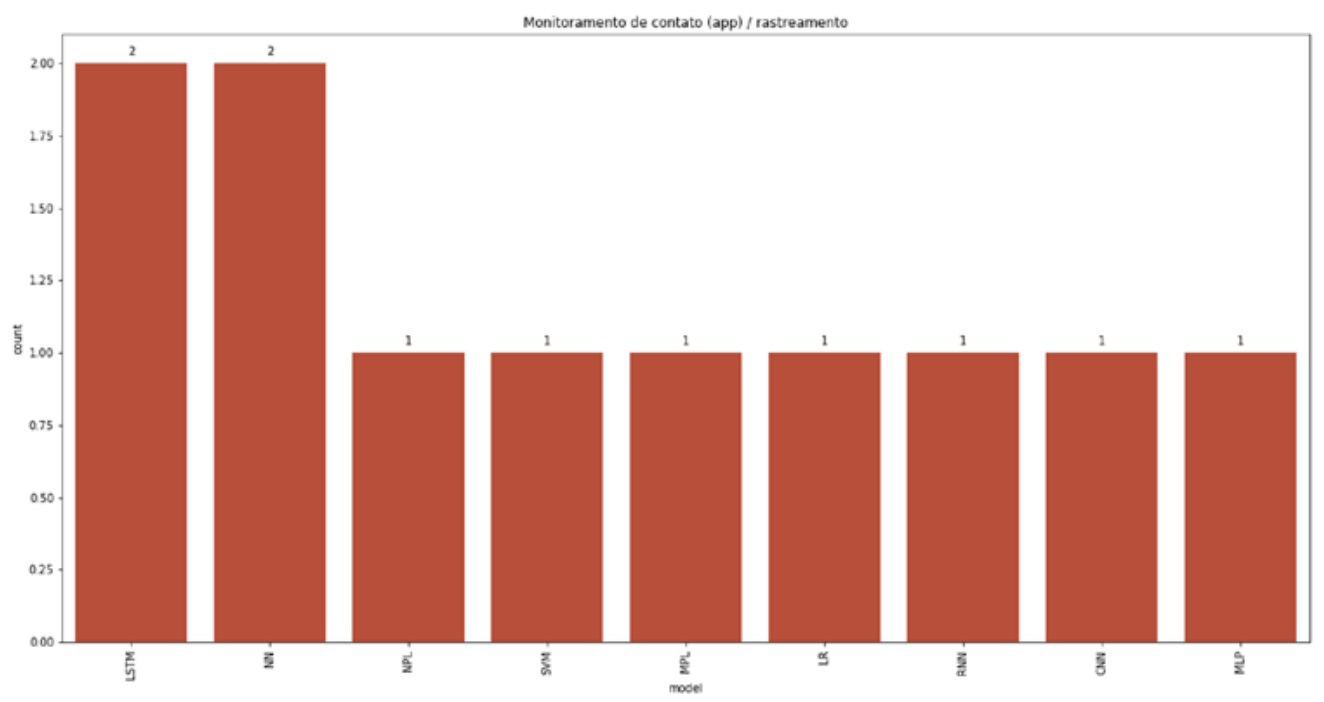

Fonte: elaborada pelos autores. 


\section{Mineração de texto}

A mineração de texto está inserida na categoria de modelos para o processamento de linguagem natural (JURAFSKY; MARTIN, 2008) e enfoca o emprego de modelos e técnicas capazes de extrair informações a partir de dados não estruturados e descritos de forma "natural", sem necessariamente seguir um jargão ou formato específico.

No contexto da COVID-19, observa-se o emprego de mineração textual em aplicações de telemedicina ou atendimento virtual, extração de dados textuais a partir de prontuários eletrônicos, assistentes virtuais - tais como chatbots - para triagem/diagnóstico ou monitoramento de pacientes, análise de sentimento em redes sociais (conforme ilustrado na Figura 15), entre outras aplicações.

Figura 15 - Exemplo de mineração textual aplicada a tweets para classificação de sentimento em redes sociais

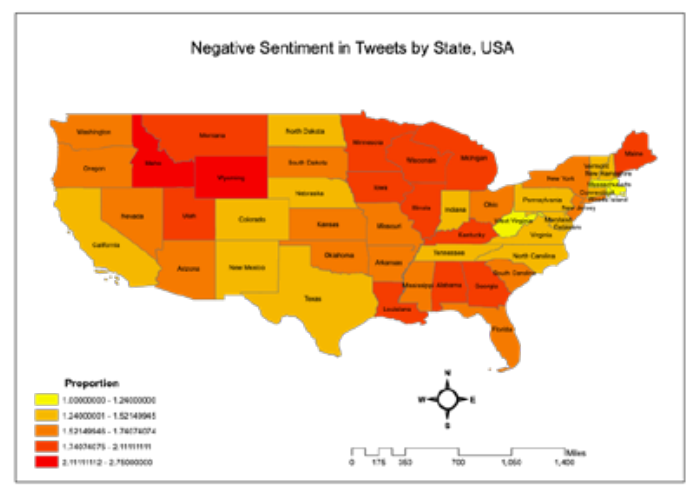

(a) Negative sentiment.

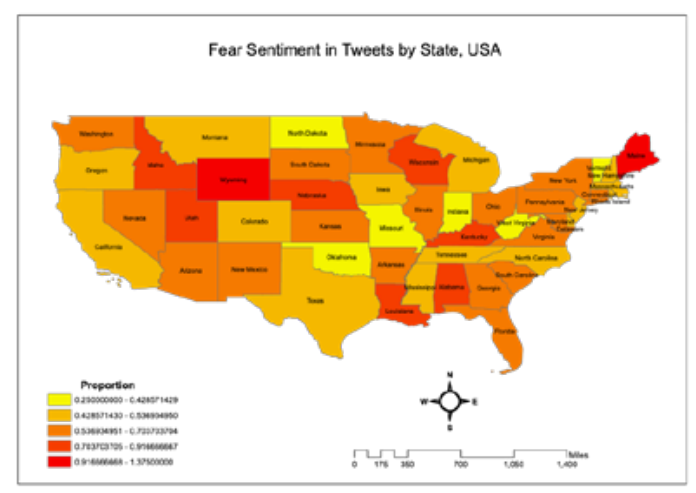

(b) Fear sentiment.

Fonte: Samuel e demais autores (2020, p. 6).

A Figura 16 sumariza os principais modelos empregados nos oito trabalhos selecionados neste estudo. Observa-se uma leve predominância de modelos supervisionados, visto que as técnicas de 
mineração textual são frequentemente empregadas em tarefas de classificação - por exemplo, estratificação e análise de sentimento -, as quais demandam dados para treinamento.

Figura 16 - Principais modelos de IA usados em aplicações envolvendo mineração textual

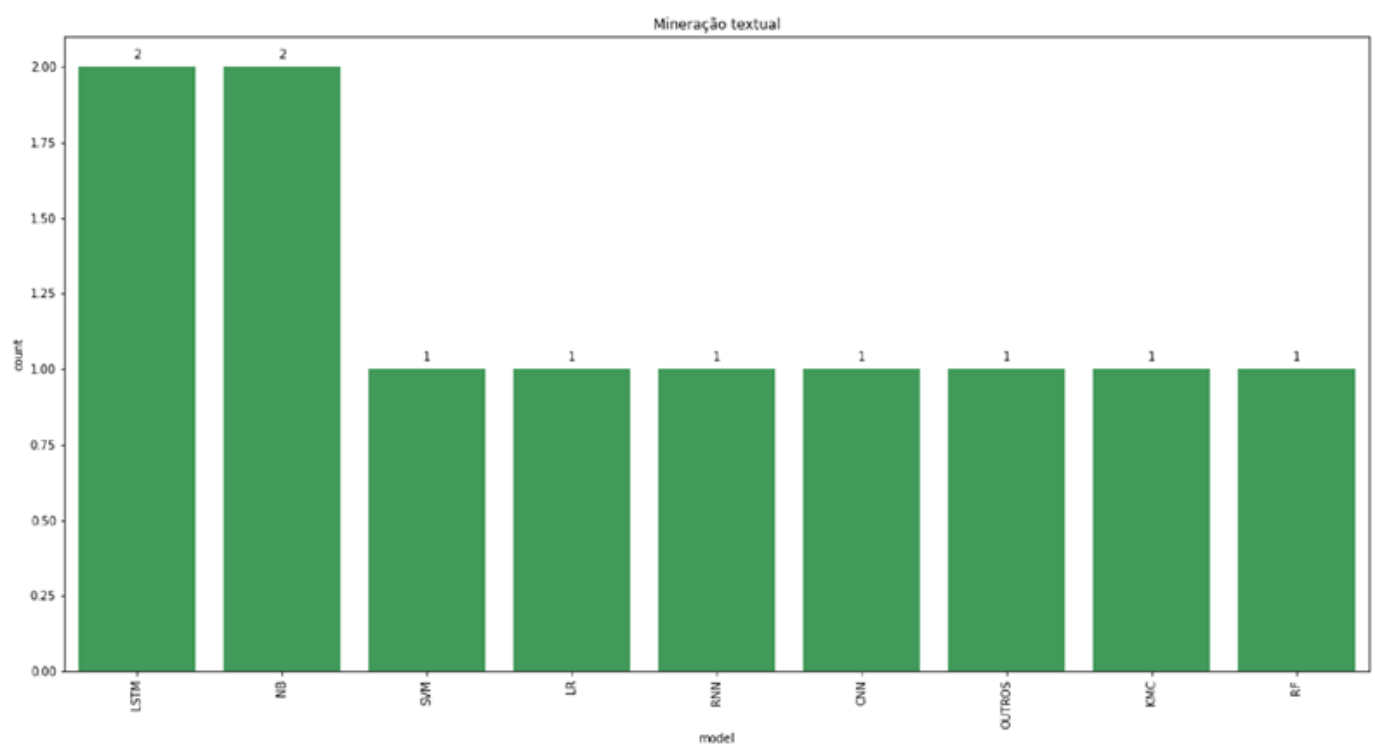

Fonte: elaborada pelos autores.

\section{Análise espacial}

Nesta categoria de aplicações, encontram-se trabalhos que fazem uso de modelos e ferramentas para análise espacial, nas quais os dados são geralmente representados em mapas e as análises levam em consideração diferentes aspectos, tais como área de cobertura de serviços médicos, áreas de contágio e população 
diretamente afetada, medidas de distanciamento social versus número de casos e/ou óbitos, entre outros.

Neste estudo, foram identificados quatro trabalhos cujo foco principal está na exploração de modelos de análise espacial no contexto da COVID-19. Entretanto, observa-se que alguns trabalhos classificados em outras categorias também apresentam elementos de análise espacial combinados com outras técnicas. Dentre os quatro trabalhos selecionados, destaca-se o uso de mapas auto-organizáveis - Self-Organizing Maps (SOM) - como uma técnica de agrupamento (clustering) para o estabelecimento de padrões e correlações entre grupos distintos de dados. A Figura 17 ilustra o emprego de SOMs para a classificação de países e estados em diferentes categorias relativas à prevalência de COVID-19.

Figura 17 - Emprego de mapas auto-organizáveis para o agrupamento de países (a) e estados (b) em relação à prevalência da Covid-19

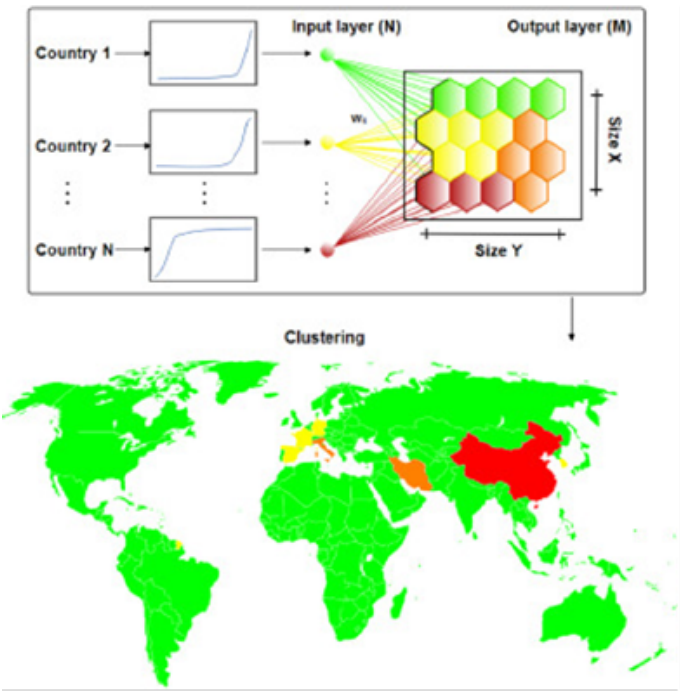

(a)

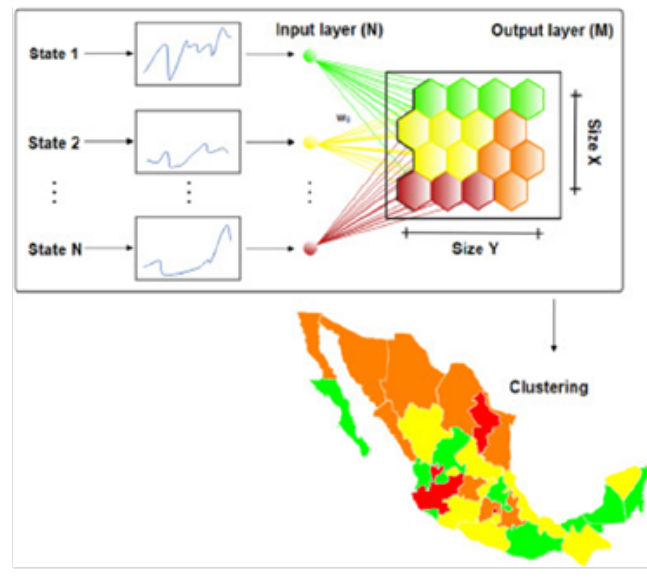

(b)

Fonte: adaptada de Melin e demais autores (2020). 
A Figura 18 sumariza os modelos de IA empregados nos quatro trabalhos selecionados neste estudo, com ênfase para redes neurais artificiais.

Figure 18 - Modelos de IA usados em aplicações de análise espacial

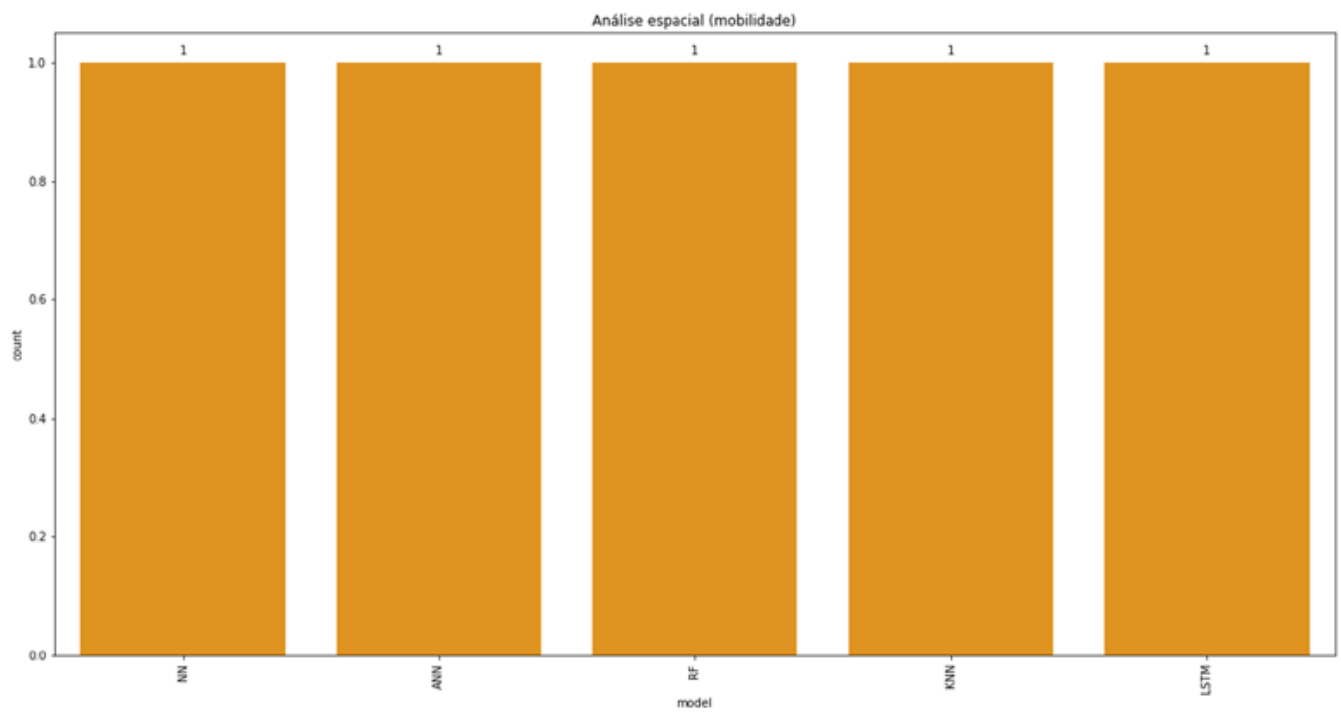

Fonte: elaborada pelos autores.

\section{Outros desfechos}

Neste estudo, foram ainda selecionados quatro trabalhos com enfoque na deteç̧ão do uso de máscaras (um trabalho), na classificação de risco de pacientes com doenças renais crônicas em relação à COVID-19 (dois trabalhos) e na análise da evolução temporal de marcadores biológicos em testes de Reação em Cadeia da Polimerase (PCR). Os modelos baseados em CNN e árvores de decisão destacam-se dentre esses trabalhos. 


\section{Síntese do uso de modelos de IA no contexto da COVID-19}

Durante a realização deste estudo, observou-se um número crescente de publicações envolvendo conceitos e modelos de IA aplicados ao contexto da COVID-19. Os critérios de inserção e remoção empregados procuraram garantir que somente trabalhos com resultados de experimentação prática fossem considerados para análise, uma vez que o objetivo foi avaliar o quão confiáveis e eficazes são os modelos de IA nas diferentes aplicações possíveis.

Modelos supervisionados e de aprendizado profundo especialmente redes neurais - destacam-se dentre o conjunto de modelos observados, uma vez que boa parte das aplicações envolve alguma tarefa de classificação ou estratificação. Alguma variabilidade foi observada nas categorias de modelos preditivos e de diagnóstico baseado em imagem, principalmente devido ao grande número de trabalhos identificados.

O Quadro 3 sumariza as principais informações dos 325 trabalhos selecionados neste estudo, de acordo com os critérios apresentados na Quadro 2.

Quadro 3 - Trabalhos recuperados

\begin{tabular}{|c|c|c|c|}
\hline ID & $\begin{array}{c}\text { Categoria de } \\
\text { aplicação }\end{array}$ & Título & DOI \\
\hline 1 & Análise espacial & $\begin{array}{c}\text { Measurement method for evaluating the } \\
\text { lockdown policies during the COVID-19 } \\
\text { pandemic }\end{array}$ & $10.3390 /$ ijerph17155574 \\
\hline 2 & Análise espacial & $\begin{array}{c}\text { Artificial intelligence-empowered mobilization of } \\
\text { assessments in COVID-19-like pandemics: A case } \\
\text { study for early flattening of the curve }\end{array}$ & $10.3390 /$ ijerph17103437 \\
\hline
\end{tabular}




\begin{tabular}{|c|c|c|c|}
\hline ID & $\begin{array}{l}\text { Categoria de } \\
\text { aplicação }\end{array}$ & Título & DOI \\
\hline 3 & Análise espacial & $\begin{array}{l}\text { Modified SEIR and AI prediction of the epidemics } \\
\text { trend of COVID-19 in China under public health } \\
\text { interventions }\end{array}$ & $10.21037 /$ jtd.2020.02.64 \\
\hline 4 & Análise espacial & $\begin{array}{c}\text { Analysis of Spatial Spread Relationships of } \\
\text { Coronavirus (COVID-19) Pandemic in the World } \\
\text { using Self Organizing Maps }\end{array}$ & 10.1016/j.chaos.2020.109917 \\
\hline 5 & Análise genômica & $\begin{array}{l}\text { Time series prediction of COVID-19 by mutation } \\
\text { rate analysis using recurrent neural network-based } \\
\text { LSTM model }\end{array}$ & 10.1016/j.chaos.2020.110018 \\
\hline 6 & Análise genômica & $\begin{array}{c}\text { Discovery of Aptamers Targeting the Receptor- } \\
\text { Binding Domain of the SARS-CoV-2 Spike } \\
\text { Glycoprotein }\end{array}$ & 10.1021/acs.analchem.0c01394 \\
\hline 7 & Análise genômica & $\begin{array}{l}\text { Genomic determinants of pathogenicity in } \\
\text { SARS-CoV-2 and other human coronaviruses }\end{array}$ & 10.1073/pnas.2008176117 \\
\hline 8 & Análise genômica & $\begin{array}{l}\text { Knowledge synthesis of } 100 \text { million biomedical } \\
\text { documents augments the deep expression } \\
\text { profiling of coronavirus receptors }\end{array}$ & 10.7554/eLife.58040 \\
\hline 9 & Análise genômica & $\begin{array}{l}\text { Machine learning using intrinsic genomic } \\
\text { signatures for rapid classification of novel } \\
\text { pathogens: COVID-19 case study }\end{array}$ & 10.1371/journal.pone.0232391 \\
\hline 10 & Análise genômica & $\begin{array}{l}\text { Proteomic and Metabolomic Characterization of } \\
\text { COVID-19 Patient Sera }\end{array}$ & 10.1101/2020.04.07.20054585 \\
\hline 11 & Análise genômica & $\begin{array}{l}\text { Upper airway gene expression differentiates } \\
\text { COVID-19 from other acute respiratory illnesses } \\
\text { and reveals suppression of innate immune } \\
\text { responses by SARS-CoV-2 }\end{array}$ & 10.1101/2020.05.18.20105171 \\
\hline 12 & Análise genômica & Smart Pooling: Al-powered COVID-19 testing & $10.1101 / 2020.07 .13 .20152983$ \\
\hline 13 & $\begin{array}{l}\text { Diagnóstico } \\
\text { baseado em } \\
\text { outros dados }\end{array}$ & $\begin{array}{l}\text { Use of Machine Learning and Artificial Intelligence } \\
\text { to predict SARS-CoV-2 infection from Full Blood } \\
\text { Counts in a population }\end{array}$ & 10.1016/j.intimp.2020.106705 \\
\hline 14 & $\begin{array}{l}\text { Diagnóstico } \\
\text { baseado em } \\
\text { outros dados }\end{array}$ & $\begin{array}{c}\text { Detection of COVID-19 Infection from Routine } \\
\text { Blood Exams with Machine Learning: A Feasibility } \\
\text { Study }\end{array}$ & $10.1007 / \mathrm{s} 10916-020-01597-4$ \\
\hline
\end{tabular}




\begin{tabular}{|c|c|c|c|}
\hline ID & $\begin{array}{l}\text { Categoria de } \\
\text { aplicação }\end{array}$ & Título & DOI \\
\hline 15 & $\begin{array}{l}\text { Diagnóstico } \\
\text { baseado em } \\
\text { outros dados }\end{array}$ & $\begin{array}{l}\text { Correlation between temperature and COVID-19 } \\
\text { (suspected, confirmed and death) cases based on } \\
\text { machine learning analysis }\end{array}$ & 10.22207/JPAM.14.SPL1.40 \\
\hline 16 & $\begin{array}{l}\text { Diagnóstico } \\
\text { baseado em } \\
\text { outros dados }\end{array}$ & $\begin{array}{l}\text { Detection of SARS-CoV-2 in nasal swabs using } \\
\text { MALDI-MS }\end{array}$ & $10.1038 / s 41587-020-0644-7$ \\
\hline 17 & $\begin{array}{l}\text { Diagnóstico } \\
\text { baseado em } \\
\text { outros dados }\end{array}$ & $\begin{array}{c}\text { Exploration on covid-19 data in india using } \\
\text { machine learning for prediction of infected and } \\
\text { death cases }\end{array}$ & 10.37418/amsj.9.7.26 \\
\hline 18 & $\begin{array}{l}\text { Diagnóstico } \\
\text { baseado em } \\
\text { outros dados }\end{array}$ & $\begin{array}{l}\text { Hemogram data as a tool for decision-making in } \\
\text { COVID-19 management: Applications to resource } \\
\text { scarcity scenarios }\end{array}$ & 10.7717/peerj.9482 \\
\hline 19 & $\begin{array}{l}\text { Diagnóstico } \\
\text { baseado em } \\
\text { outros dados }\end{array}$ & $\begin{array}{l}\text { A Novel Triage Tool of Artificial Intelligence } \\
\text { Assisted Diagnosis Aid System for Suspected } \\
\text { COVID-19 pneumonia In Fever Clinics }\end{array}$ & $10.1101 / 2020.03 .19 .20039099$ \\
\hline 20 & $\begin{array}{l}\text { Diagnóstico } \\
\text { baseado em } \\
\text { outros dados }\end{array}$ & $\begin{array}{l}\text { Rapid and accurate identification of COVID-19 } \\
\text { infection through machine learning based on } \\
\text { clinical available blood test results }\end{array}$ & $10.1101 / 2020.04 .02 .20051136$ \\
\hline 21 & $\begin{array}{l}\text { Diagnóstico } \\
\text { baseado em } \\
\text { outros dados }\end{array}$ & $\begin{array}{l}\text { COVID-19 diagnosis prediction in emergency care } \\
\text { patients: a machine learning approach }\end{array}$ & $10.1101 / 2020.04 .04 .20052092$ \\
\hline 22 & $\begin{array}{l}\text { Diagnóstico } \\
\text { baseado em } \\
\text { outros dados }\end{array}$ & $\begin{array}{c}\text { A novel specific artificial intelligence-based } \\
\text { method to identify COVID-19 cases using simple } \\
\text { blood exams }\end{array}$ & $10.1101 / 2020.04 .10 .20061036$ \\
\hline 23 & $\begin{array}{l}\text { Diagnóstico } \\
\text { baseado em } \\
\text { outros dados }\end{array}$ & $\begin{array}{l}\text { Early prediction of mortality risk among severe } \\
\text { COVID-19 patients using machine learning }\end{array}$ & $10.1101 / 2020.04 .13 .20064329$ \\
\hline 24 & $\begin{array}{l}\text { Diagnóstico } \\
\text { baseado em } \\
\text { outros dados }\end{array}$ & $\begin{array}{l}\text { Detection of COVID-19 Infection from Routine } \\
\text { Blood Exams with Machine Learning: a Feasibility } \\
\text { Study }\end{array}$ & $10.1101 / 2020.04 .22 .20075143$ \\
\hline 25 & $\begin{array}{l}\text { Diagnóstico } \\
\text { baseado em } \\
\text { outros dados }\end{array}$ & $\begin{array}{l}\text { COVID-19 diagnosis prediction by symptoms of } \\
\text { tested individuals: a machine learning approach }\end{array}$ & $10.1101 / 2020.05 .07 .20093948$ \\
\hline
\end{tabular}




\begin{tabular}{|c|c|c|c|}
\hline ID & $\begin{array}{l}\text { Categoria de } \\
\text { aplicação }\end{array}$ & Título & DOI \\
\hline 26 & $\begin{array}{l}\text { Diagnóstico } \\
\text { baseado em } \\
\text { outros dados }\end{array}$ & $\begin{array}{l}\text { Hemogram Data as a Tool for Decision-making in } \\
\text { COVID-19 Management: Applications to Resource } \\
\text { Scarcity Scenarios }\end{array}$ & $10.1101 / 2020.05 .09 .20096818$ \\
\hline 27 & $\begin{array}{l}\text { Diagnóstico } \\
\text { baseado em } \\
\text { outros dados }\end{array}$ & $\begin{array}{l}\text { Heg.IA: An intelligent system to support diagnosis } \\
\text { of Covid-19 based on blood tests }\end{array}$ & $10.1101 / 2020.05 .14 .20102533$ \\
\hline 28 & $\begin{array}{l}\text { Diagnóstico } \\
\text { baseado em } \\
\text { outros dados }\end{array}$ & $\begin{array}{l}\text { COVID-19 Outcomes in } 4712 \text { consecutively } \\
\text { confirmed SARS-CoV2 cases in the city of Madrid. }\end{array}$ & $10.1101 / 2020.05 .22 .20109850$ \\
\hline 29 & $\begin{array}{l}\text { Diagnóstico } \\
\text { baseado em } \\
\text { outros dados }\end{array}$ & $\begin{array}{l}\text { Predictive usefulness of PCR testing in different } \\
\text { patterns of Covid-19 symptomatology - Analysis } \\
\text { of a French cohort of } 12,810 \text { outpatients }\end{array}$ & $10.1101 / 2020.06 .07 .20124438$ \\
\hline 30 & $\begin{array}{l}\text { Diagnóstico } \\
\text { baseado em } \\
\text { outros dados }\end{array}$ & $\begin{array}{l}\text { Symptom clusters in Covid19: A potential clinical } \\
\text { prediction tool from the COVID Symptoma study } \\
\text { app }\end{array}$ & $10.1101 / 2020.06 .12 .20129056$ \\
\hline 31 & $\begin{array}{l}\text { Diagnóstico } \\
\text { baseado em } \\
\text { outros dados }\end{array}$ & $\begin{array}{l}\text { Covid-19 rapid test by combining a random forest } \\
\text { based web system and blood tests }\end{array}$ & $10.1101 / 2020.06 .12 .20129866$ \\
\hline 32 & $\begin{array}{l}\text { Diagnóstico } \\
\text { baseado em } \\
\text { outros dados }\end{array}$ & $\begin{array}{l}\text { Using Machine Learning of Clinical Data to } \\
\text { Diagnose COVID-19 }\end{array}$ & $10.1101 / 2020.06 .24 .20138859$ \\
\hline 33 & $\begin{array}{l}\text { Diagnóstico } \\
\text { baseado em } \\
\text { outros dados }\end{array}$ & $\begin{array}{l}\text { ESTIMATING UNDERDIAGNOSIS OF COVID-19 } \\
\text { WITH NOWCASTING AND MACHINE LEARNING: } \\
\text { EXPERIENCE FROM BRAZIL }\end{array}$ & $10.1101 / 2020.07 .01 .20144402$ \\
\hline 34 & $\begin{array}{l}\text { Diagnóstico } \\
\text { baseado em } \\
\text { outros dados }\end{array}$ & $\begin{array}{c}\text { Covid-19 automated diagnosis and risk } \\
\text { assessment through Metabolomics and } \\
\text { Machine-Learning }\end{array}$ & $10.1101 / 2020.07 .24 .20161828$ \\
\hline 35 & $\begin{array}{l}\text { Diagnóstico } \\
\text { baseado em } \\
\text { outros dados }\end{array}$ & $\begin{array}{c}\text { Severity detection for the coronavirus disease } \\
2019 \text { (COVID-19) patients using a machine } \\
\text { learning model based on the blood and urine } \\
\text { tests }\end{array}$ & $10.1101 / 2020.07 .27 .20044990$ \\
\hline 36 & $\begin{array}{l}\text { Diagnóstico } \\
\text { baseado em } \\
\text { outros dados }\end{array}$ & $\begin{array}{l}\text { A machine learning explanation of the pathogen- } \\
\text { immune relationship of SARS-CoV- } 2 \text { and machine } \\
\text { learning models of prognostic biomarkers to } \\
\text { predict asymptomatic or symptomatic infections }\end{array}$ & $10.1101 / 2020.07 .27 .20162867$ \\
\hline
\end{tabular}




\begin{tabular}{|c|c|c|c|}
\hline ID & $\begin{array}{l}\text { Categoria de } \\
\text { aplicação }\end{array}$ & Título & DOI \\
\hline 37 & $\begin{array}{l}\text { Diagnóstico } \\
\text { baseado em } \\
\text { outros dados }\end{array}$ & $\begin{array}{l}\text { A diagnostic genomic signal processing (GSP)- } \\
\text { based system for automatic feature analysis and } \\
\text { detection of COVID-19 }\end{array}$ & 10.1093/bib/bbaa170 \\
\hline 38 & $\begin{array}{l}\text { Diagnóstico } \\
\text { baseado em } \\
\text { outros dados }\end{array}$ & $\begin{array}{l}\text { Detection of Respiratory Infections using RGB- } \\
\text { infrared sensors on Portable Device }\end{array}$ & 10.1109/JSEN.2020.3004568 \\
\hline 39 & $\begin{array}{l}\text { Diagnóstico } \\
\text { baseado em } \\
\text { outros dados }\end{array}$ & $\begin{array}{c}\text { Adversarial Examples - Security Threats to } \\
\text { COVID-19 Deep Learning Systems in Medical loT } \\
\text { Devices }\end{array}$ & 10.1109/JIOT.2020.3013710 \\
\hline 40 & $\begin{array}{l}\text { Diagnóstico } \\
\text { baseado em } \\
\text { imagem }\end{array}$ & $\begin{array}{l}\text { Comparing different deep learning architectures } \\
\text { for classification of chest radiographs }\end{array}$ & 10.1038/s41598-020-70479-z \\
\hline 41 & $\begin{array}{l}\text { Diagnóstico } \\
\text { baseado em } \\
\text { imagem }\end{array}$ & $\begin{array}{l}\text { Artificial intelligence for the detection of } \\
\text { COVID-19 pneumonia on chest CT using } \\
\text { multinational datasets }\end{array}$ & $10.1038 / s 41467-020-17971-2$ \\
\hline 42 & $\begin{array}{l}\text { Diagnóstico } \\
\text { baseado em } \\
\text { imagem }\end{array}$ & $\begin{array}{l}\text { Diagnosis and detection of infected tissue of } \\
\text { COVID-19 patients based on lung } x \text {-ray image } \\
\text { using convolutional neural network approaches }\end{array}$ & 10.1016/j.chaos.2020.110170 \\
\hline 43 & $\begin{array}{l}\text { Diagnóstico } \\
\text { baseado em } \\
\text { imagem }\end{array}$ & $\begin{array}{l}\text { CoroNet: A deep neural network for detection } \\
\text { and diagnosis of COVID-19 from chest x-ray } \\
\text { images }\end{array}$ & 10.1016/j.cmpb.2020.105581 \\
\hline 44 & $\begin{array}{l}\text { Diagnóstico } \\
\text { baseado em } \\
\text { imagem }\end{array}$ & $\begin{array}{l}\text { Data science and the role of Artificial Intelligence } \\
\text { in achieving the fast diagnosis of Covid-19 }\end{array}$ & 10.1016/j.chaos.2020.110182 \\
\hline 45 & $\begin{array}{l}\text { Diagnóstico } \\
\text { baseado em } \\
\text { imagem }\end{array}$ & $\begin{array}{l}\text { Recognition of COVID-19 disease from X-ray } \\
\text { images by hybrid model consisting of 2D curvelet } \\
\text { transform, chaotic salp swarm algorithm and deep } \\
\text { learning technique }\end{array}$ & 10.1016/j.chaos.2020.110071 \\
\hline 46 & $\begin{array}{l}\text { Diagnóstico } \\
\text { baseado em } \\
\text { imagem }\end{array}$ & $\begin{array}{l}\text { Application of deep learning for fast detection of } \\
\text { COVID-19 in X-Rays using nCOVnet }\end{array}$ & 10.1016/j.chaos.2020.109944 \\
\hline 47 & $\begin{array}{l}\text { Diagnóstico } \\
\text { baseado em } \\
\text { imagem }\end{array}$ & $\begin{array}{c}\text { Deep Learning COVID-19 Features on CXR Using } \\
\text { Limited Training Data Sets }\end{array}$ & 10.1109/TMI.2020.2993291 \\
\hline
\end{tabular}




\begin{tabular}{|c|c|c|c|}
\hline ID & $\begin{array}{l}\text { Categoria de } \\
\text { aplicação }\end{array}$ & Título & DOI \\
\hline 48 & $\begin{array}{l}\text { Diagnóstico } \\
\text { baseado em } \\
\text { imagem }\end{array}$ & $\begin{array}{l}\text { Relational Modeling for Robust and Efficient } \\
\text { Pulmonary Lobe Segmentation in CT Scans }\end{array}$ & 10.1109/TMI.2020.2995108 \\
\hline 49 & $\begin{array}{l}\text { Diagnóstico } \\
\text { baseado em } \\
\text { imagem }\end{array}$ & $\begin{array}{c}\text { Diagnosis of Coronavirus Disease } 2019 \\
\text { (COVID-19) With Structured Latent Multi-View } \\
\text { Representation Learning }\end{array}$ & 10.1109/TMI.2020.2992546 \\
\hline 50 & $\begin{array}{l}\text { Diagnóstico } \\
\text { baseado em } \\
\text { imagem }\end{array}$ & $\begin{array}{l}\text { Deep learning COVID-19 detection bias: accuracy } \\
\text { through artificial intelligence }\end{array}$ & $10.1007 / s 00264-020-04609-7$ \\
\hline 51 & $\begin{array}{l}\text { Diagnóstico } \\
\text { baseado em } \\
\text { imagem }\end{array}$ & $\begin{array}{c}\text { Using Artificial Intelligence to Detect COVID-19 } \\
\text { and Community-acquired Pneumonia Based } \\
\text { on Pulmonary CT: Evaluation of the Diagnostic } \\
\text { Accuracy }\end{array}$ & 10.1148/radiol.2020200905 \\
\hline 52 & $\begin{array}{l}\text { Diagnóstico } \\
\text { baseado em } \\
\text { imagem }\end{array}$ & $\begin{array}{l}\text { Artificial intelligence-enabled rapid diagnosis of } \\
\text { patients with COVID-19 }\end{array}$ & $10.1038 / s 41591-020-0931-3$ \\
\hline 53 & $\begin{array}{l}\text { Diagnóstico } \\
\text { baseado em } \\
\text { imagem }\end{array}$ & $\begin{array}{l}\text { A fully automatic deep learning system for } \\
\text { COVID-19 diagnostic and prognostic analysis }\end{array}$ & $10.1183 / 13993003.00775-2020$ \\
\hline 54 & $\begin{array}{l}\text { Diagnóstico } \\
\text { baseado em } \\
\text { imagem }\end{array}$ & $\begin{array}{l}\text { A Rapid, Accurate and Machine-Agnostic } \\
\text { Segmentation and Quantification Method for } \\
\text { CT-Based COVID-19 Diagnosis }\end{array}$ & 10.1109/TMI.2020.3001810 \\
\hline 55 & $\begin{array}{l}\text { Diagnóstico } \\
\text { baseado em } \\
\text { imagem }\end{array}$ & $\begin{array}{c}\text { Deep Learning for Classification and Localization } \\
\text { of COVID-19 Markers in Point-of-Care Lung } \\
\text { Ultrasound }\end{array}$ & 10.1109/TMI.2020.2994459 \\
\hline 56 & $\begin{array}{l}\text { Diagnóstico } \\
\text { baseado em } \\
\text { imagem }\end{array}$ & $\begin{array}{l}\text { A Noise-robust Framework for Automatic } \\
\text { Segmentation of COVID-19 }\end{array}$ & 10.1109/TMI.2020.3000314 \\
\hline 57 & $\begin{array}{l}\text { Diagnóstico } \\
\text { baseado em } \\
\text { imagem }\end{array}$ & $\begin{array}{l}\text { Deploying Machine and Deep Learning Models } \\
\text { for Efficient Data-Augmented Detection of } \\
\text { COVID-19 Infections }\end{array}$ & $10.3390 / v 12070769$ \\
\hline 58 & $\begin{array}{l}\text { Diagnóstico } \\
\text { baseado em } \\
\text { imagem }\end{array}$ & $\begin{array}{l}\text { Deep Learning-Based Decision-Tree Classifier for } \\
\text { COVID-19 Diagnosis From Chest X-ray Imaging }\end{array}$ & 10.3389/fmed.2020.00427 \\
\hline
\end{tabular}




\begin{tabular}{|c|c|c|c|}
\hline ID & $\begin{array}{l}\text { Categoria de } \\
\text { aplicação }\end{array}$ & Título & DOI \\
\hline 59 & $\begin{array}{l}\text { Diagnóstico } \\
\text { baseado em } \\
\text { imagem }\end{array}$ & $\begin{array}{l}\text { Classification of COVID-19 patients from chest } \\
\text { CT images using multi-objective differential } \\
\text { evolution-based convolutional neural networks }\end{array}$ & $10.1007 / s 10096-020-03901-z$ \\
\hline 60 & $\begin{array}{l}\text { Diagnóstico } \\
\text { baseado em } \\
\text { imagem }\end{array}$ & $\begin{array}{l}\text { CovXNet: A multi-dilation convolutional neural } \\
\text { network for automatic COVID-19 and other } \\
\text { pneumonia detection from chest } X \text {-ray images } \\
\text { with transferable multi-receptive feature } \\
\text { optimization }\end{array}$ & $\begin{array}{c}\text { 10.1016/j. } \\
\text { compbiomed.2020.103869 }\end{array}$ \\
\hline 61 & $\begin{array}{l}\text { Diagnóstico } \\
\text { baseado em } \\
\text { imagem }\end{array}$ & $\begin{array}{c}\text { Deep learning system for COVID-19 diagnosis aid } \\
\text { using X-ray pulmonary images }\end{array}$ & 10.3390/app10134640 \\
\hline 62 & $\begin{array}{l}\text { Diagnóstico } \\
\text { baseado em } \\
\text { imagem }\end{array}$ & $\begin{array}{l}\text { COVIDiagnosis-Net: Deep Bayes-SqueezeNet } \\
\text { based diagnosis of the coronavirus disease } 2019 \\
\text { (COVID-19) from X-ray images }\end{array}$ & 10.1016/j.mehy.2020.109761 \\
\hline 63 & $\begin{array}{l}\text { Diagnóstico } \\
\text { baseado em } \\
\text { imagem }\end{array}$ & $\begin{array}{l}\text { CT radiomics can help screen the Coronavirus } \\
\text { disease } 2019 \text { (COVID-19): a preliminary study }\end{array}$ & $10.1007 / s 11432-020-2849-3$ \\
\hline 64 & $\begin{array}{l}\text { Diagnóstico } \\
\text { baseado em } \\
\text { imagem }\end{array}$ & $\begin{array}{l}\text { Deep learning-based multi-view fusion model for } \\
\text { screening } 2019 \text { novel coronavirus pneumonia: A } \\
\text { multicentre study }\end{array}$ & 10.1016/j.ejrad.2020.109041 \\
\hline 65 & $\begin{array}{l}\text { Diagnóstico } \\
\text { baseado em } \\
\text { imagem }\end{array}$ & $\begin{array}{l}\text { A deep learning based hybrid approach for } \\
\text { covid-19 disease detections }\end{array}$ & $10.18280 /$ ts.370313 \\
\hline 66 & $\begin{array}{l}\text { Diagnóstico } \\
\text { baseado em } \\
\text { imagem }\end{array}$ & $\begin{array}{c}\text { Weakly labeled data augmentation for deep } \\
\text { learning: A study on COVID-19 detection in chest } \\
\text { X-rays }\end{array}$ & 10.3390/diagnostics 10060358 \\
\hline 67 & $\begin{array}{l}\text { Diagnóstico } \\
\text { baseado em } \\
\text { imagem }\end{array}$ & $\begin{array}{c}\text { Covid-19: automatic detection from X-ray images } \\
\text { utilizing transfer learning with convolutional } \\
\text { neural networks }\end{array}$ & $10.1007 / s 13246-020-00865-4$ \\
\hline 68 & $\begin{array}{l}\text { Diagnóstico } \\
\text { baseado em } \\
\text { imagem }\end{array}$ & $\begin{array}{c}\text { Extracting Possibly Representative COVID-19 } \\
\text { Biomarkers from X-ray Images with Deep Learning } \\
\text { Approach and Image Data Related to Pulmonary } \\
\text { Diseases }\end{array}$ & $10.1007 / s 40846-020-00529-4$ \\
\hline
\end{tabular}




\begin{tabular}{|c|c|c|c|}
\hline ID & $\begin{array}{l}\text { Categoria de } \\
\text { aplicação }\end{array}$ & Título & DOI \\
\hline 69 & $\begin{array}{l}\text { Diagnóstico } \\
\text { baseado em } \\
\text { imagem }\end{array}$ & $\begin{array}{c}\text { Application of deep learning technique to manage } \\
\text { COVID-19 in routine clinical practice using } \\
\text { CT images: Results of } 10 \text { convolutional neural } \\
\text { networks }\end{array}$ & $\begin{array}{c}\text { 10.1016/j. } \\
\text { compbiomed.2020.103795 }\end{array}$ \\
\hline 70 & $\begin{array}{l}\text { Diagnóstico } \\
\text { baseado em } \\
\text { imagem }\end{array}$ & $\begin{array}{l}\text { COVID-19 pneumonia diagnosis using a simple } \\
\text { 2d deep learning framework with a single chest CT } \\
\text { image: Model development and validation }\end{array}$ & $10.2196 / 19569$ \\
\hline 71 & $\begin{array}{l}\text { Diagnóstico } \\
\text { baseado em } \\
\text { imagem }\end{array}$ & $\begin{array}{c}\text { Automated detection of COVID-19 cases using } \\
\text { deep neural networks with X-ray images }\end{array}$ & $\begin{array}{c}\text { 10.1016/j. } \\
\text { compbiomed.2020.103792 }\end{array}$ \\
\hline 72 & $\begin{array}{l}\text { Diagnóstico } \\
\text { baseado em } \\
\text { imagem }\end{array}$ & $\begin{array}{c}\text { WisdomNet: Prognosis of COVID-19 with slender } \\
\text { prospect of false negative cases and vaticinating } \\
\text { the probability of maturation to ards using } \\
\text { posteroanterior chest X-Rays }\end{array}$ & 10.22207/JPAM.14.SPL1.24 \\
\hline 73 & $\begin{array}{l}\text { Diagnóstico } \\
\text { baseado em } \\
\text { imagem }\end{array}$ & $\begin{array}{l}\text { COVID-19 on the Chest Radiograph: A Multi- } \\
\text { Reader Evaluation of an AI System }\end{array}$ & $10.1148 /$ radiol.2020201874 \\
\hline 74 & $\begin{array}{l}\text { Diagnóstico } \\
\text { baseado em } \\
\text { imagem }\end{array}$ & $\begin{array}{c}\text { Classification of Covid-19 coronavirus, pneumonia } \\
\text { and healthy lungs in CT scans using Q-deformed } \\
\text { entropy and deep learning features }\end{array}$ & $10.3390 / \mathrm{e} 22050517$ \\
\hline 75 & $\begin{array}{l}\text { Diagnóstico } \\
\text { baseado em } \\
\text { imagem }\end{array}$ & $\begin{array}{l}\text { Within the lack of chest COVID-19 X-ray dataset: } \\
\text { A novel detection model based on GAN and deep } \\
\text { transfer learning }\end{array}$ & 10.3390/SYM12040651 \\
\hline 76 & $\begin{array}{l}\text { Diagnóstico } \\
\text { baseado em } \\
\text { imagem }\end{array}$ & $\begin{array}{c}\text { COVID faster R-CNN: A novel framework to } \\
\text { Diagnose Novel Coronavirus Disease (COVID-19) } \\
\text { in X-Ray images }\end{array}$ & 10.1016/j.imu.2020.100405 \\
\hline 77 & $\begin{array}{l}\text { Diagnóstico } \\
\text { baseado em } \\
\text { imagem }\end{array}$ & $\begin{array}{c}\text { Deep learning system to screen coronavirus } \\
\text { disease } 2019 \text { pneumonia }\end{array}$ & $10.1007 / s 10489-020-01714-3$ \\
\hline 78 & $\begin{array}{l}\text { Diagnóstico } \\
\text { baseado em } \\
\text { imagem }\end{array}$ & $\begin{array}{l}\text { A modified deep convolutional neural network } \\
\text { for detecting COVID-19 and pneumonia from } \\
\text { chest X-ray images based on the concatenation of } \\
\text { Xception and ResNet50V2 }\end{array}$ & 10.1016/j.imu.2020.100360 \\
\hline
\end{tabular}




\begin{tabular}{|c|c|c|c|}
\hline ID & $\begin{array}{l}\text { Categoria de } \\
\text { aplicação }\end{array}$ & Título & DOI \\
\hline 79 & $\begin{array}{l}\text { Diagnóstico } \\
\text { baseado em } \\
\text { imagem }\end{array}$ & $\begin{array}{c}\text { Non-Invasive Technique-Based Novel } \\
\text { Corona(COVID-19) Virus Detection Using CNN }\end{array}$ & $10.1007 / s 40009-020-01009-8$ \\
\hline 80 & $\begin{array}{l}\text { Diagnóstico } \\
\text { baseado em } \\
\text { imagem }\end{array}$ & $\begin{array}{l}\text { Classification of the COVID-19 infected patients } \\
\text { using DenseNet201 based deep transfer learning }\end{array}$ & $10.1080 / 07391102.2020 .1788642$ \\
\hline 81 & $\begin{array}{l}\text { Diagnóstico } \\
\text { baseado em } \\
\text { imagem }\end{array}$ & $\begin{array}{l}\text { GoogleNet CNN neural network towards chest } \\
\text { CT-coronavirus medical image classification }\end{array}$ & 10.3844/JCSSP.2020.620.625 \\
\hline 82 & $\begin{array}{l}\text { Diagnóstico } \\
\text { baseado em } \\
\text { imagem }\end{array}$ & $\begin{array}{l}\text { Deep transfer learning artificial intelligence } \\
\text { accurately stages COVID-19 lung disease severity } \\
\text { on portable chest radiographs }\end{array}$ & 10.1371/journal.pone.0236621 \\
\hline 83 & $\begin{array}{l}\text { Diagnóstico } \\
\text { baseado em } \\
\text { imagem }\end{array}$ & $\begin{array}{c}\text { Can AI Help in Screening Viral and COVID-19 } \\
\text { Pneumonia? }\end{array}$ & 10.1109/ACCESS.2020.3010287 \\
\hline 84 & $\begin{array}{l}\text { Diagnóstico } \\
\text { baseado em } \\
\text { imagem }\end{array}$ & $\begin{array}{l}\text { Performance evaluation of the NASnet } \\
\text { convolutional network in the automatic } \\
\text { identification of COVID-19 }\end{array}$ & 10.18517/ijaseit.10.2.11446 \\
\hline 85 & $\begin{array}{l}\text { Diagnóstico } \\
\text { baseado em } \\
\text { imagem }\end{array}$ & $\begin{array}{l}\text { Detection of COVID-19 chest } x \text {-ray using support } \\
\text { vector machine and convolutional neural network }\end{array}$ & $10.28919 / \mathrm{cmbn} / 4765$ \\
\hline 86 & $\begin{array}{l}\text { Diagnóstico } \\
\text { baseado em } \\
\text { imagem }\end{array}$ & $\begin{array}{l}\text { Discovering Unknown Diseases with Explainable } \\
\text { Automated Medical Imaging }\end{array}$ & 10.1007/978-3-030-52791-4_27 \\
\hline 87 & $\begin{array}{l}\text { Diagnóstico } \\
\text { baseado em } \\
\text { imagem }\end{array}$ & $\begin{array}{l}\text { Iteratively Pruned Deep Learning Ensembles for } \\
\text { COVID-19 Detection in Chest X-Rays }\end{array}$ & 10.1109/ACCESS.2020.3003810 \\
\hline 88 & $\begin{array}{l}\text { Diagnóstico } \\
\text { baseado em } \\
\text { imagem }\end{array}$ & $\begin{array}{l}\text { CovidGAN: Data Augmentation Using Auxiliary } \\
\text { Classifier GAN for Improved Covid-19 Detection }\end{array}$ & 10.1109/ACCESS.2020.2994762 \\
\hline 89 & $\begin{array}{l}\text { Diagnóstico } \\
\text { baseado em } \\
\text { imagem }\end{array}$ & $\begin{array}{l}\text { Truncated inception net: COVID-19 outbreak } \\
\text { screening using chest X-rays }\end{array}$ & $10.1007 / s 13246-020-00888-x$ \\
\hline
\end{tabular}




\begin{tabular}{|c|c|c|c|}
\hline ID & $\begin{array}{l}\text { Categoria de } \\
\text { aplicação }\end{array}$ & Título & DOI \\
\hline 90 & $\begin{array}{l}\text { Diagnóstico } \\
\text { baseado em } \\
\text { imagem }\end{array}$ & $\begin{array}{l}\text { Efficient gan-based chest radiographs (CXR) } \\
\text { augmentation to diagnose coronavirus disease } \\
\text { pneumonia }\end{array}$ & 10.7150/ijms.46684 \\
\hline 91 & $\begin{array}{l}\text { Diagnóstico } \\
\text { baseado em } \\
\text { imagem }\end{array}$ & $\begin{array}{l}\text { Social Group Optimization-Assisted Kapur's } \\
\text { Entropy and Morphological Segmentation for } \\
\text { Automated Detection of COVID-19 Infection from } \\
\text { Computed Tomography Images }\end{array}$ & $10.1007 / s 12559-020-09751-3$ \\
\hline 92 & $\begin{array}{l}\text { Diagnóstico } \\
\text { baseado em } \\
\text { imagem }\end{array}$ & $\begin{array}{l}\text { Automated detection and quantification of } \\
\text { COVID-19 pneumonia: CT imaging analysis by a } \\
\text { deep learning-based software }\end{array}$ & $10.1007 / s 00259-020-04953-1$ \\
\hline 93 & $\begin{array}{l}\text { Diagnóstico } \\
\text { baseado em } \\
\text { imagem }\end{array}$ & $\begin{array}{l}\text { A Deep Learning System to Screen Novel } \\
\text { Coronavirus Disease } 2019 \text { Pneumonia }\end{array}$ & 10.1016/j.eng.2020.04.010 \\
\hline 94 & $\begin{array}{l}\text { Diagnóstico } \\
\text { baseado em } \\
\text { imagem }\end{array}$ & $\begin{array}{l}\text { Dynamic evolution of COVID-19 on chest } \\
\text { computed tomography: experience from Jiangsu } \\
\text { Province of China }\end{array}$ & $10.1007 / s 00330-020-06976-6$ \\
\hline 95 & $\begin{array}{l}\text { Diagnóstico } \\
\text { baseado em } \\
\text { imagem }\end{array}$ & $\begin{array}{l}\text { Using X-ray images and deep learning for } \\
\text { automated detection of coronavirus disease }\end{array}$ & $10.1080 / 07391102.2020 .1767212$ \\
\hline 96 & $\begin{array}{l}\text { Diagnóstico } \\
\text { baseado em } \\
\text { imagem }\end{array}$ & $\begin{array}{l}\text { Drawing insights from COVID-19-infected } \\
\text { patients using CT scan images and machine } \\
\text { learning techniques: a study on } 200 \text { patients }\end{array}$ & $10.1007 / \mathrm{s} 11356-020-10133-3$ \\
\hline 97 & $\begin{array}{l}\text { Diagnóstico } \\
\text { baseado em } \\
\text { imagem }\end{array}$ & $\begin{array}{c}\text { A deep learning approach to characterize } 2019 \\
\text { coronavirus disease (COVID-19) pneumonia in } \\
\text { chest CT images }\end{array}$ & $10.1007 / \mathrm{s} 00330-020-07044-9$ \\
\hline 98 & $\begin{array}{l}\text { Diagnóstico } \\
\text { baseado em } \\
\text { imagem }\end{array}$ & $\begin{array}{l}\text { From community-acquired pneumonia to } \\
\text { COVID-19: a deep learning-based method for } \\
\text { quantitative analysis of COVID-19 on thick- } \\
\text { section CT scans }\end{array}$ & $10.1007 / s 00330-020-07042-x$ \\
\hline 99 & $\begin{array}{c}\text { Diagnóstico } \\
\text { baseado em } \\
\text { imagem }\end{array}$ & $\begin{array}{l}\text { Chest CT for triage during COVID-19 on the } \\
\text { emergency department: myth or truth? }\end{array}$ & $10.1007 / s 10140-020-01821-1$ \\
\hline 100 & $\begin{array}{c}\text { Diagnóstico } \\
\text { baseado em } \\
\text { imagem }\end{array}$ & $\begin{array}{c}\text { Automated quantification of COVID-19 severity } \\
\text { and progression using chest CT images }\end{array}$ & $10.1007 / \mathrm{s} 00330-020-07156-2$ \\
\hline
\end{tabular}




\begin{tabular}{|c|c|c|c|}
\hline ID & $\begin{array}{l}\text { Categoria de } \\
\text { aplicação }\end{array}$ & Título & DOI \\
\hline 101 & $\begin{array}{l}\text { Diagnóstico } \\
\text { baseado em } \\
\text { imagem }\end{array}$ & $\begin{array}{l}\text { Weakly Supervised Deep Learning for COVID-19 } \\
\text { Infection Detection and Classification from CT } \\
\text { Images }\end{array}$ & 10.1109/ACCESS.2020.3005510 \\
\hline 102 & $\begin{array}{l}\text { Diagnóstico } \\
\text { baseado em } \\
\text { imagem }\end{array}$ & $\begin{array}{l}\text { Setting up an easy-to-use machine learning } \\
\text { pipeline for medical decision support: A case } \\
\text { study for COVID-19 diagnosis based on deep } \\
\text { learning with CT scans }\end{array}$ & 10.3233/SHTI200481 \\
\hline 103 & $\begin{array}{l}\text { Diagnóstico } \\
\text { baseado em } \\
\text { imagem }\end{array}$ & $\begin{array}{l}\text { SARS n-CoV2-19 detection from chest } x \text {-ray } \\
\text { images using deep neural networks }\end{array}$ & 10.1108/IJPCC-06-2020-0060 \\
\hline 104 & $\begin{array}{l}\text { Diagnóstico } \\
\text { baseado em } \\
\text { imagem }\end{array}$ & $\begin{array}{c}\text { Detection of coronavirus disease (COVID-19) } \\
\text { based on deep features and support vector } \\
\text { machine }\end{array}$ & 10.33889/IJMEMS.2020.5.4.052 \\
\hline 105 & $\begin{array}{l}\text { Diagnóstico } \\
\text { baseado em } \\
\text { imagem }\end{array}$ & $\begin{array}{l}\text { A deep learning algorithm using CT images to } \\
\text { screen for Corona Virus Disease (COVID-19) }\end{array}$ & $10.1101 / 2020.02 .14 .20023028$ \\
\hline 106 & $\begin{array}{l}\text { Diagnóstico } \\
\text { baseado em } \\
\text { imagem }\end{array}$ & $\begin{array}{l}\text { Deep learning Enables Accurate Diagnosis of } \\
\text { Novel Coronavirus (COVID-19) with CT images }\end{array}$ & $10.1101 / 2020.02 .23 .20026930$ \\
\hline 107 & $\begin{array}{l}\text { Diagnóstico } \\
\text { baseado em } \\
\text { imagem }\end{array}$ & $\begin{array}{l}\text { Deep learning-based model for detecting } 2019 \\
\text { novel coronavirus pneumonia on high-resolution } \\
\text { computed tomography: a prospective study }\end{array}$ & $10.1101 / 2020.02 .25 .20021568$ \\
\hline 108 & $\begin{array}{l}\text { Diagnóstico } \\
\text { baseado em } \\
\text { imagem }\end{array}$ & $\begin{array}{l}\text { Machine learning-based CT radiomics model } \\
\text { for predicting hospital stay in patients with } \\
\text { pneumonia associated with SARS-CoV-2 infection: } \\
\text { A multicenter study }\end{array}$ & $10.1101 / 2020.02 .29 .20029603$ \\
\hline 109 & $\begin{array}{l}\text { Diagnóstico } \\
\text { baseado em } \\
\text { imagem }\end{array}$ & $\begin{array}{l}\text { Deep Learning-based Detection for COVID-19 } \\
\text { from Chest CT using Weak Label }\end{array}$ & $10.1101 / 2020.03 .12 .20027185$ \\
\hline 110 & $\begin{array}{l}\text { Diagnóstico } \\
\text { baseado em } \\
\text { imagem }\end{array}$ & $\begin{array}{l}\text { Al-assisted CT imaging analysis for COVID-19 } \\
\text { screening: Building and deploying a medical AI } \\
\text { system in four weeks }\end{array}$ & 10.1101/2020.03.19.20039354 \\
\hline 111 & $\begin{array}{l}\text { Diagnóstico } \\
\text { baseado em } \\
\text { imagem }\end{array}$ & $\begin{array}{l}\text { Development and Evaluation of an Al System for } \\
\text { COVID-19 Diagnosis }\end{array}$ & $10.1101 / 2020.03 .20 .20039834$ \\
\hline
\end{tabular}




\begin{tabular}{|c|c|c|c|}
\hline ID & $\begin{array}{l}\text { Categoria de } \\
\text { aplicação }\end{array}$ & Título & DOI \\
\hline 112 & $\begin{array}{l}\text { Diagnóstico } \\
\text { baseado em } \\
\text { imagem }\end{array}$ & $\begin{array}{l}\text { A Fully Automatic Deep Learning System for } \\
\text { COVID-19 Diagnostic and Prognostic Analysis }\end{array}$ & $10.1101 / 2020.03 .24 .20042317$ \\
\hline 113 & $\begin{array}{l}\text { Diagnóstico } \\
\text { baseado em } \\
\text { imagem }\end{array}$ & $\begin{array}{l}\text { Improved deep learning model for differentiating } \\
\text { novel coronavirus pneumonia and influenza } \\
\text { pneumonia }\end{array}$ & $10.1101 / 2020.03 .24 .20043117$ \\
\hline 114 & $\begin{array}{l}\text { Diagnóstico } \\
\text { baseado em } \\
\text { imagem }\end{array}$ & $\begin{array}{l}\text { The diagnostic evaluation of Convolutional } \\
\text { NeuralNetwork (CNN) for the assessment of chest } \\
\text { X-ray ofpatients infected with COVID-19 }\end{array}$ & $10.1101 / 2020.03 .26 .20044610$ \\
\hline 115 & $\begin{array}{l}\text { Diagnóstico } \\
\text { baseado em } \\
\text { imagem }\end{array}$ & $\begin{array}{l}\text { Deep Learning-Based Recognizing COVID-19 and } \\
\text { other Common Infectious Diseases of the Lung by } \\
\text { Chest CT Scan Images }\end{array}$ & $10.1101 / 2020.03 .28 .20046045$ \\
\hline 116 & $\begin{array}{l}\text { Diagnóstico } \\
\text { baseado em } \\
\text { imagem }\end{array}$ & $\begin{array}{l}\text { Classification of COVID-19 in chest X-ray images } \\
\text { using DeTraC deep convolutional neural network }\end{array}$ & $10.1101 / 2020.03 .30 .20047456$ \\
\hline 117 & $\begin{array}{l}\text { Diagnóstico } \\
\text { baseado em } \\
\text { imagem }\end{array}$ & $\begin{array}{c}\text { Classification of Coronavirus Images using } \\
\text { Shrunken Features }\end{array}$ & $10.1101 / 2020.04 .03 .20048868$ \\
\hline 118 & $\begin{array}{l}\text { Diagnóstico } \\
\text { baseado em } \\
\text { imagem }\end{array}$ & $\begin{array}{l}\text { Artificial intelligence applied on chest X-ray can } \\
\text { aid in the diagnosis of COVID-19 infection: a first } \\
\text { experience from Lombardy, Italy }\end{array}$ & $10.1101 / 2020.04 .08 .20040907$ \\
\hline 119 & $\begin{array}{l}\text { Diagnóstico } \\
\text { baseado em } \\
\text { imagem }\end{array}$ & $\begin{array}{c}\text { Improving Coronavirus (COVID-19) Diagnosis } \\
\text { using Deep Transfer Learning }\end{array}$ & $10.1101 / 2020.04 .11 .20054643$ \\
\hline 120 & $\begin{array}{l}\text { Diagnóstico } \\
\text { baseado em } \\
\text { imagem }\end{array}$ & $\begin{array}{l}\text { Artificial intelligence-enabled rapid diagnosis of } \\
\text { COVID-19 patients }\end{array}$ & $10.1101 / 2020.04 .12 .20062661$ \\
\hline 121 & $\begin{array}{l}\text { Diagnóstico } \\
\text { baseado em } \\
\text { imagem }\end{array}$ & $\begin{array}{c}\text { Accurate Prediction of COVID-19 using Chest } \\
\text { X-Ray Images through Deep Feature Learning } \\
\text { model with SMOTE and Machine Learning } \\
\text { Classifiers }\end{array}$ & $10.1101 / 2020.04 .13 .20063461$ \\
\hline 122 & $\begin{array}{l}\text { Diagnóstico } \\
\text { baseado em } \\
\text { imagem }\end{array}$ & $\begin{array}{l}\text { CoroNet: A Deep Network Architecture for Semi- } \\
\text { Supervised Task-Based Identification of COVID-19 } \\
\text { from Chest X-ray Images }\end{array}$ & $10.1101 / 2020.04 .14 .20065722$ \\
\hline
\end{tabular}




\begin{tabular}{|c|c|c|c|}
\hline ID & $\begin{array}{l}\text { Categoria de } \\
\text { aplicação }\end{array}$ & Título & DOI \\
\hline 123 & $\begin{array}{l}\text { Diagnóstico } \\
\text { baseado em } \\
\text { imagem }\end{array}$ & $\begin{array}{l}\text { Diagnosis and Prediction Model for COVID19 } \\
\text { Patients Response to Treatment based on } \\
\text { Convolutional Neural Networks and Whale } \\
\text { Optimization Algorithm Using CT Images }\end{array}$ & $10.1101 / 2020.04 .16 .20063990$ \\
\hline 124 & $\begin{array}{l}\text { Diagnóstico } \\
\text { baseado em } \\
\text { imagem }\end{array}$ & $\begin{array}{c}\text { Multi-task Deep Learning Based CT Imaging } \\
\text { Analysis For COVID-19: Classification and } \\
\text { Segmentation }\end{array}$ & $10.1101 / 2020.04 .16 .20064709$ \\
\hline 125 & $\begin{array}{l}\text { Diagnóstico } \\
\text { baseado em } \\
\text { imagem }\end{array}$ & $\begin{array}{l}\text { Holistic Al-Driven Quantification, Staging and } \\
\text { Prognosis of COVID-19 Pneumonia }\end{array}$ & $10.1101 / 2020.04 .17 .20069187$ \\
\hline 126 & $\begin{array}{l}\text { Diagnóstico } \\
\text { baseado em } \\
\text { imagem }\end{array}$ & $\begin{array}{l}\text { From Community Acquired Pneumonia to } \\
\text { COVID-19: A Deep Learning Based Method for } \\
\text { Quantitative Analysis of COVID-19 on thick- } \\
\text { section CT Scans }\end{array}$ & $10.1101 / 2020.04 .17 .20070219$ \\
\hline 127 & $\begin{array}{l}\text { Diagnóstico } \\
\text { baseado em } \\
\text { imagem }\end{array}$ & $\begin{array}{l}\text { A web-based Diagnostic Tool for COVID-19 Using } \\
\text { Machine Learning on Chest Radiographs (CXR) }\end{array}$ & $10.1101 / 2020.04 .21 .20063263$ \\
\hline 128 & $\begin{array}{l}\text { Diagnóstico } \\
\text { baseado em } \\
\text { imagem }\end{array}$ & $\begin{array}{l}\text { SARS-CoV-2 CT-scan dataset: A large dataset } \\
\text { of real patients CT scans for SARS-CoV-2 } \\
\text { identification }\end{array}$ & $10.1101 / 2020.04 .24 .20078584$ \\
\hline 129 & $\begin{array}{l}\text { Diagnóstico } \\
\text { baseado em } \\
\text { imagem }\end{array}$ & $\begin{array}{l}\text { Automated Diagnosis of COVID-19 Using Deep } \\
\text { Learning and Data Augmentation on Chest CT }\end{array}$ & $10.1101 / 2020.04 .24 .20078998$ \\
\hline 130 & $\begin{array}{l}\text { Diagnóstico } \\
\text { baseado em } \\
\text { imagem }\end{array}$ & $\begin{array}{l}\text { Distinguishing } \mathrm{L} \text { and } \mathrm{H} \text { phenotypes of COVID-19 } \\
\text { using a single x-ray image }\end{array}$ & $10.1101 / 2020.04 .27 .20081984$ \\
\hline 131 & $\begin{array}{l}\text { Diagnóstico } \\
\text { baseado em } \\
\text { imagem }\end{array}$ & $\begin{array}{l}\text { TRACKING AND PREDICTING COVID-19 } \\
\text { RADIOLOGICAL TRAJECTORY USING DEEP } \\
\text { LEARNING ON CHEST X-RAYS: INITIAL } \\
\text { ACCURACY TESTING }\end{array}$ & $10.1101 / 2020.05 .01 .20086207$ \\
\hline 132 & $\begin{array}{l}\text { Diagnóstico } \\
\text { baseado em } \\
\text { imagem }\end{array}$ & $\begin{array}{c}\text { Classification of COVID-19 from Chest X-ray } \\
\text { images using Deep Convolutional Neural } \\
\text { Networks }\end{array}$ & $10.1101 / 2020.05 .01 .20088211$ \\
\hline
\end{tabular}




\begin{tabular}{|c|c|c|c|}
\hline ID & $\begin{array}{l}\text { Categoria de } \\
\text { aplicação }\end{array}$ & Título & DOI \\
\hline 133 & $\begin{array}{l}\text { Diagnóstico } \\
\text { baseado em } \\
\text { imagem }\end{array}$ & $\begin{array}{l}\text { ai-corona: Radiologist-Assistant Deep Learning } \\
\text { Framework for COVID-19 Diagnosis in Chest CT } \\
\text { Scans }\end{array}$ & $10.1101 / 2020.05 .04 .20082081$ \\
\hline 134 & $\begin{array}{l}\text { Diagnóstico } \\
\text { baseado em } \\
\text { imagem }\end{array}$ & $\begin{array}{l}\text { Deep Learning for Screening COVID-19 using } \\
\text { Chest X-Ray Images }\end{array}$ & $10.1101 / 2020.05 .04 .20090423$ \\
\hline 135 & $\begin{array}{l}\text { Diagnóstico } \\
\text { baseado em } \\
\text { imagem }\end{array}$ & $\begin{array}{l}\text { MantisCOVID: Rapid X-Ray Chest Radiograph } \\
\text { and Mortality Rate Evaluation With Artificial } \\
\text { Intelligence For COVID-19 }\end{array}$ & $10.1101 / 2020.05 .04 .20090779$ \\
\hline 136 & $\begin{array}{l}\text { Diagnóstico } \\
\text { baseado em } \\
\text { imagem }\end{array}$ & $\begin{array}{l}\text { Training deep learning algorithms with weakly } \\
\text { labeled pneumonia chest X-ray data for } \\
\text { COVID-19 detection }\end{array}$ & $10.1101 / 2020.05 .04 .20090803$ \\
\hline 137 & $\begin{array}{l}\text { Diagnóstico } \\
\text { baseado em } \\
\text { imagem }\end{array}$ & $\begin{array}{l}\text { Al based Chest X-Ray (CXR) Scan Texture Analysis } \\
\text { Algorithm for Digital Test of COVID-19 Patients }\end{array}$ & $10.1101 / 2020.05 .05 .20091561$ \\
\hline 138 & $\begin{array}{l}\text { Diagnóstico } \\
\text { baseado em } \\
\text { imagem }\end{array}$ & $\begin{array}{l}\text { Deep learning models for COVID-19 infected area } \\
\text { segmentation in CT images }\end{array}$ & $10.1101 / 2020.05 .08 .20094664$ \\
\hline 139 & $\begin{array}{l}\text { Diagnóstico } \\
\text { baseado em } \\
\text { imagem }\end{array}$ & $\begin{array}{l}\text { COVID-Classifier: An automated machine learning } \\
\text { model to assist in the diagnosis of COVID-19 } \\
\text { infection in chest } x \text {-ray images }\end{array}$ & $10.1101 / 2020.05 .09 .20096560$ \\
\hline 140 & $\begin{array}{l}\text { Diagnóstico } \\
\text { baseado em } \\
\text { imagem }\end{array}$ & $\begin{array}{l}\text { A collaborative online Al engine for CT-based } \\
\text { COVID-19 diagnosis }\end{array}$ & $10.1101 / 2020.05 .10 .20096073$ \\
\hline 141 & $\begin{array}{l}\text { Diagnóstico } \\
\text { baseado em } \\
\text { imagem }\end{array}$ & $\begin{array}{l}\text { Automatic Detection of COVID-19 Infection from } \\
\text { Chest X-ray using Deep Learning }\end{array}$ & $10.1101 / 2020.05 .10 .20097063$ \\
\hline 142 & $\begin{array}{l}\text { Diagnóstico } \\
\text { baseado em } \\
\text { imagem }\end{array}$ & $\begin{array}{l}\text { Assisting Scalable Diagnosis Automatically via CT } \\
\text { Images in the Combat against COVID-19 }\end{array}$ & $10.1101 / 2020.05 .11 .20093732$ \\
\hline 143 & $\begin{array}{l}\text { Diagnóstico } \\
\text { baseado em } \\
\text { imagem }\end{array}$ & $\begin{array}{l}\text { Online COVID-19 diagnosis with chest CT images: } \\
\text { Lesion-attention deep neural networks }\end{array}$ & $10.1101 / 2020.05 .11 .20097907$ \\
\hline
\end{tabular}




\begin{tabular}{|c|c|c|c|}
\hline ID & $\begin{array}{l}\text { Categoria de } \\
\text { aplicação }\end{array}$ & Título & DOI \\
\hline 144 & $\begin{array}{l}\text { Diagnóstico } \\
\text { baseado em } \\
\text { imagem }\end{array}$ & $\begin{array}{c}\text { Problems of Deploying CNN Transfer Learning to } \\
\text { Detect COVID-19 from Chest X-rays }\end{array}$ & $10.1101 / 2020.05 .12 .20098954$ \\
\hline 145 & $\begin{array}{l}\text { Diagnóstico } \\
\text { baseado em } \\
\text { imagem }\end{array}$ & $\begin{array}{l}\text { The Evaluation of Deep Neural Networks and } \\
\text { X-Ray as a Practical Alternative for Diagnosis and } \\
\text { Management of COVID-19 }\end{array}$ & $10.1101 / 2020.05 .12 .20099481$ \\
\hline 146 & $\begin{array}{l}\text { Diagnóstico } \\
\text { baseado em } \\
\text { imagem }\end{array}$ & $\begin{array}{l}\text { Deep Transfer Learning-based COVID-19 } \\
\text { prediction using Chest X-rays }\end{array}$ & $10.1101 / 2020.05 .12 .20099937$ \\
\hline 147 & $\begin{array}{l}\text { Diagnóstico } \\
\text { baseado em } \\
\text { imagem }\end{array}$ & $\begin{array}{l}\text { COVID Faster R-CNN: A Novel Framework to } \\
\text { Diagnose Novel Coronavirus Disease (COVID-19) } \\
\text { in X-Ray Images }\end{array}$ & $10.1101 / 2020.05 .14 .20101873$ \\
\hline 148 & $\begin{array}{l}\text { Diagnóstico } \\
\text { baseado em } \\
\text { imagem }\end{array}$ & $\begin{array}{l}\text { Al-based multi-modal integration of clinical } \\
\text { characteristics, lab tests and chest CTs improves } \\
\text { COVID-19 outcome prediction of hospitalized } \\
\text { patients }\end{array}$ & $10.1101 / 2020.05 .14 .20101972$ \\
\hline 149 & $\begin{array}{l}\text { Diagnóstico } \\
\text { baseado em } \\
\text { imagem }\end{array}$ & $\begin{array}{c}\text { Interpretable Artificial Intelligence for COVID-19 } \\
\text { Diagnosis from Chest CT Reveals Specificity of } \\
\text { Ground-Glass Opacities }\end{array}$ & $10.1101 / 2020.05 .16 .20103408$ \\
\hline 150 & $\begin{array}{l}\text { Diagnóstico } \\
\text { baseado em } \\
\text { imagem }\end{array}$ & $\begin{array}{l}\text { Automated assessment of COVID-19 pulmonary } \\
\text { disease severity on chest radiographs using } \\
\text { convolutional Siamese neural networks }\end{array}$ & $10.1101 / 2020.05 .20 .20108159$ \\
\hline 151 & $\begin{array}{l}\text { Diagnóstico } \\
\text { baseado em } \\
\text { imagem }\end{array}$ & $\begin{array}{c}\text { Using Artificial Intelligence for COVID-19 Chest } \\
\text { X-ray Diagnosis }\end{array}$ & $10.1101 / 2020.05 .21 .20106518$ \\
\hline 152 & $\begin{array}{l}\text { Diagnóstico } \\
\text { baseado em } \\
\text { imagem }\end{array}$ & $\begin{array}{l}\text { COVID-19 detection from chest X-Ray images } \\
\text { using Deep Learning and Convolutional Neural } \\
\text { Networks }\end{array}$ & $10.1101 / 2020.05 .22 .20110817$ \\
\hline 153 & $\begin{array}{l}\text { Diagnóstico } \\
\text { baseado em } \\
\text { imagem }\end{array}$ & $\begin{array}{l}\text { AIDCOV: An Interpretable Artificial Intelligence } \\
\text { Model for Detection of COVID-19 from Chest } \\
\text { Radiography Images }\end{array}$ & $10.1101 / 2020.05 .24 .20111922$ \\
\hline 154 & $\begin{array}{l}\text { Diagnóstico } \\
\text { baseado em } \\
\text { imagem }\end{array}$ & $\begin{array}{l}\text { A chest radiography-based artificial intelligence } \\
\text { deep-learning model to predict severe Covid-19 } \\
\text { patient outcomes: the CAPE (Covid-19 AI } \\
\text { Predictive Engine) Model }\end{array}$ & $10.1101 / 2020.05 .25 .20113084$ \\
\hline
\end{tabular}




\begin{tabular}{|c|c|c|c|}
\hline ID & $\begin{array}{l}\text { Categoria de } \\
\text { aplicação }\end{array}$ & Título & DOI \\
\hline 155 & $\begin{array}{l}\text { Diagnóstico } \\
\text { baseado em } \\
\text { imagem }\end{array}$ & $\begin{array}{l}\text { Differentiating COVID-19 from other types of } \\
\text { pneumonia with convolutional neural networks }\end{array}$ & $10.1101 / 2020.05 .26 .20113761$ \\
\hline 156 & $\begin{array}{l}\text { Diagnóstico } \\
\text { baseado em } \\
\text { imagem }\end{array}$ & $\begin{array}{c}\text { Automatic Detection of COVID-19 and } \\
\text { Pneumonia from Chest X-Ray using Transfer } \\
\text { Learning }\end{array}$ & $10.1101 / 2020.05 .27 .20100297$ \\
\hline 157 & $\begin{array}{l}\text { Diagnóstico } \\
\text { baseado em } \\
\text { imagem }\end{array}$ & $\begin{array}{c}\text { Early Detection of Coronavirus Cases Using Chest } \\
\text { X-ray Images Employing Machine Learning and } \\
\text { Deep Learning Approaches }\end{array}$ & $10.1101 / 2020.06 .07 .20124594$ \\
\hline 158 & $\begin{array}{l}\text { Diagnóstico } \\
\text { baseado em } \\
\text { imagem }\end{array}$ & $\begin{array}{l}\text { A Fully Automated Deep Learning-based Network } \\
\text { For Detecting COVID-19 from a New And Large } \\
\text { Lung CT Scan Dataset }\end{array}$ & $10.1101 / 2020.06 .08 .20121541$ \\
\hline 159 & $\begin{array}{l}\text { Diagnóstico } \\
\text { baseado em } \\
\text { imagem }\end{array}$ & $\begin{array}{c}\text { Benchmarking Deep Learning Models and } \\
\text { Automated Model Design for COVID-19 } \\
\text { Detection with Chest CT Scans }\end{array}$ & $10.1101 / 2020.06 .08 .20125963$ \\
\hline 160 & $\begin{array}{l}\text { Diagnóstico } \\
\text { baseado em } \\
\text { imagem }\end{array}$ & $\begin{array}{l}\text { Improving effectiveness of different deep learning- } \\
\text { based models for detecting COVID-19 from } \\
\text { computed tomography (CT) images }\end{array}$ & $10.1101 / 2020.06 .12 .20129643$ \\
\hline 161 & $\begin{array}{l}\text { Diagnóstico } \\
\text { baseado em } \\
\text { imagem }\end{array}$ & $\begin{array}{c}\text { A Combined Deep CNN-LSTM Network for the } \\
\text { Detection of Novel Coronavirus (COVID-19) Using } \\
\text { X-ray Images }\end{array}$ & $10.1101 / 2020.06 .18 .20134718$ \\
\hline 162 & $\begin{array}{l}\text { Diagnóstico } \\
\text { baseado em } \\
\text { imagem }\end{array}$ & $\begin{array}{l}\text { Chest } \mathrm{X} \text {-ray classification using Deep learning for } \\
\text { automated COVID-19 screening }\end{array}$ & $10.1101 / 2020.06 .21 .20136598$ \\
\hline 163 & $\begin{array}{l}\text { Diagnóstico } \\
\text { baseado em } \\
\text { imagem }\end{array}$ & $\begin{array}{l}\text { A Multi-Task Pipeline with Specialized } \\
\text { Streams forClassification and Segmentation of } \\
\text { InfectionManifestations in COVID-19 Scans }\end{array}$ & $10.1101 / 2020.06 .24 .20139238$ \\
\hline 164 & $\begin{array}{l}\text { Diagnóstico } \\
\text { baseado em } \\
\text { imagem }\end{array}$ & $\begin{array}{l}\text { An Automatic Computer-Based Method for Fast } \\
\text { and Accurate Covid-19 Diagnosis }\end{array}$ & $10.1101 / 2020.07 .02 .20136721$ \\
\hline 165 & $\begin{array}{l}\text { Diagnóstico } \\
\text { baseado em } \\
\text { imagem }\end{array}$ & $\begin{array}{l}\text { COVIDPEN: A Novel COVID-19 Detection Model } \\
\text { using Chest X-Rays and CT Scans }\end{array}$ & $10.1101 / 2020.07 .08 .20149161$ \\
\hline
\end{tabular}




\begin{tabular}{|c|c|c|c|}
\hline ID & $\begin{array}{l}\text { Categoria de } \\
\text { aplicação }\end{array}$ & Título & DOI \\
\hline 166 & $\begin{array}{l}\text { Diagnóstico } \\
\text { baseado em } \\
\text { imagem }\end{array}$ & $\begin{array}{l}\text { ReCoNet: Multi-level Preprocessing of } \\
\text { Chest X-rays for COVID-19 Detection Using } \\
\text { Convolutional Neural Networks }\end{array}$ & 10.1101/2020.07.11.20149112 \\
\hline 167 & $\begin{array}{l}\text { Diagnóstico } \\
\text { baseado em } \\
\text { imagem }\end{array}$ & $\begin{array}{c}\text { Diagnosis of COVID-19 using CT scan images and } \\
\text { deep learning techniques }\end{array}$ & $10.1101 / 2020.07 .11 .20151332$ \\
\hline 168 & $\begin{array}{l}\text { Diagnóstico } \\
\text { baseado em } \\
\text { imagem }\end{array}$ & $\begin{array}{l}\text { A Quantitative Lung Computed Tomography } \\
\text { Image Feature for Multi-Center Severity } \\
\text { Assessment of COVID-19 }\end{array}$ & $10.1101 / 2020.07 .13 .20152231$ \\
\hline 169 & $\begin{array}{l}\text { Diagnóstico } \\
\text { baseado em } \\
\text { imagem }\end{array}$ & $\begin{array}{l}\text { Computer-aided covid-19 patient screening using } \\
\text { chest images (X-Ray and CT scans) }\end{array}$ & $10.1101 / 2020.07 .16 .20155093$ \\
\hline 170 & $\begin{array}{l}\text { Diagnóstico } \\
\text { baseado em } \\
\text { imagem }\end{array}$ & $\begin{array}{c}\text { Artificial Intelligence Augmentation of Radiologist } \\
\text { Performance in Distinguishing COVID-19 from } \\
\text { Pneumonia of Other Origin at Chest CT }\end{array}$ & 10.1148/radiol.2020201491 \\
\hline 171 & $\begin{array}{l}\text { Diagnóstico } \\
\text { baseado em } \\
\text { imagem }\end{array}$ & $\begin{array}{c}\text { A review on the use of artificial intelligence for } \\
\text { medical imaging of the lungs of patients with } \\
\text { coronavirus disease } 2019\end{array}$ & 10.5152/dir.2019.20294 \\
\hline 172 & $\begin{array}{l}\text { Diagnóstico } \\
\text { baseado em } \\
\text { imagem }\end{array}$ & $\begin{array}{l}\text { Deep learning for detecting corona virus disease } \\
2019 \text { (COVID-19) on high-resolution computed } \\
\text { tomography: a pilot study }\end{array}$ & 10.21037/atm.2020.03.132 \\
\hline 173 & $\begin{array}{l}\text { Diagnóstico } \\
\text { baseado em } \\
\text { imagem }\end{array}$ & $\begin{array}{l}\text { Relational Modeling for Robust and Efficient } \\
\text { Pulmonary Lobe Segmentation in CT Scans }\end{array}$ & 10.1109/TMI.2020.2995108 \\
\hline 174 & $\begin{array}{l}\text { Diagnóstico } \\
\text { baseado em } \\
\text { imagem }\end{array}$ & $\begin{array}{l}\text { Chest CT evaluation of } 11 \text { persistent } \\
\text { asymptomatic patients with SARS-CoV-2 infection }\end{array}$ & 10.7883/yoken.JJID.2020.264 \\
\hline 175 & $\begin{array}{l}\text { Diagnóstico } \\
\text { baseado em } \\
\text { imagem }\end{array}$ & $\begin{array}{l}\text { Identification of COVID-19 samples from chest } \\
\text { X-Ray images using deep learning: A comparison } \\
\text { of transfer learning approaches }\end{array}$ & 10.3233/XST-200715 \\
\hline 176 & $\begin{array}{l}\text { Diagnóstico } \\
\text { baseado em } \\
\text { imagem }\end{array}$ & $\begin{array}{l}\text { Iteratively Pruned Deep Learning Ensembles for } \\
\text { COVID-19 Detection in Chest X-rays }\end{array}$ & 10.1109/access.2020.3003810 \\
\hline
\end{tabular}




\begin{tabular}{|c|c|c|c|}
\hline ID & $\begin{array}{l}\text { Categoria de } \\
\text { aplicação }\end{array}$ & Título & DOI \\
\hline 177 & $\begin{array}{l}\text { Diagnóstico } \\
\text { baseado em } \\
\text { imagem }\end{array}$ & $\begin{array}{c}\text { Implementation of a Deep Learning-Based } \\
\text { Computer-Aided Detection System for the } \\
\text { Interpretation of Chest Radiographs in Patients } \\
\text { Suspected for COVID-19 }\end{array}$ & 10.3348/kjr.2020.0536 \\
\hline 178 & $\begin{array}{l}\text { Diagnóstico } \\
\text { baseado em } \\
\text { imagem }\end{array}$ & $\begin{array}{l}\text { A Deep Neural Network to Distinguish COVID-19 } \\
\text { from other Chest Diseases using X-ray Images }\end{array}$ & $\begin{array}{c}10.2174 / 157340561666620060 \\
4163954\end{array}$ \\
\hline 179 & $\begin{array}{l}\text { Diagnóstico } \\
\text { baseado em } \\
\text { imagem }\end{array}$ & $\begin{array}{l}\text { End-to-end automatic differentiation of the } \\
\text { coronavirus disease } 2019 \text { (COVID-19) from viral } \\
\text { pneumonia based on chest CT }\end{array}$ & $10.1007 / \mathrm{s} 00259-020-04929-1$ \\
\hline 180 & $\begin{array}{l}\text { Diagnóstico } \\
\text { baseado em } \\
\text { imagem }\end{array}$ & $\begin{array}{c}\text { Detection of coronavirus disease from X-ray } \\
\text { images using deep learning and transfer learning } \\
\text { algorithms }\end{array}$ & 10.3233/XST-200720 \\
\hline 181 & $\begin{array}{l}\text { Diagnóstico } \\
\text { baseado em } \\
\text { imagem }\end{array}$ & $\begin{array}{l}\text { Quantitative analysis of chest CT imaging findings } \\
\text { with the risk of ARDS in COVID-19 patients: a } \\
\text { preliminary study }\end{array}$ & 10.21037/atm-20-3554 \\
\hline 182 & $\begin{array}{l}\text { Diagnóstico } \\
\text { baseado em } \\
\text { imagem }\end{array}$ & $\begin{array}{l}\text { Interpretable artificial intelligence framework for } \\
\text { COVID-19 screening on chest X-rays }\end{array}$ & 10.3892/etm.2020.8797 \\
\hline 183 & $\begin{array}{l}\text { Diagnóstico } \\
\text { baseado em } \\
\text { imagem }\end{array}$ & $\begin{array}{l}\text { Automated Assessment of CO-RADS and Chest } \\
\text { CT Severity Scores in Patients with Suspected } \\
\text { COVID-19 Using Artificial Intelligence }\end{array}$ & 10.1148/radiol.2020202439 \\
\hline 184 & $\begin{array}{l}\text { Diagnóstico } \\
\text { baseado em } \\
\text { imagem }\end{array}$ & $\begin{array}{l}\text { Machine learning-based CT radiomics method } \\
\text { for predicting hospital stay in patients with } \\
\text { pneumonia associated with SARS-CoV-2 infection: } \\
\text { a multicenter study }\end{array}$ & 10.21037/atm-20-3026 \\
\hline 185 & $\begin{array}{l}\text { Diagnóstico } \\
\text { baseado em } \\
\text { imagem }\end{array}$ & $\begin{array}{l}\text { Rapid identification of COVID-19 severity in CT } \\
\text { scans through classification of deep features }\end{array}$ & $10.1186 / s 12938-020-00807-x$ \\
\hline 186 & $\begin{array}{l}\text { Diagnóstico } \\
\text { baseado em } \\
\text { imagem }\end{array}$ & $\begin{array}{l}\text { Inf-Net: Automatic COVID-19 Lung Infection } \\
\text { Segmentation From CT Images }\end{array}$ & 10.1109/TMI.2020.2996645 \\
\hline 187 & $\begin{array}{l}\text { Diagnóstico } \\
\text { baseado em } \\
\text { imagem }\end{array}$ & $\begin{array}{l}\text { COVID-19 Detection through Transfer Learning } \\
\text { using Multimodal Imaging Data }\end{array}$ & 10.1109/ACCESS.2020.3016780 \\
\hline
\end{tabular}




\begin{tabular}{|c|c|c|c|}
\hline ID & $\begin{array}{l}\text { Categoria de } \\
\text { aplicação }\end{array}$ & Título & DOI \\
\hline 188 & $\begin{array}{l}\text { Diagnóstico } \\
\text { baseado em } \\
\text { imagem }\end{array}$ & $\begin{array}{l}\text { A Weakly-Supervised Framework for COVID-19 } \\
\text { Classification and Lesion Localization From Chest } \\
\text { CT }\end{array}$ & 10.1109/TMI.2020.2995965 \\
\hline 189 & $\begin{array}{l}\text { Diagnóstico } \\
\text { baseado em } \\
\text { imagem }\end{array}$ & $\begin{array}{l}\text { Deep bidirectional classification model for } \\
\text { COVID-19 disease infected patients }\end{array}$ & 10.1109/TCBB.2020.3009859 \\
\hline 190 & $\begin{array}{l}\text { Diagnóstico } \\
\text { baseado em } \\
\text { imagem }\end{array}$ & $\begin{array}{l}\text { Deep Learning for The Detection of COVID-19 } \\
\text { Using Transfer Learning and Model Integration }\end{array}$ & $\begin{array}{c}10.1109 / \\
\text { ICEIEC49280.2020.9152329 }\end{array}$ \\
\hline 191 & $\begin{array}{l}\text { Identificação } \\
\text { de padrões e } \\
\text { estratificação }\end{array}$ & $\begin{array}{c}\text { Spatial modeling, risk mapping, change detection, } \\
\text { and outbreak trend analysis of coronavirus } \\
\text { (COVID-19) in Iran (days between February } 19 \\
\text { and June } 14,2020 \text { ) }\end{array}$ & 10.1016/j.jijid.2020.06.058 \\
\hline 192 & $\begin{array}{l}\text { Identificação } \\
\text { de padrões e } \\
\text { estratificação }\end{array}$ & $\begin{array}{l}\text { A clustering approach to classify italian regions } \\
\text { and provinces based on prevalence and trend of } \\
\text { sars-cov- } 2 \text { cases }\end{array}$ & 10.3390/ijerph17155286 \\
\hline 193 & $\begin{array}{l}\text { Identificação } \\
\text { de padrões e } \\
\text { estratificação }\end{array}$ & $\begin{array}{l}\text { An epidemiological study on the prevalence of } \\
\text { the clinical features of SARS-CoV- } 2 \text { infection in } \\
\text { Romanian people }\end{array}$ & 10.3390/ijerph17145082 \\
\hline 194 & $\begin{array}{l}\text { Identificação } \\
\text { de padrões e } \\
\text { estratificação }\end{array}$ & $\begin{array}{l}\text { Investigating a serious challenge in the sustainable } \\
\text { development process: Analysis of confirmed cases } \\
\text { of COVID-19 (new type of Coronavirus) through } \\
\text { a binary classification using artificial intelligence } \\
\text { and regression analysis }\end{array}$ & $10.3390 /$ su12062427 \\
\hline 195 & $\begin{array}{l}\text { Identificação } \\
\text { de padrões e } \\
\text { estratificação }\end{array}$ & $\begin{array}{l}\text { Any unique image biomarkers associated with } \\
\text { COVID-19? }\end{array}$ & $10.1007 / s 00330-020-06956-w$ \\
\hline 196 & $\begin{array}{l}\text { Identificação } \\
\text { de padrões e } \\
\text { estratificação }\end{array}$ & $\begin{array}{l}\text { Early epidemiological and clinical manifestations } \\
\text { of COVID-19 in Japan }\end{array}$ & $10.1101 / 2020.04 .17 .20070276$ \\
\hline 197 & $\begin{array}{l}\text { Identificação } \\
\text { de padrões e } \\
\text { estratificação }\end{array}$ & $\begin{array}{l}\text { Augmented Curation of Clinical Notes from } \\
\text { a Massive EHR System Reveals Symptoms of } \\
\text { Impending COVID-19 Diagnosis }\end{array}$ & $10.1101 / 2020.04 .19 .20067660$ \\
\hline
\end{tabular}




\begin{tabular}{|c|c|c|c|}
\hline ID & $\begin{array}{l}\text { Categoria de } \\
\text { aplicação }\end{array}$ & Título & DOI \\
\hline 198 & $\begin{array}{l}\text { Identificação } \\
\text { de padrões e } \\
\text { estratificação }\end{array}$ & $\begin{array}{l}\text { Countries are Clustered but Number of Tests is } \\
\text { not Vital to Predict Global COVID-19 Confirmed } \\
\text { Cases: A Machine Learning Approach }\end{array}$ & $10.1101 / 2020.04 .24 .20078238$ \\
\hline 199 & $\begin{array}{l}\text { Identificação } \\
\text { de padrões e } \\
\text { estratificação }\end{array}$ & $\begin{array}{l}\text { Assessment of the outbreak risk, mapping and } \\
\text { infestation behavior of COVID-19: Application of } \\
\text { the autoregressive and moving average (ARMA) } \\
\text { and polynomial models }\end{array}$ & $10.1101 / 2020.04 .28 .20083998$ \\
\hline 200 & $\begin{array}{l}\text { Identificação } \\
\text { de padrões e } \\
\text { estratificação }\end{array}$ & $\begin{array}{l}\text { Effect of Temperature on the Transmission of } \\
\text { COVID-19: A Machine Learning Case Study in } \\
\text { Spain }\end{array}$ & $10.1101 / 2020.05 .01 .20087759$ \\
\hline 201 & $\begin{array}{l}\text { Identificação } \\
\text { de padrões e } \\
\text { estratificação }\end{array}$ & $\begin{array}{l}\text { Risk stratification of hospitalized COVID-19 } \\
\text { patients through comparative studies of } \\
\text { laboratory results with influenza }\end{array}$ & 10.1101/2020.05.18.20101709 \\
\hline 202 & $\begin{array}{l}\text { Identificação } \\
\text { de padrões e } \\
\text { estratificação }\end{array}$ & $\begin{array}{l}\text { Explainable machine learning models to } \\
\text { understand determinants of COVID-19 mortality } \\
\text { in the United States }\end{array}$ & 10.1101/2020.05.23.20110189 \\
\hline 203 & $\begin{array}{l}\text { Identificação } \\
\text { de padrões e } \\
\text { estratificação }\end{array}$ & $\begin{array}{l}\text { A Novel Machine Learning-derived Radiomic } \\
\text { Signature of the Whole Lung Differentiates } \\
\text { Stable From Progressive COVID-19 Infection: A } \\
\text { Retrospective Cohort Study }\end{array}$ & 10.1097/RTI.0000000000000544 \\
\hline 204 & $\begin{array}{l}\text { Identificação } \\
\text { de padrões e } \\
\text { estratificação }\end{array}$ & $\begin{array}{l}\text { 冈-Satellite: An Al-driven System and Benchmark } \\
\text { Datasets for Dynamic COVID-19 Risk Assessment } \\
\text { in the United States }\end{array}$ & 10.1109/JBHI.2020.3009314 \\
\hline 205 & $\begin{array}{l}\text { Identificação } \\
\text { de padrões e } \\
\text { estratificação }\end{array}$ & $\begin{array}{l}\text { Identification of COVID-19 Spreaders Using } \\
\text { Multiplex Networks Approach }\end{array}$ & 10.1109/ACCESS.2020.3007726 \\
\hline 206 & Mineração textual & $\begin{array}{l}\text { Characterizing the Propagation of Situational } \\
\text { Information in Social Media during COVID-19 } \\
\text { Epidemic: A Case Study on Weibo }\end{array}$ & 10.1109/TCSS.2020.2980007 \\
\hline 207 & Mineração textual & $\begin{array}{l}\text { COVID-19 Public Sentiment Insights and } \\
\text { MachineLearning for Tweets Classification }\end{array}$ & $10.1101 / 2020.06 .01 .20119347$ \\
\hline 208 & Mineração textual & $\begin{array}{c}\text { Predicting COVID-19 Incidence Through Analysis } \\
\text { of Google Trends Data in Iran: Data Mining and } \\
\text { Deep Learning Pilot Study }\end{array}$ & $10.2196 / 18828$ \\
\hline
\end{tabular}




\begin{tabular}{|c|c|c|c|}
\hline ID & $\begin{array}{l}\text { Categoria de } \\
\text { aplicação }\end{array}$ & Título & DOI \\
\hline 209 & Mineração textual & $\begin{array}{l}\text { An Al approach to COVID-19 infection risk } \\
\text { assessment in virtual visits: a case report }\end{array}$ & 10.1093/jamia/ocaa105 \\
\hline 210 & Mineração textual & $\begin{array}{c}\text { Deep Sentiment Classification and Topic } \\
\text { Discovery on Novel Coronavirus or COVID-19 } \\
\text { Online Discussions: NLP Using LSTM Recurrent } \\
\text { Neural Network Approach }\end{array}$ & 10.1109/JBHI.2020.3001216 \\
\hline 211 & Mineração textual & $\begin{array}{l}\text { Social Media Data Analytics on Telehealth During } \\
\text { the COVID-19 Pandemic }\end{array}$ & $10.7759 /$ cureus. 7838 \\
\hline 212 & Mineração textual & $\begin{array}{l}\text { Use of Health Belief Model-Based Deep Learning } \\
\text { Classifiers for COVID-19 Social Media Content to } \\
\text { Examine Public Perceptions of Physical Distancing: } \\
\text { Model Development and Case Study }\end{array}$ & $10.2196 / 20493$ \\
\hline 213 & Mineração textual & $\begin{array}{c}\text { Al Chatbot Design during an Epidemic Like the } \\
\text { Novel Coronavirus }\end{array}$ & $10.3390 /$ healthcare 8020154 \\
\hline 214 & $\begin{array}{l}\text { Modelos } \\
\text { preditivos }\end{array}$ & $\begin{array}{l}\text { Early triage of critically ill COVID-19 patients using } \\
\text { deep learning }\end{array}$ & $10.1038 / s 41467-020-17280-8$ \\
\hline 215 & $\begin{array}{l}\text { Modelos } \\
\text { preditivos }\end{array}$ & $\begin{array}{l}\text { Deep learning methods for forecasting COVID-19 } \\
\text { time-Series data: A Comparative study }\end{array}$ & 10.1016/j.chaos.2020.110121 \\
\hline 216 & $\begin{array}{l}\text { Modelos } \\
\text { preditivos }\end{array}$ & COVID-19 in Italy and extreme data mining & 10.1016/j.physa.2020.124991 \\
\hline 217 & $\begin{array}{l}\text { Modelos } \\
\text { preditivos }\end{array}$ & $\begin{array}{l}\text { Prediction and analysis of COVID-19 positive } \\
\text { cases using deep learning models: A descriptive } \\
\text { case study of India }\end{array}$ & 10.1016/j.chaos.2020.110017 \\
\hline 218 & $\begin{array}{l}\text { Modelos } \\
\text { preditivos }\end{array}$ & $\begin{array}{l}\text { A multicriteria approach for risk assessment of } \\
\text { Covid-19 in urban district lockdown }\end{array}$ & 10.1016/j.ssci.2020.104862 \\
\hline 219 & $\begin{array}{l}\text { Modelos } \\
\text { preditivos }\end{array}$ & $\begin{array}{c}\text { Forecasting Brazilian and American COVID-19 } \\
\text { cases based on artificial intelligence coupled with } \\
\text { climatic exogenous variables }\end{array}$ & 10.1016/j.chaos.2020.110027 \\
\hline 220 & $\begin{array}{l}\text { Modelos } \\
\text { preditivos }\end{array}$ & $\begin{array}{l}\text { COVID-19 outbreak: Application of multi-gene } \\
\text { genetic programming to country-based prediction } \\
\text { models }\end{array}$ & 10.29333/ejgm/8232 \\
\hline 221 & $\begin{array}{l}\text { Modelos } \\
\text { preditivos }\end{array}$ & $\begin{array}{l}\text { Partial derivative Nonlinear Global Pandemic } \\
\text { Machine Learning prediction of COVID } 19\end{array}$ & 10.1016/j.chaos.2020.110056 \\
\hline
\end{tabular}




\begin{tabular}{|c|c|c|c|}
\hline ID & $\begin{array}{l}\text { Categoria de } \\
\text { aplicação }\end{array}$ & Título & DOI \\
\hline 222 & $\begin{array}{l}\text { Modelos } \\
\text { preditivos }\end{array}$ & $\begin{array}{c}\text { An empirical overview of nonlinearity and } \\
\text { overfitting in machine learning using COVID-19 } \\
\text { data }\end{array}$ & 10.1016/j.chaos.2020.110055 \\
\hline 223 & $\begin{array}{l}\text { Modelos } \\
\text { preditivos }\end{array}$ & $\begin{array}{l}\text { Modeling and prediction of COVID-19 in Mexico } \\
\text { applying mathematical and computational } \\
\text { models }\end{array}$ & 10.1016/j.chaos.2020.109946 \\
\hline 224 & $\begin{array}{l}\text { Modelos } \\
\text { preditivos }\end{array}$ & $\begin{array}{l}\text { Comparative analysis and forecasting of } \\
\text { COVID-19 cases in various European countries } \\
\text { with ARIMA, NARNN and LSTM approaches }\end{array}$ & 10.1016/j.chaos.2020.110015 \\
\hline 225 & $\begin{array}{l}\text { Modelos } \\
\text { preditivos }\end{array}$ & $\begin{array}{l}\text { Mathematical models and deep learning for } \\
\text { predicting the number of individuals reported to } \\
\text { be infected with SARS-CoV-2 }\end{array}$ & 10.1098/rsif.2020.0494 \\
\hline 226 & $\begin{array}{l}\text { Modelos } \\
\text { preditivos }\end{array}$ & $\begin{array}{l}\text { Risk of a second wave of Covid-19 infections: } \\
\text { using artificial intelligence to investigate } \\
\text { stringency of physical distancing policies in North } \\
\text { America }\end{array}$ & $10.1007 / \mathrm{s} 00264-020-04653-3$ \\
\hline 227 & $\begin{array}{l}\text { Modelos } \\
\text { preditivos }\end{array}$ & $\begin{array}{c}\text { Analysis of clinical features and imaging signs } \\
\text { of COVID-19 with the assistance of artificial } \\
\text { intelligence }\end{array}$ & 10.26355/eurrev_202008_22510 \\
\hline 228 & $\begin{array}{l}\text { Modelos } \\
\text { preditivos }\end{array}$ & $\begin{array}{l}\text { Forecasting covid-19 dynamics in brazil: A data } \\
\text { driven approach }\end{array}$ & 10.3390/ijerph17145115 \\
\hline 229 & $\begin{array}{l}\text { Modelos } \\
\text { preditivos }\end{array}$ & $\begin{array}{l}\text { Predicting COVID-19 in China Using Hybrid AI } \\
\text { Model }\end{array}$ & 10.1109/ТСYВ.2020.2990162 \\
\hline 230 & $\begin{array}{l}\text { Modelos } \\
\text { preditivos }\end{array}$ & $\begin{array}{l}\text { Artificial neural network modeling of novel } \\
\text { coronavirus (COVID-19) incidence rates across the } \\
\text { continental United States }\end{array}$ & 10.3390/ijerph17124204 \\
\hline 231 & $\begin{array}{l}\text { Modelos } \\
\text { preditivos }\end{array}$ & $\begin{array}{l}\text { Time series forecasting of COVID-19 transmission } \\
\text { in Canada using LSTM networks }\end{array}$ & 10.1016/j.chaos.2020.109864 \\
\hline 232 & $\begin{array}{l}\text { Modelos } \\
\text { preditivos }\end{array}$ & $\begin{array}{l}\text { Prioritizing and analyzing the role of climate } \\
\text { and urban parameters in the confirmed cases } \\
\text { of COVID-19 based on artificial intelligence } \\
\text { applications }\end{array}$ & 10.3390/ijerph17103730 \\
\hline 233 & $\begin{array}{l}\text { Modelos } \\
\text { preditivos }\end{array}$ & $\begin{array}{l}\text { Towards an artificial intelligence framework for } \\
\text { data-driven prediction of coronavirus clinical } \\
\text { severity }\end{array}$ & 10.32604/cmc.2020.010691 \\
\hline
\end{tabular}




\begin{tabular}{|c|c|c|c|}
\hline ID & $\begin{array}{l}\text { Categoria de } \\
\text { aplicação }\end{array}$ & Título & DOI \\
\hline 234 & $\begin{array}{l}\text { Modelos } \\
\text { preditivos }\end{array}$ & $\begin{array}{l}\text { Tourism demand and the COVID-19 pandemic: an } \\
\text { LSTM approach }\end{array}$ & $10.1080 / 02508281.2020 .1777053$ \\
\hline 235 & $\begin{array}{l}\text { Modelos } \\
\text { preditivos }\end{array}$ & $\begin{array}{l}\text { A classifier prediction model to predict the status } \\
\text { of Coronavirus CoVID-19 patients in South Korea }\end{array}$ & 10.26355/eurrev_202003_20709 \\
\hline 236 & $\begin{array}{l}\text { Modelos } \\
\text { preditivos }\end{array}$ & $\begin{array}{c}\text { A Machine Learning Model Reveals Older Age and } \\
\text { Delayed Hospitalization as Predictors of Mortality } \\
\text { in Patients with COVID-19 }\end{array}$ & $10.1101 / 2020.03 .25 .20043331$ \\
\hline 237 & $\begin{array}{l}\text { Modelos } \\
\text { preditivos }\end{array}$ & $\begin{array}{l}\text { Predicting Mortality Risk in Patients with } \\
\text { COVID-19 Using Artificial Intelligence to Help } \\
\text { Medical Decision-Making }\end{array}$ & $10.1101 / 2020.03 .30 .20047308$ \\
\hline 238 & $\begin{array}{l}\text { Modelos } \\
\text { preditivos }\end{array}$ & $\begin{array}{l}\text { COVID-19 Epidemic Analysis using Machine } \\
\text { Learning and Deep Learning Algorithms }\end{array}$ & $10.1101 / 2020.04 .08 .20057679$ \\
\hline 239 & $\begin{array}{l}\text { Modelos } \\
\text { preditivos }\end{array}$ & $\begin{array}{l}\text { Forecasting Covid-19 Outbreak Progression in } \\
\text { Italian Regions: A model based on neural network } \\
\text { training from Chinese data }\end{array}$ & $10.1101 / 2020.04 .09 .20059055$ \\
\hline 240 & $\begin{array}{l}\text { Modelos } \\
\text { preditivos }\end{array}$ & $\begin{array}{l}\text { Predicting the epidemic curve of the coronavirus } \\
\text { (SARS-CoV-2) disease (COVID-19) using artificial } \\
\text { intelligence }\end{array}$ & $10.1101 / 2020.04 .17 .20069666$ \\
\hline 241 & $\begin{array}{l}\text { Modelos } \\
\text { preditivos }\end{array}$ & COVID-19 Asymptomatic Infection Estimation & $10.1101 / 2020.04 .19 .20068072$ \\
\hline 242 & $\begin{array}{l}\text { Modelos } \\
\text { preditivos }\end{array}$ & $\begin{array}{c}\text { Machine Learning to Predict Mortality and Critical } \\
\text { Events in COVID-19 Positive New York City } \\
\text { Patients }\end{array}$ & $10.1101 / 2020.04 .26 .20073411$ \\
\hline 243 & $\begin{array}{l}\text { Modelos } \\
\text { preditivos }\end{array}$ & $\begin{array}{c}\text { Preparedness and Mitigation by projecting the risk } \\
\text { against COVID-19 transmission using Machine } \\
\text { Learning Techniques }\end{array}$ & $10.1101 / 2020.04 .26 .20080655$ \\
\hline 244 & $\begin{array}{l}\text { Modelos } \\
\text { preditivos }\end{array}$ & $\begin{array}{c}\text { Predicting community mortality risk due } \\
\text { to CoVID-19 using machine learning and } \\
\text { development of a prediction tool }\end{array}$ & $10.1101 / 2020.04 .27 .20081794$ \\
\hline 245 & $\begin{array}{l}\text { Modelos } \\
\text { preditivos }\end{array}$ & $\begin{array}{l}\text { Using Supervised Machine Learning and Empirical } \\
\text { Bayesian Kriging to reveal Correlates and Patterns } \\
\text { of COVID-19 Disease outbreak in sub-Saharan } \\
\text { Africa: Exploratory Data Analysis }\end{array}$ & $10.1101 / 2020.04 .27 .20082057$ \\
\hline
\end{tabular}




\begin{tabular}{|c|c|c|c|}
\hline ID & $\begin{array}{l}\text { Categoria de } \\
\text { aplicação }\end{array}$ & Título & DOI \\
\hline 246 & $\begin{array}{l}\text { Modelos } \\
\text { preditivos }\end{array}$ & $\begin{array}{c}\text { Novel Spatiotemporal Feature Extraction Parallel } \\
\text { Deep Neural Network for Forecasting Confirmed } \\
\text { Cases of Coronavirus Disease } 2019\end{array}$ & $10.1101 / 2020.04 .30 .20086538$ \\
\hline 247 & $\begin{array}{l}\text { Modelos } \\
\text { preditivos }\end{array}$ & $\begin{array}{l}\text { COVID-19 Pandemic Prediction for Hungary; a } \\
\text { Hybrid Machine Learning Approach }\end{array}$ & $10.1101 / 2020.05 .02 .20088427$ \\
\hline 248 & $\begin{array}{l}\text { Modelos } \\
\text { preditivos }\end{array}$ & $\begin{array}{l}\text { Spread of Covid-19 in the United States is } \\
\text { controlled }\end{array}$ & $10.1101 / 2020.05 .04 .20091272$ \\
\hline 249 & $\begin{array}{l}\text { Modelos } \\
\text { preditivos }\end{array}$ & $\begin{array}{l}\text { A Novel Intervention Recurrent autoencoder for } \\
\text { real time forecasting and non-pharmaceutical } \\
\text { intervention selection to curb the spread of } \\
\text { Covid-19 in the world }\end{array}$ & $10.1101 / 2020.05 .05 .20091827$ \\
\hline 250 & $\begin{array}{l}\text { Modelos } \\
\text { preditivos }\end{array}$ & $\begin{array}{l}\text { ProgNet: Covid-19 prognosis using recurrent } \\
\text { andconvolutional neural networks }\end{array}$ & $10.1101 / 2020.05 .06 .20092874$ \\
\hline 251 & $\begin{array}{l}\text { Modelos } \\
\text { preditivos }\end{array}$ & $\begin{array}{l}\text { Development and validation of the COVID-19 } \\
\text { severity index (CSI): a prognostic tool for early } \\
\text { respiratory decompensation }\end{array}$ & $10.1101 / 2020.05 .07 .20094573$ \\
\hline 252 & $\begin{array}{l}\text { Modelos } \\
\text { preditivos }\end{array}$ & $\begin{array}{l}\text { Machine learning model estimating number of } \\
\text { COVID-19 infection cases over coming } 24 \text { days } \\
\text { in every province of South Korea (XGBoost and } \\
\text { MultiOutputRegressor) }\end{array}$ & $10.1101 / 2020.05 .10 .20097527$ \\
\hline 253 & $\begin{array}{l}\text { Modelos } \\
\text { preditivos }\end{array}$ & $\begin{array}{c}\text { Forecasting Covid-19 dynamics in Brazil: a data } \\
\text { driven approach }\end{array}$ & $10.1101 / 2020.05 .11 .20098392$ \\
\hline 254 & $\begin{array}{l}\text { Modelos } \\
\text { preditivos }\end{array}$ & $\begin{array}{c}\text { Predicting the COVID-19 positive cases in India } \\
\text { with concern to Lockdown by using Mathematical } \\
\text { and Machine Learning based Models }\end{array}$ & $10.1101 / 2020.05 .16 .20104133$ \\
\hline 255 & $\begin{array}{l}\text { Modelos } \\
\text { preditivos }\end{array}$ & $\begin{array}{c}\text { An Interpretable Machine Learning Framework for } \\
\text { Accurate Severe vs Non-severe COVID-19 Clinical } \\
\text { Type Classification }\end{array}$ & $10.1101 / 2020.05 .18 .20105841$ \\
\hline 256 & $\begin{array}{l}\text { Modelos } \\
\text { preditivos }\end{array}$ & $\begin{array}{c}\text { Early risk assessment for COVID-19 patients from } \\
\text { emergency department data using machine } \\
\text { learning }\end{array}$ & $10.1101 / 2020.05 .19 .20086488$ \\
\hline 257 & $\begin{array}{l}\text { Modelos } \\
\text { preditivos }\end{array}$ & Clinical predictors of COVID-19 mortality & $10.1101 / 2020.05 .19 .20103036$ \\
\hline
\end{tabular}




\begin{tabular}{|c|c|c|c|}
\hline ID & $\begin{array}{l}\text { Categoria de } \\
\text { aplicação }\end{array}$ & Título & DOI \\
\hline 258 & $\begin{array}{l}\text { Modelos } \\
\text { preditivos }\end{array}$ & $\begin{array}{l}\text { MACHINE LEARNING PREDICTION FOR COVID } \\
19 \text { PANDEMIC IN INDIA }\end{array}$ & $10.1101 / 2020.05 .20 .20107847$ \\
\hline 259 & $\begin{array}{l}\text { Modelos } \\
\text { preditivos }\end{array}$ & $\begin{array}{c}\text { Worldwide and Regional Forecasting of } \\
\text { Coronavirus (Covid-19) Spread using a Deep } \\
\text { Learning Model }\end{array}$ & $10.1101 / 2020.05 .23 .20111039$ \\
\hline 260 & $\begin{array}{l}\text { Modelos } \\
\text { preditivos }\end{array}$ & $\begin{array}{l}\text { COVID-Net: A deep learning based and } \\
\text { interpretable predication model for the county- } \\
\text { wise trajectories of COVID-19 in the United States }\end{array}$ & $10.1101 / 2020.05 .26 .20113787$ \\
\hline 261 & $\begin{array}{l}\text { Modelos } \\
\text { preditivos }\end{array}$ & $\begin{array}{l}\text { Machine learning in predicting respiratory } \\
\text { failure in patients with COVID-19 pneumonia } \\
\text { - challenges, strengths, and opportunities in a } \\
\text { global health emergency }\end{array}$ & $10.1101 / 2020.05 .30 .20107888$ \\
\hline 262 & $\begin{array}{l}\text { Modelos } \\
\text { preditivos }\end{array}$ & $\begin{array}{l}\text { Development and Prospective Validation of } \\
\text { a Transparent Deep Learning Algorithm for } \\
\text { Predicting Need for Mechanical Ventilation }\end{array}$ & $10.1101 / 2020.05 .30 .20118109$ \\
\hline 263 & $\begin{array}{l}\text { Modelos } \\
\text { preditivos }\end{array}$ & $\begin{array}{l}\text { A prediction model based on machine learning for } \\
\text { diagnosing the early COVID-19 patients }\end{array}$ & $10.1101 / 2020.06 .03 .20120881$ \\
\hline 264 & $\begin{array}{l}\text { Modelos } \\
\text { preditivos }\end{array}$ & $\begin{array}{l}\text { Deep Learning and Holt-Trend Algorithms for } \\
\text { predicting COVID-19 pandemic }\end{array}$ & $10.1101 / 2020.06 .03 .20121590$ \\
\hline 265 & $\begin{array}{l}\text { Modelos } \\
\text { preditivos }\end{array}$ & $\begin{array}{c}\text { A Machine Learning Explanation of Incidence } \\
\text { Inequalities of SARS-CoV-2 Across } 88 \text { Days in } 157 \\
\text { Countries }\end{array}$ & $10.1101 / 2020.06 .06 .20124529$ \\
\hline 266 & $\begin{array}{l}\text { Modelos } \\
\text { preditivos }\end{array}$ & $\begin{array}{l}\text { Tracking and Classifying Global COVID-19 Cases } \\
\text { by using 1D Deep Convolution Neural Network }\end{array}$ & $10.1101 / 2020.06 .09 .20126565$ \\
\hline 267 & $\begin{array}{l}\text { Modelos } \\
\text { preditivos }\end{array}$ & $\begin{array}{l}\text { Identifying novel factors associated with } \\
\text { COVID-19 transmission and fatality using the } \\
\text { machine learning approach }\end{array}$ & $10.1101 / 2020.06 .10 .20127472$ \\
\hline 268 & $\begin{array}{l}\text { Modelos } \\
\text { preditivos }\end{array}$ & $\begin{array}{l}\text { COVID-19 Deaths: Which Explanatory Variables } \\
\text { Matter the Most? }\end{array}$ & $10.1101 / 2020.06 .11 .20129007$ \\
\hline 269 & $\begin{array}{l}\text { Modelos } \\
\text { preditivos }\end{array}$ & $\begin{array}{l}\text { An interpretable mortality prediction model for } \\
\text { COVID-19 patients - alternative approach }\end{array}$ & $10.1101 / 2020.06 .14 .20130732$ \\
\hline 270 & $\begin{array}{l}\text { Modelos } \\
\text { preditivos }\end{array}$ & $\begin{array}{l}\text { Routine laboratory blood tests predict } \\
\text { SARS-CoV-2 infection using machine learning }\end{array}$ & $10.1101 / 2020.06 .17 .20133892$ \\
\hline
\end{tabular}




\begin{tabular}{|c|c|c|c|}
\hline ID & $\begin{array}{l}\text { Categoria de } \\
\text { aplicação }\end{array}$ & Título & DOI \\
\hline 271 & $\begin{array}{l}\text { Modelos } \\
\text { preditivos }\end{array}$ & $\begin{array}{l}\text { Predicting the disease outcome in COVID-19 } \\
\text { positive patients through Machine Learning: a } \\
\text { retrospective cohort study with Brazilian data }\end{array}$ & $10.1101 / 2020.06 .26 .20140764$ \\
\hline 272 & $\begin{array}{l}\text { Modelos } \\
\text { preditivos }\end{array}$ & $\begin{array}{l}\text { Forecasting COVID-19 cases using Machine } \\
\text { Learning models }\end{array}$ & $10.1101 / 2020.07 .02 .20145474$ \\
\hline 273 & $\begin{array}{l}\text { Modelos } \\
\text { preditivos }\end{array}$ & $\begin{array}{l}\text { COVID-19 Mortality Risk Assessment: An } \\
\text { International Multi-Center Study }\end{array}$ & $10.1101 / 2020.07 .07 .20148304$ \\
\hline 274 & $\begin{array}{l}\text { Modelos } \\
\text { preditivos }\end{array}$ & $\begin{array}{l}\text { Recurrent Neural Reinforcement Learning for } \\
\text { Counterfactual Evaluation of Public Health } \\
\text { Interventions on the Spread of Covid-19 in the } \\
\text { world }\end{array}$ & $10.1101 / 2020.07 .08 .20149146$ \\
\hline 275 & $\begin{array}{l}\text { Modelos } \\
\text { preditivos }\end{array}$ & $\begin{array}{l}\text { A Recurrent Neural Network and Differential } \\
\text { Equation Based Spatiotemporal Infectious Disease } \\
\text { Model with Application to COVID-19 }\end{array}$ & $10.1101 / 2020.07 .20 .20158568$ \\
\hline 276 & $\begin{array}{l}\text { Modelos } \\
\text { preditivos }\end{array}$ & $\begin{array}{l}\text { Alternative Approaches for Modelling COVID- } \\
\text { 19:High-Accuracy Low-Data Predictions }\end{array}$ & $10.1101 / 2020.07 .22 .20159731$ \\
\hline 277 & $\begin{array}{l}\text { Modelos } \\
\text { preditivos }\end{array}$ & $\begin{array}{l}\text { Eleven Routine Clinical Features Predict COVID-19 } \\
\text { Severity }\end{array}$ & $10.1101 / 2020.07 .28 .20163022$ \\
\hline 278 & $\begin{array}{l}\text { Modelos } \\
\text { preditivos }\end{array}$ & $\begin{array}{l}\text { Using the spike protein feature to predict infection } \\
\text { risk and monitor the evolutionary dynamic of } \\
\text { coronavirus }\end{array}$ & $10.1186 / s 40249-020-00649-8$ \\
\hline 279 & $\begin{array}{l}\text { Modelos } \\
\text { preditivos }\end{array}$ & $\begin{array}{l}\text { Development and validation of prognosis model } \\
\text { of mortality risk in patients with COVID-19 }\end{array}$ & $10.1017 / S 0950268820001727$ \\
\hline 280 & $\begin{array}{l}\text { Modelos } \\
\text { preditivos }\end{array}$ & $\begin{array}{c}\text { Innovative use of artificial intelligence and digital } \\
\text { communication in acute stroke pathway in } \\
\text { response to COVID-19 }\end{array}$ & 10.7861/fhj.2020-0034 \\
\hline 281 & $\begin{array}{l}\text { Modelos } \\
\text { preditivos }\end{array}$ & $\begin{array}{c}\text { Early Stage Machine Learning Based Prediction } \\
\text { of US County Vulnerability to the COVID-19 } \\
\text { Pandemic }\end{array}$ & $10.2196 / 19446$ \\
\hline 282 & $\begin{array}{l}\text { Modelos } \\
\text { preditivos }\end{array}$ & $\begin{array}{l}\text { Statistical Explorations and Univariate Timeseries } \\
\text { Analysis on COVID-19 Datasets to Understand the } \\
\text { Trend of Disease Spreading and Death }\end{array}$ & $10.3390 / s 20113089$ \\
\hline 283 & $\begin{array}{l}\text { Modelos } \\
\text { preditivos }\end{array}$ & $\begin{array}{l}\text { Short-term forecasting COVID-19 cumulative } \\
\text { confirmed cases: Perspectives for Brazil }\end{array}$ & 10.1016/j.chaos.2020.109853 \\
\hline
\end{tabular}




\begin{tabular}{|c|c|c|c|}
\hline ID & $\begin{array}{l}\text { Categoria de } \\
\text { aplicação }\end{array}$ & Título & DOI \\
\hline 284 & $\begin{array}{l}\text { Modelos } \\
\text { preditivos }\end{array}$ & $\begin{array}{l}\text { Multiple Ensemble Neural Network Models } \\
\text { with Fuzzy Response Aggregation for Predicting } \\
\text { COVID-19 Time Series: The Case of Mexico }\end{array}$ & $10.3390 /$ healthcare 8020181 \\
\hline 285 & $\begin{array}{l}\text { Modelos } \\
\text { preditivos }\end{array}$ & $\begin{array}{l}\text { COVID-19 Patient Health Prediction Using } \\
\text { Boosted Random Forest Algorithm }\end{array}$ & 10.3389/fpubh.2020.00357 \\
\hline 286 & $\begin{array}{l}\text { Monitoramento } \\
\text { de contato e } \\
\text { rastreamento }\end{array}$ & $\begin{array}{l}\text { Pervasive computing in the context of COVID-19 } \\
\text { prediction with Al-based algorithms }\end{array}$ & 10.1108/IJPCC-07-2020-0082 \\
\hline 287 & $\begin{array}{l}\text { Monitoramento } \\
\text { de contato e } \\
\text { rastreamento }\end{array}$ & $\begin{array}{l}\text { Learning from Large-Scale Wearable Device Data } \\
\text { for Predicting Epidemics Trend of COVID-19 }\end{array}$ & $10.1155 / 2020 / 6152041$ \\
\hline 288 & $\begin{array}{l}\text { Monitoramento } \\
\text { de contato e } \\
\text { rastreamento }\end{array}$ & $\begin{array}{l}\text { A Novel Deep Convolutional Neural Network } \\
\text { Model to Monitor People following Guidelines to } \\
\text { Avoid COVID-19 }\end{array}$ & $10.1155 / 2020 / 8856801$ \\
\hline 289 & $\begin{array}{l}\text { Monitoramento } \\
\text { de contato e } \\
\text { rastreamento }\end{array}$ & $\begin{array}{l}\text { Modeling the Spread of COVID-19 Infection Using } \\
\text { a Multilayer Perceptron }\end{array}$ & $10.1155 / 2020 / 5714714$ \\
\hline 290 & $\begin{array}{l}\text { Monitoramento } \\
\text { de contato e } \\
\text { rastreamento }\end{array}$ & $\begin{array}{c}\text { Machine learning and statistical modelling for } \\
\text { prediction of Novel COVID-19 patients case study: } \\
\text { Jordan }\end{array}$ & 10.14569/IJACSA.2020.0110518 \\
\hline 291 & $\begin{array}{l}\text { Monitoramento } \\
\text { de contato e } \\
\text { rastreamento }\end{array}$ & $\begin{array}{l}\text { Predicting COVID-19 malignant progression with } \\
\qquad \text { Al techniques }\end{array}$ & $10.1101 / 2020.03 .20 .20037325$ \\
\hline 292 & $\begin{array}{l}\text { Monitoramento } \\
\text { de contato e } \\
\text { rastreamento }\end{array}$ & $\begin{array}{c}\text { Quantifying the effect of quarantine control } \\
\text { in Covid-19 infectious spread using machine } \\
\text { learning }\end{array}$ & $10.1101 / 2020.04 .03 .20052084$ \\
\hline 293 & $\begin{array}{l}\text { Monitoramento } \\
\text { de contato e } \\
\text { rastreamento }\end{array}$ & $\begin{array}{l}\text { Experience with Social Distancing Early in } \\
\text { the COVID-19 Pandemic in the United States: } \\
\text { Implications for Public Health Messaging }\end{array}$ & $10.1101 / 2020.04 .08 .20057067$ \\
\hline 294 & $\begin{array}{l}\text { Monitoramento } \\
\text { de contato e } \\
\text { rastreamento }\end{array}$ & $\begin{array}{l}\text { COVID-19 Infection Forecasting based on Deep } \\
\text { Learning in Iran }\end{array}$ & $10.1101 / 2020.05 .16 .20104182$ \\
\hline 295 & Outros desfechos & $\begin{array}{l}\text { Application of a Novel and Improved VGG-19 } \\
\text { Network in the Detection of Workers Wearing } \\
\text { Masks }\end{array}$ & $\begin{array}{c}10.1088 / 1742- \\
6596 / 1518 / 1 / 012041\end{array}$ \\
\hline
\end{tabular}




\begin{tabular}{|c|c|c|c|}
\hline ID & $\begin{array}{l}\text { Categoria de } \\
\text { aplicação }\end{array}$ & Título & DOI \\
\hline 296 & Outros desfechos & $\begin{array}{l}\text { Acute Kidney Injury in Hospitalized Patients with } \\
\text { COVID-19 }\end{array}$ & $10.1101 / 2020.05 .04 .20090944$ \\
\hline 297 & Outros desfechos & $\begin{array}{l}\text { Longitudinal laboratory testing tied to PCR } \\
\text { diagnostics in COVID-19 patients reveals temporal } \\
\text { evolution of distinctive coagulopathy signatures }\end{array}$ & $10.1101 / 2020.05 .21 .20109439$ \\
\hline 298 & Outros desfechos & $\begin{array}{c}\text { Artificial Intelligence for COVID-19 Risk } \\
\text { Classification in Kidney Disease: Can Technology } \\
\text { Unmask an Unseen Disease? }\end{array}$ & $10.1101 / 2020.06 .15 .20131680$ \\
\hline 299 & $\begin{array}{l}\text { Pesquisa de } \\
\text { fármacos e } \\
\text { vacinas }\end{array}$ & $\begin{array}{l}\text { Deep Learning Based Drug Screening for Novel } \\
\text { Coronavirus 2019-nCov }\end{array}$ & $10.1007 / s 12539-020-00376-6$ \\
\hline 300 & $\begin{array}{l}\text { Pesquisa de } \\
\text { fármacos e } \\
\text { vacinas }\end{array}$ & $\begin{array}{l}\text { Rapid Identification of Potential Inhibitors of } \\
\text { SARS-CoV-2 Main Protease by Deep Docking of } \\
1.3 \text { Billion Compounds }\end{array}$ & 10.1002/minf.202000028 \\
\hline 301 & $\begin{array}{l}\text { Pesquisa de } \\
\text { fármacos e } \\
\text { vacinas }\end{array}$ & $\begin{array}{l}\text { Predicting novel drugs for SARS-CoV- } 2 \text { using } \\
\text { machine learning from a }>10 \text { million chemical } \\
\text { space }\end{array}$ & 10.1016/j.heliyon.2020.e04639 \\
\hline 302 & $\begin{array}{l}\text { Pesquisa de } \\
\text { fármacos e } \\
\text { vacinas }\end{array}$ & $\begin{array}{l}\text { Repositioning of } 8565 \text { Existing Drugs for } \\
\text { COVID-19 }\end{array}$ & 10.1021/acs.jpclett.0c01579 \\
\hline 303 & $\begin{array}{l}\text { Pesquisa de } \\
\text { fármacos e } \\
\text { vacinas }\end{array}$ & $\begin{array}{l}\text { Predictive modeling by deep learning, virtual } \\
\text { screening and molecular dynamics study of } \\
\text { natural compounds against SARS-CoV- } 2 \text { main } \\
\text { protease }\end{array}$ & $10.1080 / 07391102.2020 .1802341$ \\
\hline 304 & $\begin{array}{l}\text { Pesquisa de } \\
\text { fármacos e } \\
\text { vacinas }\end{array}$ & $\begin{array}{l}\text { Repurposing Therapeutics for COVID-19: Rapid } \\
\text { Prediction of Commercially available drugs } \\
\text { through Machine Learning and Docking }\end{array}$ & $10.1101 / 2020.04 .05 .20054254$ \\
\hline 305 & $\begin{array}{l}\text { Pesquisa de } \\
\text { fármacos e } \\
\text { vacinas }\end{array}$ & $\begin{array}{c}\text { Screening of Therapeutic Agents for COVID-19 } \\
\text { Using Machine Learning and Ensemble Docking } \\
\text { Studies }\end{array}$ & 10.1021/acs.jpclett.0c02278 \\
\hline 306 & $\begin{array}{l}\text { Pesquisa de } \\
\text { fármacos e } \\
\text { vacinas }\end{array}$ & $\begin{array}{c}\text { Advanced bioinformatics rapidly identifies } \\
\text { existing therapeutics for patients with coronavirus } \\
\text { disease-2019 (COVID-19) }\end{array}$ & $10.1186 / s 12967-020-02430-9$ \\
\hline
\end{tabular}




\begin{tabular}{|c|c|c|c|}
\hline ID & $\begin{array}{l}\text { Categoria de } \\
\text { aplicação }\end{array}$ & Título & DOI \\
\hline 307 & $\begin{array}{l}\text { Pesquisa de } \\
\text { fármacos e } \\
\text { vacinas }\end{array}$ & $\begin{array}{l}\text { Shape-based Machine Learning Models for the } \\
\text { potential Novel COVID-19 protease inhibitors } \\
\text { assisted by Molecular Dynamics Simulation }\end{array}$ & $\begin{array}{c}10.2174 / 156802662066620070 \\
4135327\end{array}$ \\
\hline 308 & $\begin{array}{l}\text { Pesquisa de } \\
\text { fármacos e } \\
\text { vacinas }\end{array}$ & $\begin{array}{l}\text { Repurpose Open Data to Discover Therapeutics } \\
\text { for COVID-19 Using Deep Learning }\end{array}$ & 10.1021/acs.jproteome.0c00316 \\
\hline 309 & $\begin{array}{l}\text { Pesquisa de } \\
\text { fármacos e } \\
\text { vacinas }\end{array}$ & $\begin{array}{l}\text { Computational analysis of microRNA-mediated } \\
\text { interactions in SARS-CoV-2 infection }\end{array}$ & 10.7717/peerj.9369 \\
\hline 310 & $\begin{array}{l}\text { Pesquisa de } \\
\text { fármacos e } \\
\text { vacinas }\end{array}$ & $\begin{array}{l}\text { A deep learning framework for high-throughput } \\
\text { mechanism-driven phenotype compound } \\
\text { screening }\end{array}$ & 10.1101/2020.07.19.211235 \\
\hline 311 & Triagem hospitalar & $\begin{array}{l}\text { Helping doctors hasten COVID- } 19 \text { treatment: } \\
\text { Towards a rescue framework for the transfusion } \\
\text { of best convalescent plasma to the most critical } \\
\text { patients based on biological requirements via ml } \\
\text { and novel MCDM methods }\end{array}$ & 10.1016/j.cmpb.2020.105617 \\
\hline 312 & Triagem hospitalar & $\begin{array}{l}\text { Prediction of respiratory decompensation in } \\
\text { Covid-19 patients using machine learning: The } \\
\text { READY trial }\end{array}$ & $\begin{array}{c}\text { 10.1016/j. } \\
\text { compbiomed.2020.103949 }\end{array}$ \\
\hline 313 & Triagem hospitalar & $\begin{array}{l}\text { Development and Validation of a Deep Learning- } \\
\text { Based Model Using Computed Tomography } \\
\text { Imaging for Predicting Disease Severity of } \\
\text { Coronavirus Disease } 2019\end{array}$ & 10.3389/fbioe.2020.00898 \\
\hline 314 & Triagem hospitalar & $\begin{array}{c}\text { Severity Detection for the Coronavirus Disease } \\
2019 \text { (COVID-19) Patients Using a Machine } \\
\text { Learning Model Based on the Blood and Urine } \\
\text { Tests }\end{array}$ & 10.3389/fcell.2020.00683 \\
\hline 315 & Triagem hospitalar & $\begin{array}{l}\text { Proteomic and Metabolomic Characterization of } \\
\text { COVID-19 Patient Sera }\end{array}$ & 10.1016/j.cell.2020.05.032 \\
\hline 316 & Triagem hospitalar & $\begin{array}{l}\text { Augmented curation of clinical notes from } \\
\text { a massive EHR system reveals symptoms of } \\
\text { impending COVID-19 diagnosis }\end{array}$ & 10.7554/eLife.58227 \\
\hline 317 & Triagem hospitalar & $\begin{array}{l}\text { A neural network aided real-time hospital } \\
\text { recommendation system }\end{array}$ & 10.17509/ijost.v5i2.24585 \\
\hline
\end{tabular}




\begin{tabular}{|c|c|c|c|}
\hline ID & $\begin{array}{l}\text { Categoria de } \\
\text { aplicação }\end{array}$ & Título & DOI \\
\hline 318 & Triagem hospitalar & $\begin{array}{l}\text { Development of a Clinical Decision Support } \\
\text { System for Severity Risk Prediction and Triage } \\
\text { of COVID-19 Patients at Hospital Admission: an } \\
\text { International Multicenter Study }\end{array}$ & $10.1101 / 2020.05 .01 .20053413$ \\
\hline 319 & Triagem hospitalar & $\begin{array}{l}\text { Intensive care risk estimation in COVID-19 } \\
\text { pneumonia based on clinical and imaging } \\
\text { parameters: experiences from the Munich cohort }\end{array}$ & $10.1101 / 2020.05 .04 .20076349$ \\
\hline 320 & Triagem hospitalar & $\begin{array}{l}\text { CLINICAL CHARACTERISTICS AND PROGNOSTIC } \\
\text { FACTORS FOR ICU ADMISSION OF PATIENTS } \\
\text { WITH COVID-19 USING MACHINE LEARNING } \\
\text { AND NATURAL LANGUAGE PROCESSING }\end{array}$ & 10.1101/2020.05.22.20109959 \\
\hline 321 & Triagem hospitalar & $\begin{array}{c}\text { Artificial intelligence driven assessment of } \\
\text { routinely collected healthcare data is an effective } \\
\text { screening test for COVID-19 in patients presenting } \\
\text { to hospital }\end{array}$ & 10.1101/2020.07.07.20148361 \\
\hline 322 & Triagem hospitalar & $\begin{array}{c}\text { Development of a severity of disease score and } \\
\text { classification model by machine learning for } \\
\text { hospitalized COVID-19 patients }\end{array}$ & 10.1101/2020.07.13.20150177 \\
\hline 323 & Triagem hospitalar & $\begin{array}{l}\text { Prognostic modelling of COVID-19 using artificial } \\
\text { intelligence in a UK population }\end{array}$ & $10.2196 / 20259$ \\
\hline 324 & Triagem hospitalar & $\begin{array}{l}\text { Using Machine Learning to Predict ICU Transfer in } \\
\text { Hospitalized COVID-19 Patients }\end{array}$ & 10.3390/jcm9061668 \\
\hline 325 & Triagem hospitalar & $\begin{array}{l}\text { Development of a Clinical Decision Support } \\
\text { System for Severity Risk Prediction and Triage } \\
\text { of COVID-19 Patients at Hospital Admission: an } \\
\text { International Multicenter Study }\end{array}$ & $10.1183 / 13993003.01104-2020$ \\
\hline
\end{tabular}

Fonte: elaborado pelos autores.

\section{Referências}

ERTEL, W. Introduction to artificial intelligence. 2nd.ed. London: Springer, 2017. 
GOODFELLOW, I.; BENGIO, Y.; COURVILLE, A. Deep learning. Cambridge: The MIT Press, 2016.

HARKO, T.; LOBO, F. S. N.; MAK, M. K. Exact analytical solutions of the SusceptibleInfected-Recovered (SIR) epidemic model and of the SIR model with equal death and birth rates. Applied Mathematics and Computation, New York, n. 236, p. 184-194, 2014, doi:10.1016/j.amc.2014.03.030

JURAFSKY, D.; MARTIN, J. Speech and language processing: an introduction to natural language processing, computational linguistics, and speech recognition. 2nd ed. New York: Prentice Hall, 2008.

KHAN, A.; SHAH, J.; BHAT, M. CoroNet: a deep neural network for detection and diagnosis of COVID-19 from chest X-ray images. Computer Methods and Programs in Biomedicine, Limerick, v. 196, 2020. DOI: https://doi. org/10.1016/j.cmpb.2020.105581. Disponível em: https://www.sciencedirect.com/ science/article/abs/pii/S0169260720314140?via\%3Dihub. Acesso em: 20 jul. 2020.

KOWALEWSKI, J.; RAY, A. Predicting novel drugs for SARS-CoV-2

using machine learning from a $>10$ million chemical space.

Heliyon, London, v. 6, n. 8, p. E04639, 2020. DOI: https://doi.org/10.1016/j. heliyon.2020.e04639. Disponível em: https://www.cell.com/heliyon/fulltext/ S2405-8440(20)31483-3?_returnURL=https\%3A\%2F\%2Flinkinghub.elsevier. com\%2Fretrieve\%2Fpii\%2FS2405844020314833\%3Fshowall\%3Dtrue.

Acesso em: 20 jul. 2020.

MELIN, P. et al. Analysis of spatial spread relationships of Coronavirus (COVID19) pandemic in the world using self-organizing maps. Chaos, Solitons $\&$ Fractals, Oxford, v.138, 2020. DOI: https://doi.org/10.1016/j.chaos.2020.109917. Disponível em: https://www.sciencedirect.com/science/article/abs/pii/ S0960077920303179?via\%3Dihub. Acesso em: 20 jul. 2020.

NG, A. AI for everyone. 2020. Disponível em: https://www.deeplearning.ai/ai-foreveryone. Acesso em: 20 jul.2020.

RUSSELL, S.; NORVIG, P. Artificial intelligence: a modern approach. $4^{\text {th }}$. ed. New York: Pearson, 2020.

SAMUEL, Jim et al. COVID-19 public sentiment insights and machine learning for tweets classification. MedRxiv, [s. l.], 2020. DOI: https:// doi.org/10.1101/2020.06.01.20119347. Disponível em: https://www.medrxiv.org/ content/10.1101/2020.06.01.20119347v1. Acesso em: 20 jul. 2020. 